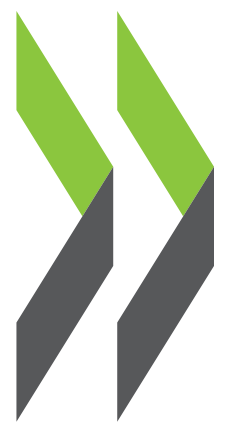

\title{
Balancing School Choice and Equity
}

AN INTERNATIONAL PERSPECTIVE BASED ON PISA

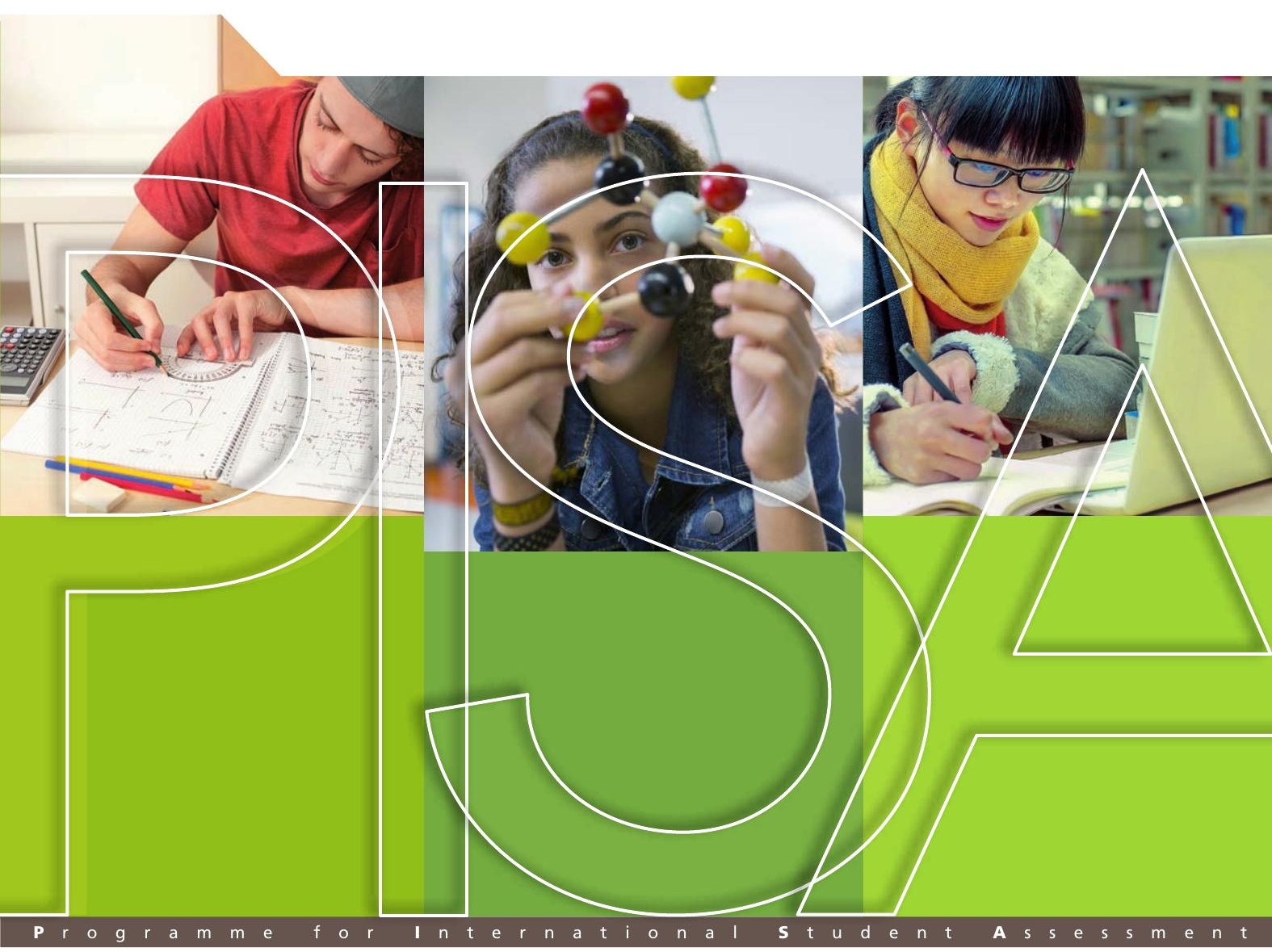

O 

PISA

\section{Balancing School Choice and Equity}

AN INTERNATIONAL PERSPECTIVE BASED ON PISA 
This work is published under the responsibility of the Secretary-General of the OECD. The opinions expressed and arguments employed herein do not necessarily reflect the official views of the OECD member countries.

This document, as well as any data and any map included herein, are without prejudice to the status of or sovereignty over any territory, to the delimitation of international frontiers and boundaries and to the name of any territory, city or area.

Please cite this publication as:

OECD (2019) Balancing School Choice and Equity: An International Perspective Based on PISA, PISA, OECD Publishing, Paris.

https://doi.org/10.1787/2592c974-en

ISBN 978-92-64-69571-9 (print)

ISBN 978-92-64-74129-4 (PDF)

ISBN 978-92-64-79129-9 (HTML)

ISBN 978-92-64-89411-2 (epub)

Series: PISA

ISSN: $1990-8539$ (print)

ISSN: 1996-3777 (online)

The statistical data for Israel are supplied by and under the responsibility of the relevant Israeli authorities. The use of such data by the OECD is without prejudice to the status of the Golan Heights, East Jerusalem and Israeli settlements in the West Bank under the terms of international law.

\section{Photo credits:}

๑) RelaXimages/Corbis

(๑) Hero Images Inc./Getty Images

(c) LIUSHENGFILM/Shutterstock

(c) Tyler Olsen/Shutterstock

(c) Flying Colours Ltd/Getty Images

() Jacobs Stock Photography/Getty Images

(c) Geostock/GO Premium/GraphicObsesion

Corrigenda to OECD publications may be found on line at: www.oecd.org/publishing/corrigenda.

(c) OECD 2019

This work is available under the Creative Commons Attribution-NonCommercial-ShareAlike 3.0 IGO (CC BY-NC-SA 3.0 IGO). For specific information regarding the scope and terms of the licence as well as possible commercial use of this work or the use of PISA data please consult Terms and Conditions on www.oecd.org. 


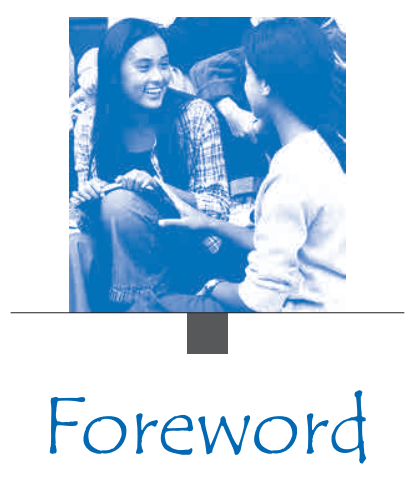

Many countries are struggling to reconcile their aspirations for greater flexibility and more opportunities for parents to choose their child's school with the need to ensure quality, equity and coherence in their school systems. The new analyses from PISA presented in this report suggest that this is an achievable goal. School choice, in and of itself, neither assures nor undermines the quality of education. What matters are smart policies that maximise the benefits of choice while minimising the risks, and establishing a level playing field for all providers to contribute to the school system.

School choice will only generate the anticipated benefits when the choice is real, relevant and meaningful, i.e. when parents can choose an important aspect of their child's education, such as the pedagogical approaches used to teach them. If schools are not allowed to respond to diverse student populations, and to distinguish themselves from each other, choice is meaningless. In turn, private schools need to accept the public steering and accountability mechanisms that ensure the attainment of public-policy objectives in exchange for the funding they receive from the public purse.

All parents must be able to exercise their right to choose the school of their preference; that means government and schools need to invest in developing their relationships with parents and local communities, and help parents make informed decisions. Successful choice-based systems have carefully designed checks and balances that prevent choice from leading to inequity and segregation. Not least, the more flexibility there is in a school system, the stronger public policy needs to be. While greater school autonomy, decentralisation and a more demand-driven school system seek to devolve decision making to the frontline, central authorities need to maintain a strategic vision and clear guidelines for education, and offer meaningful feedback to local school networks and individual schools.

In other words, only through a concerted effort by central and local education authorities will school choice benefit all students.

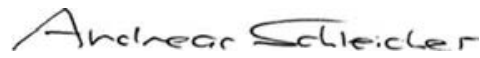

\section{Andreas Schleicher}

Director for Education and Skills Special Advisor on Education Policy

to the Secretary-General 



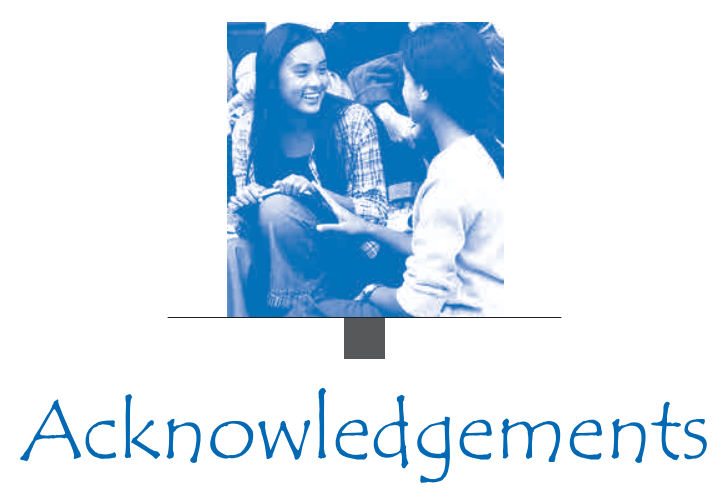

This report is the product of a joint effort between the countries participating in PISA and the OECD Secretariat. The report was prepared by Pauline Givord, with contributions from Andreas Schleicher. Marilyn Achiron edited the report. Statistical and analytical support was provided by Camille Marec with the help of Ariel Gruver and Giannina Rech. Francesco Avvisati, Yuri Belfali, Luka Boeskens, Eric Charbonnier, Miyako Ikeda, Noémie Le Donné, Deborah Nusche, Paulo Santiago and Dirk Van Damme provided valuable feedback at various stages of the report. Rebecca Tessier co-ordinated production and JOUVE designed the publication. Administrative support was provided by Juliet Evans, Thomas Marwood, Lesley O'Sullivan and Hanna Varkki. The development of the report was steered by the PISA Governing Board, chaired by Michele Bruniges (Australia), with Peggy Carr (United States), Jimin Cho (Korea), Maria Helena Guimarães de Castro (Brazil) and Carmen Tovar Sánchez (Spain) as vice chairs. 



\section{Table of Contents}

EXECUTIVE SUMMARY

CHAPTER 1 SCHOOL CHOICE, STUDENT SORTING AND EQUITY

Impact of school choice on student achievement

Impact of school choice on student sorting.

Scope of this report

\section{CHAPTER 2 HOW SCHOOL CHOICE CAN BE MEASURED BY PISA AND HOW THESE} INDICATORS HAVE EVOLVED OVER TIME.

In most PISA-participating countries, the proportion of students in private schools

did not change significantly between 2000 and 2015

More competition for school principals does not always translate into more choice

for families

In many PISA-participating countries, the allocation of students to schools depended

less on residence in 2015 than in 2000, and schools became more selective over

the period.

\section{CHAPTER 3 THE LEVEL OF SOCIAL AND ACADEMIC SEGREGATION ACROSS}

SCHOOLS.

Academic segregation is often more widespread across schools than social

segregation

In most countries, a high concentration of low achievers in certain schools

is more common than a high concentration of high achievers

In most countries, there are more schools with a high concentration of advantaged students

than with a high concentration of disadvantaged students.

\section{CHAPTER 4 HOW SOCIAL AND ACADEMIC SEGREGATION ARE RELATED}

TO SCHOOL-CHOICE POLICIES

Private schools are usually more socially stratified than public schools

The relationship between segregation across schools and school enrolment practices is ambiguous 
CHAPTER 5 HOW SCHOOL-CHOICE POLICIES ARE RELATED TO QUALITY AND EQUITY IN EDUCATION

Sorting by socio-economic status across schools is negatively related to equity in education

The direct impact of school admissions policies on performance and social equity

in education is small

CHAPTER 6 BALANCING CHOICE AND EQUITY: CONSIDERATIONS FOR POLICY

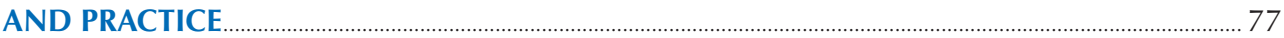

Provide the checks and balances that prevent choice from leading to more segregation.......... 79

Where there is free school choice, ensure that all parents can exercise their right

to choose the school of their preference

ANNEX A MEASURES OF SEGREGATION

ANNEX B ADDITIONAL FIGURES AND ROBUSTNESS CHECKS ………...................................... 95

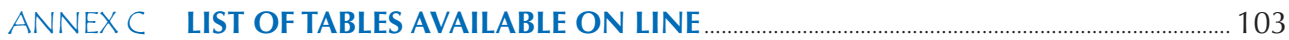

\section{BOXES}

Box 2.1 Public school, government-dependent and government-independent, privately managed schools

Box 6.1 Controlled-choice reforms in the Belgian Communities

Box 6.2 Regulating publicly funded private schools in Chile: The 2016 Inclusion Law

\section{FIGURES}

Figure 2.1 Change between 2000 and 2015 in the percentage of students enrolled in a private school ...............29

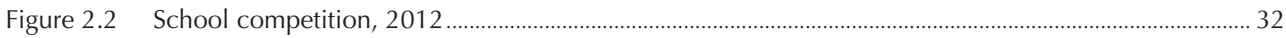

Figure 2.3 Percentage of students in schools that compete with at least one other local school, 2012 ................ 33

Figure 2.4 Change between 2000 and 2015 in school admissions based on residence........................................ 36

Figure 2.5 Change between 2000 and 2015 in school admissions based on academic performance................... 37

Figure 2.6 School admissions based on academic performance, by school type ..................................................... 38

Figure 3.1 Dissimilarity index for low-achieving students in reading and for disadvantaged students

Figure 3.2 Isolation of low-achieving and high-achieving students in reading ................................................ 47

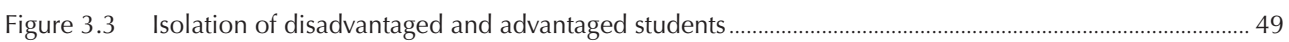

Figure 3.4 Isolation of disadvantaged students from national high achievers in reading.........................................50 
Figure 4.1 Contributions of public and private schools to social segregation amongst schools

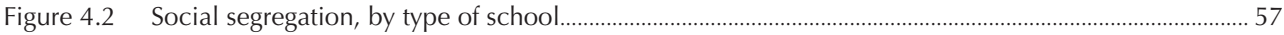

Figure 4.3 Dissimilarity index for low-achieving students in reading and school admissions based on academic performance.

Figure 4.4 Dissimilarity index for disadvantaged students and school admissions based on residence

Figure 5.1 School-choice policies, segregation in schools and education outcomes

Figure 5.2 Equity in reading performance and no-diversity index for disadvantaged students.....

Figure 5.3 Estimated impact of segregation and school type on reading performance, by socio-economic status

Figure 5.4 Equity in reading performance and school admissions based on academic performance

Figure A.1 Complete vs no segregation cases (illustrative example).

Figure A.2 High dissimilarity, high vs medium isolation (illustrative example) 92

Figure A.3 Dissimilarity index, no-diversity index and isolation of students with an immigrant background

Figure B.1 Equity in reading performance and school admissions based on residence 96

Figure B.2 Reading performance and school admissions based on academic performance 97

Figure B.3 Percentage of students in schools whose parents/principal reported school competition, 2012

\section{TABLES}

Table 2.1 Freedom for parents to choose a public school for their children, 2009

Table 4.1 Social and academic segregation, and school-stratification policies, 2009-15

Table 5.1 Social gradient and reading performance related to social and academic segregation, 2009-15.

Table 5.2 Reading performance, by school practices, academic and social segregation, 2009-15 ..................... 70

Table 5.3 Social gradient and reading performance related to admissions criteria, 2009-15

Table B.1 Reading performance, by school practices and social segregation

Table B.2 Variation in the main variables

Table B.3 Modal grade by country/economy 


\section{Follow OECD Publications on:}

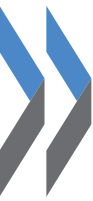

.

http://twitter.com/OECD_Pubs

f http://www.facebook.com/OECDPublications

in. http://www.linkedin.com/groups/OECD-Publications-4645871

Your

http://www.youtube.com/oecdilibrary

OECD

Alerts

http://www.oecd.org/oecddirect/

\section{This book has...}

Look for the StatLinks ants at the bottom of the tables or graphs in this book. To download the matching Excel® spreadsheet, just type the link into your Internet browser, starting with the $h t t p: / / d x$.doi.org prefix, or click on the link from the e-book edition. 


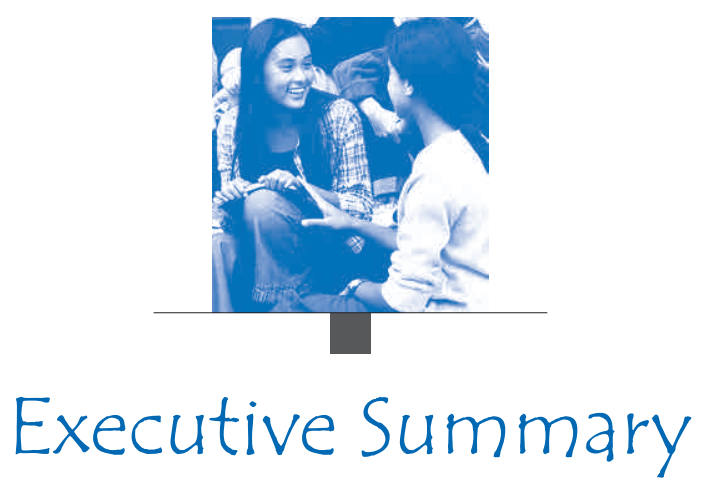

This report documents the changes in school enrolment that have recently occurred in the countries that participated in the Programme for International Student Assessment (PISA). It questions whether school-choice policies may have consequences on the sorting of students, by both ability and socio-economic status, and whether they may be associated with both the effectiveness and equity of education systems.

The results suggest that private schooling has increased in only a limited number of the countries that participated in PISA from 2000 to 2015. On the other hand, students were less frequently allocated to schools according to residence-based rules in 2015 than 15 years earlier. This may have intensified the competition between schools, and may also have resulted in greater sorting by ability, as more schools in 2015 than in 2000 reported that they consider prior academic achievement for admissions.

This report draws a comprehensive picture of sorting by ability and socio-economic factors across schools using a variety of segregation indicators in order to account for the diversity of the processes by which students are allocated to schools. While in most countries the indices of academic segregation amongst schools are higher than those measuring socio-economic segregation, the opposite is observed in several countries. These are also those countries where socio-economic differences in enrolment between private and public schools contribute, to a large extent, to the overall level of school segregation.

The organisation of the school system also affects the type of segregation. In some countries and economies, academic segregation of students is mainly due to the isolation of low achievers "left behind" in some schools, while in other systems, it reflects a significant concentration of high achievers in "elite" schools. These specifics may have distinct consequences for student performance.

One concern associated with increased school choice is the impact on the segregation of students by ability or socio-economic status. Empirical results in this volume suggest that weakening the link between place of residence and school allocation is related to a higher level of school segregation by social status. Some resilient disadvantaged students may have access to schools that would otherwise be inaccessible if a strict residence-based policy were applied. But that, in itself, 
does not offset the social-sorting effects that result when it is mostly middle- or upper-class families that take advantage of school-choice policies. At the aggregate level, this may have a negative impact on equity but also, in some cases, on the general performance of the school system if low achievers are more harmed when they attend schools that concentrate low-achieving students than high achievers benefit from being in schools that concentrate high-achieving students. Panel estimates in this report show that an increase in the isolation of high achievers from other students is associated with lower scores in PISA amongst socio-economically disadvantaged students, without any significant impact on advantaged students.

How can school systems combine sufficient flexibility to fulfil the aspirations of many parents and provide enough incentives for schools to improve the performance of all students without reducing equity in education? There is no single solution to this dilemma.

However, policy makers can:

\section{- Provide the checks and balances that prevent choice from leading to more segregation}

School policies may have to balance both the risk of increasing residential segregation with the risk of greater sorting of students by both ability and socio-economic status. Providing choice to parents without exacerbating segregation can be achieved by introducing specific criteria to the allocation of students across the set of local schools. Incentives can also be provided to schools for selecting disadvantaged students, for example, by weighting the funds received by the schools, depending on the socio-economic profile of their student populations.

\section{- Ensure that all parents can exercise their right to choose the school of their preference}

Policies should provide targeted support to disadvantaged families, not only by offering financial assistance but also by promoting mobility through adequate public transportation. In order to avoid unfair competition between public and private schools, it should be required that all publicly funded providers adhere to the same regulations regarding tuition and admissions policies. Evidence shows that attending a school with a large proportion of high achievers does not always result in individual improvements in performance. Given those findings, school systems should ensure that all parents are provided with relevant information about the schools available to them, including a measure of the actual "value-added" of schools, meaning whether those schools succeed in improving the performance of all of their students. 


\section{Reader's Guide}

\section{Data underlying the figures}

The data referred to in this report are presented in tables available in some chapters and on line (see list in Annex C).

Three symbols are used to denote missing data:

c There are too few observations or no observation to provide reliable estimates (i.e. there are fewer than 30 students or fewer than 5 schools with valid data).

$\mathrm{m}$ Data are not available. These data were not submitted by the country or were collected but subsequently removed from the publication for technical reasons.

w Data have been withdrawn or have not been collected at the request of the country concerned.

\section{Country coverage}

This publication features data on 71 countries and economies, including all 36 OECD countries and 35 partner countries and economies.

Lithuania became a member of the OECD on 5 July 2018. However, consistent with other publications based on PISA 2015 data, Lithuania is shown as a partner country and is not included in the OECD average.

The statistical data for Israel are supplied by and under the responsibility of the relevant Israeli authorities. The use of such data by the OECD is without prejudice to the status of the Golan Heights, East Jerusalem and Israeli settlements in the West Bank under the terms of international law.

B-S-J-G (China) refers to the four PISA-participating Chinese provinces of Beijing, Shanghai, Jiangsu and Guangdong.

For the countries below, when results are based on students' or school principals' responses:

Argentina: Only data for the adjudicated region of Ciudad Autónoma de Buenos Aires (CABA) are reported in figures and in the text. Results for Argentina are reported in tables only.

Kazakhstan: Results for Kazakhstan are reported in tables only.

Malaysia: Results for Malaysia are reported in tables only.

See Annex A4 of PISA 2015 Results Volume 1 for more information (OECD, 2016 $[1]$ ). 


\section{International averages}

The OECD average corresponds to the arithmetic mean of the respective country estimates. It was calculated for most indicators presented in this report. For some indicators, data may not be available for all countries, or specific categories may not apply. Readers should, therefore, keep in mind that the term "OECD average" refers to the OECD countries included in the respective comparisons. In cases where data are not available or do not apply to all sub-categories of a given population or indicator, the "OECD average" may be consistent within each column of a table but not necessarily across all columns of a table.

In analyses involving data from multiple years, the OECD average is reported on consistent sets of OECD countries, and several averages may be reported in the same table. For instance, the "OECD average-34" includes only 34 OECD countries that have non-missing values across all the assessments for which this average itself is calculated. This restriction allows for valid comparisons of the OECD average across the same countries over time. As noted previously, consistently with other publications based on PISA 2015 data, Lithuania is shown as a partner country and is not included in the OECD average.

\section{Rounding figures}

Because of rounding, some figures in tables may not add up exactly to the expected totals. Totals, differences and averages are always calculated on the basis of exact numbers and are rounded only after calculation.

All standard errors in this publication have been rounded to one or two decimal places. Where the value 0.0 or 0.00 is shown, this does not imply that the standard error is zero, but that it is smaller than 0.05 or 0.005 , respectively.

\section{Reporting student data}

The report uses "15-year-olds" as shorthand for the PISA target population. PISA covers students who are aged between 15 years 3 months and 16 years 2 months at the time of assessment and who are enrolled in school and have completed at least 6 years of formal schooling, regardless of the type of institution in which they are enrolled, whether they are in full-time or part-time education, whether they attend academic or vocational programmes, and whether they attend public or private schools or foreign schools within the country.

\section{Reporting school data}

The principals of the schools in which students were assessed provided information on their schools' characteristics by completing a school questionnaire. Where responses from school principals are presented in this publication, they are weighted so that they are proportionate to the number of 15 -year-olds enrolled in the school. 


\section{Modal ISCED level}

All the analyses presented in this report are restricted to schools with the "modal ISCED level" for 15-year-old students. The "modal ISCED level" is defined here as a level attended by at least one-third of the PISA sample. As PISA students are sampled to represent all 15-year-old students, whatever type of schools they are enrolled in, they may not be representative of their schools. Restricting the sampling to schools with the modal ISCED level for 15-year-old students ensures that the characteristics of students sampled for PISA represent the profile of the typical student attending the school. Details are provided in Table B.3 in Annex B.

\section{Focusing on statistically significant differences}

This report discusses only statistically significant differences or changes (at the $5 \%$ level of significance), unless explicitly stated. These are denoted in darker colours in figures and in bold font in tables.

\section{Abbreviations used in this report}

\begin{tabular}{ll}
\hline Dif. & Difference \\
\hline$\%$ dif. & Percentage-point difference \\
\hline Score dif. & Score-point difference \\
\hline S.D. & Standard deviation \\
\hline S.E. & Standard error \\
\hline ESCS & PISA index of economic, social and cultural status \\
\hline ISCED & International Standard Classification of Education \\
\hline
\end{tabular}

\section{Categorising student performance}

PISA provides an assessment of students' level of proficiency in science, reading, mathematics and certain innovative domains. For the purpose of the analyses in this report, two different definitions were used:

- Low achievers are students who score among the bottom $25 \%$ of students within their country or economy on the PISA test.

- High achievers are students who score among the top 25\% of students within their country or economy on the PISA test.

\section{Categorising students and schools according to their socio-economic profile}

PISA classifies students into different categories according to their socio-economic status. For the purpose of the analyses in this report, two different definitions were used:

- Socio-economically disadvantaged students are those whose values on the PISA index of economic, social and cultural status (ESCS) are amongst the bottom $25 \%$ of students within their country or economy.

- Socio-economically advantaged students are those whose values on the ESCS are amongst the top $25 \%$ of students within their country or economy. 


\section{Measuring segregation by ability and socio-economic status across schools}

This report uses several measures of school segregation, depending on the focus of the analysis. All of these indicators range from 0 to 1, with 0 corresponding to no segregation and 1 to full segregation (see Annex A for details on the computation of this index).

- The dissimilarity index measures the departure from evenness in the allocation of students of a specific type (a) across schools. It may be interpreted as the proportion of one or the other type that has to be displaced in order to achieve evenness.

- The isolation index measures whether students of type (a) are more concentrated in some schools. The index is related to the likelihood of a representative type (a) student to be enrolled in schools that enrolled students of another type.

- The no-diversity index measures whether the diversity of students observed within schools reflects the diversity of students observed at the country or economy level.

\section{Further documentation}

For further information on the PISA assessment instruments and the methods used in PISA, see the PISA 2015 Technical Report (OECD, 2017 ${ }_{[2]}$ ).

\section{Statlinks}

This report uses the OECD StatLinks service. Below each table and chart is a URL leading to a corresponding Excel ${ }^{\mathrm{TM}}$ workbook containing the underlying data. These urls are stable and will remain unchanged over time. In addition, readers of the e-books will be able to click directly on these links and the workbook will open in a separate window, if their Internet browser is open and running.

\section{References}

OECD (2017), PISA 2015 Technical Report, OECD, Paris, 


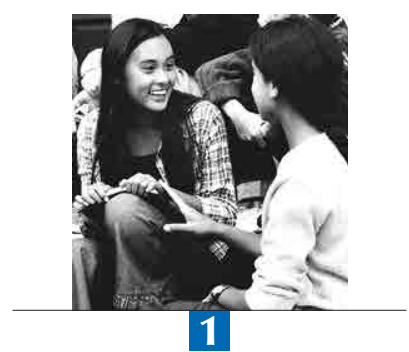

\section{School choice, student sorting and equity}

This chapter gives a general introduction to the various types of school choice programmes. It discusses the reasons these programmes may affect the composition of schools - notably the social diversity within schools, and why that may matter for both the performance and the equity of education systems.

\section{A note regarding Israel}

The statistical data for Israel are supplied by and under the responsibility of the relevant Israeli authorities. The use of such data by the OECD is without prejudice to the status of the Golan Heights, East Jerusalem and Israeli settlements in the West Bank under the terms of international law.

\section{A note regarding Lithuania}

Lithuania became a member of the OECD on 5 July 2018. However, consistent with other publications based on PISA 2015 data, Lithuania is shown as a partner country and is not included in the OECD average.

This document, as well as any data and map included herein, are without prejudice to the status of or sovereignty over any territory, to the delimitation of international frontiers and boundaries and to the name of any territory, city or area. 
Over the past decades, school-choice programmes have expanded in scope and size in most of the countries with available data. More than two-thirds of OECD countries have increased school-choice opportunities for students since the 1980s (Musset, 2012 ${ }_{[1]}$ ). These opportunities take diverse forms and vary widely in scope across countries. Several school systems promote open enrolment - the possibility for parents to choose any public school - instead of being assigned to only one, usually depending on the location of the family residence (catchment areas). School-assignment mechanisms, through which students are allocated to schools based on their expressed preferences and not only on geographic considerations, have been introduced in different places. ${ }^{1}$

In addition, private schools (also referred to as independent schools) are a common alternative to state or public schools. ${ }^{2}$ Private schools offer children a type of education that may better suit their parents' child-rearing preferences, such as, for instance, providing religious instruction. ${ }^{3}$ Usually, parents must pay fees or school charges for enrolling their children in private schools, but several school-choice programmes try to reduce the cost of private schooling for families. The most popular of these are educational voucher programmes, whereby parents are given a tuition certificate by the government that can be used to pay tuition at any "approved" school (which could be private or public, depending on the programme). The tuition may be distributed to families or directly to schools.

In many countries, private schools are primarily funded by the government - sometimes to the same extent as public schools (OECD, 2012 $\left.{ }_{[2]}\right)$. This is the case in several European countries, including Belgium, France and the Netherlands, where private schools are mostly distinguished by religion or ideological ideas, but are funded and regulated in the same way as public schools. ${ }^{4}$ In 1981, Chile implemented a universal school-voucher system for both elementary and secondary school students. In the 1990s, several countries, namely Colombia, New Zealand, Sweden and the United States, introduced market-based policies in education, promoting school choice either through school-voucher systems or by establishing charter schools (publicly funded schools that operate independently of the state-run system); similar reforms were adopted more recently in the United Kingdom.

In addition to the availability of private or independent schools, more school-choice opportunities may be fostered by simply relaxing the rules related to assigning students to public schools. In the end, families are left with a wide range of options. For instance, in some states in the United States, families may choose, as an alternative to their local public school, from amongst charter schools, magnet schools or religious private schools, and the choice may be expanded to out-of-district schools (OECD, 2018 $\left.{ }_{[3]}\right)$.

\section{IMPACT OF SCHOOL CHOICE ON STUDENT ACHIEVEMENT}

School choice is based on various ideas. Some systems provide extensive parental choice based on the conviction that parents have a general right to educate their children according to their personal preferences (in terms of religion or lifestyle) and the right to choose the school that best matches these child-rearing preferences. As such, encouraging diversity in the types of education provided appears to be self-evident (Levin, $\left.1998_{[4]}\right)$. More important, the introduction of "market-based" policies is based on the idea, first advocated by Friedman $\left(1955_{[5]}\right)$, that 
competition between schools will foster innovation and improve school efficiency. The fact that parents may select their child's school puts pressure on schools to improve the education they provide in order to attract and retain students.

Empirical evidence on whether student achievement is higher when there is greater competition between schools is mixed, however (Boeskens, 2016 $6_{[6]}$; Urquiola, 2016 $\left.6_{[7]}\right)$. On the one hand, most school-choice programmes seem to benefit the students who attend private or alternative schools. However, these benefits are usually modest (Epple, Romano and Urquiola, 2017 $7_{[8]}$ ) and may even sometimes be detrimental to the targeted population (Abdulkadiroğlu, Pathak and Walters, $\left.2018_{[9]}\right)$. The consequences for the schools "left behind" in the competition, and notably whether state schools respond to greater competition by enhancing their productivity, is less clear. While some studies conclude that public schools do respond to greater competition (Hoxby, 2002 ${ }_{[10]}$ ), including by improving teacher quality (Hanushek and Rivkin, $2003_{[11]}$ ), several analyses show more disappointing results. It is still an open question whether inter-school competition leads to better matches between the education provided and students' preferences or needs, or to conformity and risk-adverse behaviour amongst providers (Lubienski, 2009 ${ }_{[12]}$ ).

The impact of competition on student performance may be affected by several factors. One may assume, for instance, that these effects may vary depending on the level of autonomy provided to schools, but also on the mechanisms available to hold schools accountable for their students' performance (Woessmann, $\left.2007_{[13]}\right)$. As school choice may shape the composition of each school's student body, it may be difficult to disentangle the effect of being enrolled with the best-performing - or worst-performing - peers from the effect of the school itself (its "value-added") on student learning.

\section{IMPACT OF SCHOOL CHOICE ON STUDENT SORTING}

There is a lively debate about whether greater choice results in a higher incidence of student sorting - by both socio-economic status and ability - across schools. Arguments favouring school choice emphasise that these programmes are based on the right of all students, wherever they live, to enrol in any school. Residence-based school assignment may result in low social diversity within schools, especially in urban areas where housing segregation, based on socio-economic status, is usually pervasive. But school-choice policies may allow students from low-income families to enrol in the best schools, which are often located in other, more well-off neighbourhoods.

Indeed, strict residence-based school allocation is expected to reinforce urban segregation (Epple and Romano, 2000 $[14]$; Nechyba, 2003 $[15])$. In the absence of school choice, the housing prices in school catchment areas are expected to reflect the quality of the area's schools (Black, Sandra E. and Machin, 2011 $\left.1_{[16]}\right)$. Only the wealthiest parents can afford to live near the best schools. Reducing the cost of private schools or weakening the link between school choice and place of residence may thus improve equity in education.

But school-choice programmes have also been criticised for intensifying, rather than reducing, the incidence of student sorting across schools. To make the best use of their right to choose their child's school, all parents should have access to objective information on the quality of schools. In practice, better-educated and more motivated parents are often better informed when they select schools and are also those most likely to make use of school choice instead of enrolling 
their children in the assigned school. In addition, financial costs (school fees, transportation costs or time constraints) may limit the options available to some students from low-income families. Even where vouchers or similar programmes reduce the cost of publicly funded private schools, top-up fees or "hidden" parental contributions (for extracurricular activities, school uniforms, etc.) might make them unaffordable in practice (Boeskens, 2016 $6_{[6]}$ ).

The social mix of schools may eventually suffer because of school-choice policies. In addition, parents' freedom to choose actually translates into a greater likelihood that the schools most in demand will screen ("cream skim") for the most promising students - resulting in greater sorting of students by ability (referred to below as "academic segregation").

Empirical evidence from systems with country- or state-wide school-choice policies, such as Chile, New Zealand, Sweden and the United States, suggests that providing more opportunities may increase school stratification based on students' ability, socio-economic status and ethnicity (Burgess and Briggs, 2010 ${ }_{[17]}$; Ladd and Fiske, 2001 ${ }_{[18]}$; Ladd, Fiske and Ruijs, $2011_{[19]}$; Hsieh and Urquiola, 2006 $[20]$; Levin, 1998 ${ }_{[4]}$; Söderström and Uusitalo, 2010 $0_{[21]}$; Urquiola, 2005 [22]). The magnitude of the sorting effect of school choice depends on the design of the school-choice policy (Epple, Romano and Urquiola, 2017 ${ }_{[8]}$ ). Vouchers for enrolment in private or charter schools can be targeted at low-income families, rather than offered to all families, or schools can be prevented from "skimming" wealthier and more able students (Altonji, Huang and Taber, 2015 [23]; OECD, 2017 [24]).

The reason there is such interest in measuring the consequences of school-choice policies on sorting students by ability or socio-economic status across schools relates to the impact of school composition on student achievement. If a student's schoolmates influence his or her own progress, then school stratification matters for performance in education. Empirical evidence has repeatedly emphasised the role of a school's social composition on the academic performance of its students (Nash, 2003 [25]; Thrupp, 1995 ${ }_{[26]}$ ). The degree of influence a student's peers has on his or her own performance is highly debated. However, over the past decade, some consensus has emerged on the detrimental impact of attending schools with many low achievers - and the benefits of having high-achieving schoolmates (Burke and Sass, 2013 [27]; Hanushek et al., $2003_{[28]}$; Lavy, Silva and Weinhardt, 2012 $2_{[29]}$ ). In addition, several studies show that high- and low-ability students' performance may not be affected in the same way by their peers (Sacerdote, $2011_{[30]}$ ).

Taken together, this evidence suggests that sorting students into schools by ability or social status may adversely affect both the efficiency and equity of the school system. For instance, if low-ability students are more sensitive than high-achieving students to the composition of their classes, sorting students by ability across schools may have a negative impact on the aggregated performance of the school system; the reverse may also be true, depending on the nature and magnitude of peer effects. In addition, as disadvantaged students often struggle at school (because, for instance, they do not benefit from the same parental support as more advantaged students do), social and academic segregation in schools may create additional barriers to success for disadvantaged children and reduce equity in education (OECD, 2018 $8_{[31]}$ ). 
School stratification may also have long-term negative consequences for social mobility. Disadvantaged students may develop biased education and career aspirations because of the absence of inspiring role models that are usually found in schools with a greater social mix. More generally, social stratification amongst schools may threaten social cohesion, as children are not accustomed to social or ethnic diversity. ${ }^{5}$

\section{SCOPE OF THIS REPORT}

This report focuses on how school-enrolment policies have evolved over the past 15 years in a large set of countries. It examines whether these policies are related to school segregation based on students' ability and socio-economic status, and whether these changes may be associated with education performance and equity, as measured by the Programme for International Student Assessment (PISA). So far, most empirical evidence focuses on a specific country or state, making generalisations difficult. School-choice programmes vary greatly in scope and features. It would thus be difficult to draw any general conclusions from the evaluation of any one programme. Large-scale comparative analyses help to describe in a more general way the relations between school-choice programmes, school segregation and student performance.

One should be cautious in interpreting these associations, as it may be difficult to isolate enrolment practices related to school-choice policies from other specificities of the school system (such as age at first tracking or grade-repetition policies). Segregation may be mostly driven by structural factors, such as segregation in housing (Gutiérrez, Jerrim and Torres, 2017 ${ }_{[32]}$ ). Pre-existing amplifying trends in school segregation may lead to reforms that modify the rules regulating the allocation of students to schools (for instance by relaxing the link between the place where students live and the school they have been assigned to). Using different cycles of PISA reduces the risk of finding spurious correlations. One may disentangle the effects on performance related to changes in national school-choice policies (such as the share of private schools in a system or catchment-area enrolment practices) from those related to specificities of the school system. Using panel estimations with country-fixed effects is a common way of taking into account school-system specificities that are fixed over time (Hanushek and Woessmann, 2006 ${ }_{[33] ;}$; Hanushek, Link and Woessmann, 2013 $\left.[34]\right) .{ }^{6}$

In this study, all analyses are restricted to schools with the modal ISCED level for 15-year-old students. PISA students are sampled to represent all 15-year-old students, whatever type of schools they are enrolled in, but they may not be representative of their schools. This may make comparisons of school-level indicators complicated in some cases. For example, in France, there is a high rate of grade retention, and repeaters are enrolled in middle school, while 15-year-old students who have not repeated a grade are enrolled in high school. Restricting the sampling to schools with the modal ISCED level for 15-year-old students ensures that the characteristics of students sampled for PISA represent the typical profile of students attending the school. ${ }^{7}$ 


\section{Notes}

1. Using, for instance, mechanisms aimed at optimising school-student matching, as described in Abdulkadiroğlu, Che and Yasuda $\left(2015_{[40]}\right)$.

2. The term "public school" refers to a school operated by the government, while "private school" refers to an independent school (see Box 2.1 in Chapter 2 for the definition of private and public schools in PISA).

3. West and Woessmann $\left(2010_{[37]}\right)$, for instance, illustrate how the share of the private sector in a school system is explained by the opposition of Catholic minorities to state-run schooling in non-Catholic countries.

4. For details for the Flemish Community of Belgium (Nusche et al., 2015 $5_{[38]}$ ), for the French Community of Belgium (Ministère de la Fédération Wallonie-Bruxelles, Direction des Relations internationales, 2016 [36]).

5. On a related subject, the Moving to Opportunity experimental programme that proposed, from 1994 to 1998 , that low-income families move from poor to more affluent neighbourhoods, showed impact on long-term outcomes (Raj Chetty et al., 2016 $6_{[39]}$ ) and the subjective well-being (Ludwig et al., 2013 $3_{[35]}$ ) of having been raised in a better neighbourhood compared to similar (randomly selected) families.

6. Some concern may remain related to reverse causality, though.

7. The "modal ISCED level" is defined here as the level attended by at least one-third of the PISA sample. In Albania, B-S-J-G (China), Colombia, Costa Rica, the Czech Republic, Indonesia, Luxembourg, Macao (China), Mexico, Portugal, the Slovak Republic, Chinese Taipei, Trinidad and Tobago, Tunisia and Uruguay, both lower secondary (ISCED level 2) and upper secondary (ISCED level 3) schools meet this definition. In all other countries, analyses are restricted to either lower secondary or upper secondary schools (see Table B.3 in Annex B for details). In several countries, lower and upper secondary education are provided in the same school. As the restriction is made at the school level, some students from a grade other than the modal grade in the country may also be used in the analysis.

\section{References}

Abdulkadiroğlu, A., Y. Che and Y. Yasuda (2015), "Expanding 'Choice' in School Choice", American Economic Journal: Microeconomics, Vol. 7/1, pp. 1-42, http://dx.doi.org/10.1257/mic.20120027.

Abdulkadiroğlu, A., P. Pathak and C. Walters (2018), "Free to Choose: Can School Choice Reduce Student Achievement?", American Economic Journal: Applied Economics, Vol. 10/1, pp. 175-206, http://dx.doi.org/10.1257/app.20160634.

Altonji, J., C. Huang and C. Taber (2015), "Estimating the Cream Skimming Effect of School Choice", Journal of Political Economy, Vol. 123/2, pp. 266-324, http://dx.doi.org/10.1086/679497.

Black, Sandra E. and Machin, S. (2011), "Housing Valuations of School Performance", in Eric A. Hanushek, Stephen Machin, L. (ed.), Handbook of the Economics of Education, Volume 3, Elsevier, http://dx.doi.org/10.1016/B978-0-444-53429-3.00010-7.

Boeskens, L. (2016), "Regulating Publicly Funded Private Schools: A Literature Review on Equity and Effectiveness", OECD Education Working Papers, No. 147, OECD Publishing, Paris, https://dx.doi.org/10.1787/5jln6jcg80r4-en.

Burgess, S. and A. Briggs (2010), "School assignment, school choice and social mobility", Economics of Education Review, Vol. 29/4, pp. 639-649, http://dx.doi.org/10.1016/I.ECONEDUREV.2009.10.011.

Burke, M. and T. Sass (2013), "Classroom Peer Effects and Student Achievement", Journal of Labor Economics, Vol. 31/1, pp. 51-82, http://dx.doi.org/10.1086/666653. 
Epple, D. and R. Romano (2000), Neighborhood Schools, Choice, and the Distribution of Educational Benefits, National Bureau of Economic Research, Cambridge, MA, http://dx.doi.org/10.3386/w7850.

Epple, D., R. Romano and M. Urquiola (2017), "SchoolVouchers: A Survey of the Economics Literature", Journal of Economic Literature, Vol. 55/2, pp. 441-492, http://dx.doi.org/10.1257/jel.20150679.

Friedman, M. (1955), "The Role of Government in Education", in Solo, R. (ed.), Economics and the Public Interest, Rutgers University Press.

Gutiérrez, G., J. Jerrim and R. Torres (2017), School segregation across the world: has any progress been made in reducing the separation of the rich from the poor?,

https://www.semanticscholar.org/paper/School-segregation-across-the-world-\%3A-has-any-beenGuti\%C3\%A9rrez-Jerrim/0c3b26b483360b3659ca64ac68cc4628338b92fa (accessed on 13 November 2018).

Hanushek, E. et al. (2003), "Does peer ability affect student achievement?", Journal of Applied Econometrics, Vol. 18/5, pp. 527-544, http://dx.doi.org/10.1002/jae.741.

Hanushek, E., S. Link and L. Woessmann (2013), "Does school autonomy make sense everywhere? Panel estimates from PISA", Journal of Development Economics, Vol. 104, pp. 212-232, http://dx.doi.org/10.1016/j.jdeveco.2012.08.002.

Hanushek, E. and S. Rivkin (2003), "Does Public School Competition Affect Teacher Quality?", in Hoxby, C. (ed.), The Economics of School Choice, University of Chicago Press, https://www.nber.org/chapters/c10084.pdf (accessed on 4 January 2019).

Hanushek, E. and L. Woessmann (2006), "Does Educational Tracking Affect Performance and Inequality? Differences- in-Differences Evidence Across Countries", The Economic Journal, Vol. 116/510, pp. C63-C76, http://dx.doi.org/10.1111/j.1468-0297.2006.01076.x.

Hoxby, C. (2002), School Choice and School Productivity (or Could School Choice be a Tide that Lifts All Boats?), National Bureau of Economic Research, Cambridge, MA, http://dx.doi.org/10.3386/w8873.

Hsieh, C. and M. Urquiola (2006), "The effects of generalized school choice on achievement and stratification: Evidence from Chile's voucher program", Journal of Public Economics, Vol. 90/8-9, pp. 1477-1503, http://dx.doi.org/10.1016/.JPUBECO.2005.11.002.

Ladd, H. and E. Fiske (2001), "The uneven playing field of school choice: Evidence from New

Zealand", Journal of Policy Analysis and Management, Vol. 20/1, pp. 43-64,

http://dx.doi.org/10.1002/1520-6688(200124)20:1<43::AID-PAM1003>3.0.CO;2-4.

Ladd, H., E. Fiske and N. Ruijs (2011), "Does parental choice foster segregated schools? Insights from the Netherlands", in Berends, M., Cannata, M., Goldring, E. (ed.), School choice and school improvement, Harvard Education Press,

https://www.narcis.nl/publication/RecordID/oai\%3Adare.uva.nl\%3Apublications\%2Fb134401813d1-45fa-bc7c-ea2fb28485bc (accessed on 21 June 2018).

Lavy, V., O. Silva and F. Weinhardt (2012), "The Good, the Bad, and the Average: Evidence on Ability Peer Effects in Schools", Journal of Labor Economics, Vol. 30/2, pp. 367-414,

http://dx.doi.org/10.1086/663592.

Levin, H. (1998), "Educational vouchers: Effectiveness, choice, and costs", Journal of Policy Analysis and Management, Vol. 17/3, pp. 373-392,

http://dx.doi.org/10.1002/(SICI)1520-6688(199822)17:3<373::AID-PAM1>3.0.CO;2-D. 
Lubienski, C. (2009), "Do Quasi-markets Foster Innovation in Education?: A Comparative

Perspective", OECD Education Working Papers, No. 25, OECD Publishing, Paris,

https://dx.doi.org/10.1787/221583463325.

Ludwig, J. et al. (2013), "Long-Term Neighborhood Effects on Low-Income Families: Evidence from Moving to Opportunity", American Economic Review, Vol. 103/3, pp. 226-231,

http://dx.doi.org/10.1257/aer.103.3.226.

Ministère de la Fédération Wallonie-Bruxelles, Direction des Relations internationales (2016), Rapport pays (Communauté française de Belgique), Examen de l'OCDE des politiques pour un usage plus efficace des ressources scolaires,

http://www.oecd.org/education/school/School-Resources-Country-Background-Review-FrenchCommunity-Belgium.pdf (accessed on 17 January 2019).

Musset, P. (2012), "School Choice and Equity: Current Policies in OECD Countries and a Literature Review", OECD Education Working Papers, No. 66, OECD Publishing, Paris,

https://dx.doi.org/10.1787/5k9fq23507vc-en.

Nash, R. (2003), "Is the School Composition Effect Real?: A Discussion With Evidence From the UK PISA Data", School Effectiveness and School Improvement, Vol. 14/4, pp. 441-457,

http://dx.doi.org/10.1076/sesi.14.4.441.17153.

Nechyba, T. (2003), "School finance, spatial income segregation, and the nature of communities", Journal of Urban Economics, Vol. 54/1, pp. 61-88, http://dx.doi.org/10.1016/S0094-1190(03)00041-X.

Nusche, D. et al. (2015), OECD Reviews of School Resources: Flemish Community of Belgium 2015, OECD Reviews of School Resources, OECD Publishing, Paris,

https://dx.doi.org/10.1787/9789264247598-en.

OECD (2018), Equity in Education: Breaking Down Barriers to Social Mobility, PISA, OECD Publishing, Paris, http://dx.doi.org/10.1787/9789264073234-en.

OECD (2018), Responsive School Systems: Connecting Facilities, Sectors and Programmes for Student Success, OECD Reviews of School Resources, OECD Publishing, Paris, https://dx.doi.org/10.1787/9789264306707-en.

OECD (2017), School choice and school vouchers: An OECD perspective, OECD, Paris, http://www.oecd.org/education/School-choice-and-school-vouchers-an-OECD-perspective.pdf.

OECD (2012), Public and Private Schools: How Management and Funding Relate to their Socio-economic Profile, PISA, OECD Publishing, Paris, http://dx.doi.org/10.1787/9789264175006-en.

Raj Chetty, B. et al. (2016), "The Effects of Exposure to Better Neighborhoods on Children: New Evidence from the Moving to Opportunity Experiment", American Economic Review, Vol. 106/4, pp. 855-902, http://dx.doi.org/10.1257/aer.20150572.

Sacerdote, B. (2011), "Peer Effects in Education: How Might They Work, How Big Are They and How Much Do We Know Thus Far?", in Handbook of the Economics of Education, Elsevier, http://dx.doi.org/10.1016/b978-0-444-53429-3.00004-1.

Söderström, M. and R. Uusitalo (2010), "School Choice and Segregation: Evidence from an Admission Reform", Scandinavian Journal of Economics, Vol. 112/1, pp. 55-76, http://dx.doi.org/10.1111/j.1467-9442.2009.01594.x.

Thrupp, M. (1995), "The School Mix Effect: the history of an enduring problem in educational research, policy and practice", British Journal of Sociology of Education, Vol. 16/2, pp. 183-203, http://dx.doi.org/10.1080/0142569950160204. 
Urquiola, M. (2016), "Competition Among Schools: Traditional Public and Private Schools", [7] Handbook of the Economics of Education, Vol. 5, pp. 209-237, http://dx.doi.org/10.1016/B978-0-444-63459-7.00004-X.

Urquiola, M.(2005), "Does School Choice Lead to Sorting? Evidence fromTieboutVariation", American [22] Economic Review, Vol. 95/4, pp. 1310-1326, http://dx.doi.org/10.1257/0002828054825484.

West, M. and L. Woessmann (2010), "Every Catholic Child in a Catholic School': Historical

Resistance to State Schooling, Contemporary Private Competition and Student Achievement across Countries", The Economic Journal, Vol. 120/546, pp. F229-F255, http://dx.doi.org/10.1111/j.1468-0297.2010.02375.x.

Woessmann, L. (2007), "International Evidence on School Competition, Autonomy, and [13] Accountability: A Review", Peabody Journal of Education, Vol. 82/2-3, pp. 473-497, http://dx.doi.org/10.1080/01619560701313176. 



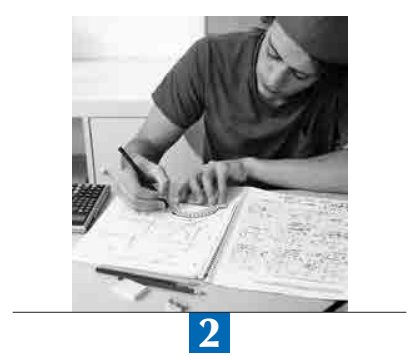

\section{How school choice can be measured by PISA and how these indicators have evolved over time}

This chapter presents several indicators in PISA for measuring school choice. It examines where the proportion of students in private schools has changed between the early 2000s and 2015, and discusses the admissions criteria schools use, notably those related to residence and to academic performance. The chapter also compares the degree of local school competition as perceived by parents and school principals.

\section{A note regarding Israel}

The statistical data for Israel are supplied by and under the responsibility of the relevant Israeli authorities. The use of such data by the OECD is without prejudice to the status of the Golan Heights, East Jerusalem and Israeli settlements in the West Bank under the terms of international law.

\section{A note regarding Lithuania}

Lithuania became a member of the OECD on 5 July 2018. However, consistent with other publications based on PISA 2015 data, Lithuania is shown as a partner country and is not included in the OECD average.

This document, as well as any data and map included herein, are without prejudice to the status of or sovereignty over any territory, to the delimitation of international frontiers and boundaries and to the name of any territory, city or area. 
Most education systems promote some kind of school choice for families. Numerous countries that participated in PISA in 2015 reported that, since 1985, they have introduced reforms aimed to enhance the choice of lower secondary school - either by providing a larger supply of both private and more independent public schools, or by offering financial aid. ${ }^{1}$ However, as school choice is a complex concept, and as corresponding policies may take various forms, one cannot isolate one single measure of the prevalence of school choice. One may consider several types of measures. The first is related to the availability of different options for parents. This measure is especially useful in determining the degree of school competition - and thus whether the existence of competitors in their areas may increase pressure on schools to maintain their attractiveness. Using PISA data, this may be approximated by the proportion of students in private schools, and also by the degree of competition between schools (as measured by a question asked of school principals).

The second approach focuses on the extent to which parents are actually able to exercise some form of school choice. Schools may, for example, select students based on socio-economic status or academic ability, and that could exacerbate school segregation, with possible adverse effects on equity. School selectivity also undermines the anticipated positive impact of competition on school quality - as positive outcomes or rankings may be more easily achieved by selecting the brightest students than by improving a school's teaching efficiency. In PISA, school-enrolment practices are proxies for school selectivity. The proportion of schools reporting that they always consider students' records of academic performance (including placement tests) for admission provides a first measure of cream skimming. By contrast, the proportion of schools that always consider a student's home address as a criterion for admission is an indicator that the set of choices (and the quality of schools) depends on where the student lives. The two hotly debated issues related to school choice focus on whether school choice promotes competition between schools (as a way of improving performance) and whether it leads to the sorting of students by ability and social status. How does school choice actually translate into school competition and the allocation of students across schools? How is school choice related to school segregation by socio-economic status and ability?

\section{IN MOST PISA-PARTICIPATING COUNTRIES, THE PROPORTION OF STUDENTS IN PRIVATE SCHOOLS DID NOT CHANGE SIGNIFICANTLY BETWEEN 2000 AND 2015}

According to PISA data, on average across OECD countries, $18.2 \%$ of 15 -year-old students were enrolled in a private school in 2015 (see Box 2.1 for the definition of private and public schools in PISA). In many countries (amongst OECD countries, Estonia, Finland, Iceland, Italy, Latvia, Norway, Poland, Slovenia and Turkey), this share is smaller than $5 \%$, but in several countries and economies (Chile, Hong Kong [China], Ireland, Lebanon, Macao [China], the Netherlands, the United Arab Emirates and the United Kingdom) more than half of students were enrolled in a privately managed school that year (Table 2.2).

In most of the countries that have participated in PISA since 2000, this share has not evolved significantly. The United Kingdom is a striking exception. In 2000, less than 10\% of 15-year-old students in the United Kingdom were enrolled in a privately managed school; by 2015, 56\% were (Figure 2.1). Such a dramatic increase may be related to the adoption of market-oriented policies that provide public funding to independent schools, such as academies or "free schools". In the United Kingdom, academies were first introduced in 2000 through the Learning and Skills Act, which allowed public schools to convert into more autonomous schools (depending on the 
type of enrolment), and the Academy Reform of 2010, which widened the academies' remit. While fewer than 150 secondary schools operated as academies in the school year 2008/2009,

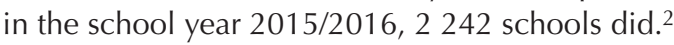

Figure 2.1 - Change between 2000 and 2015 in the percentage of students enrolled in a private school

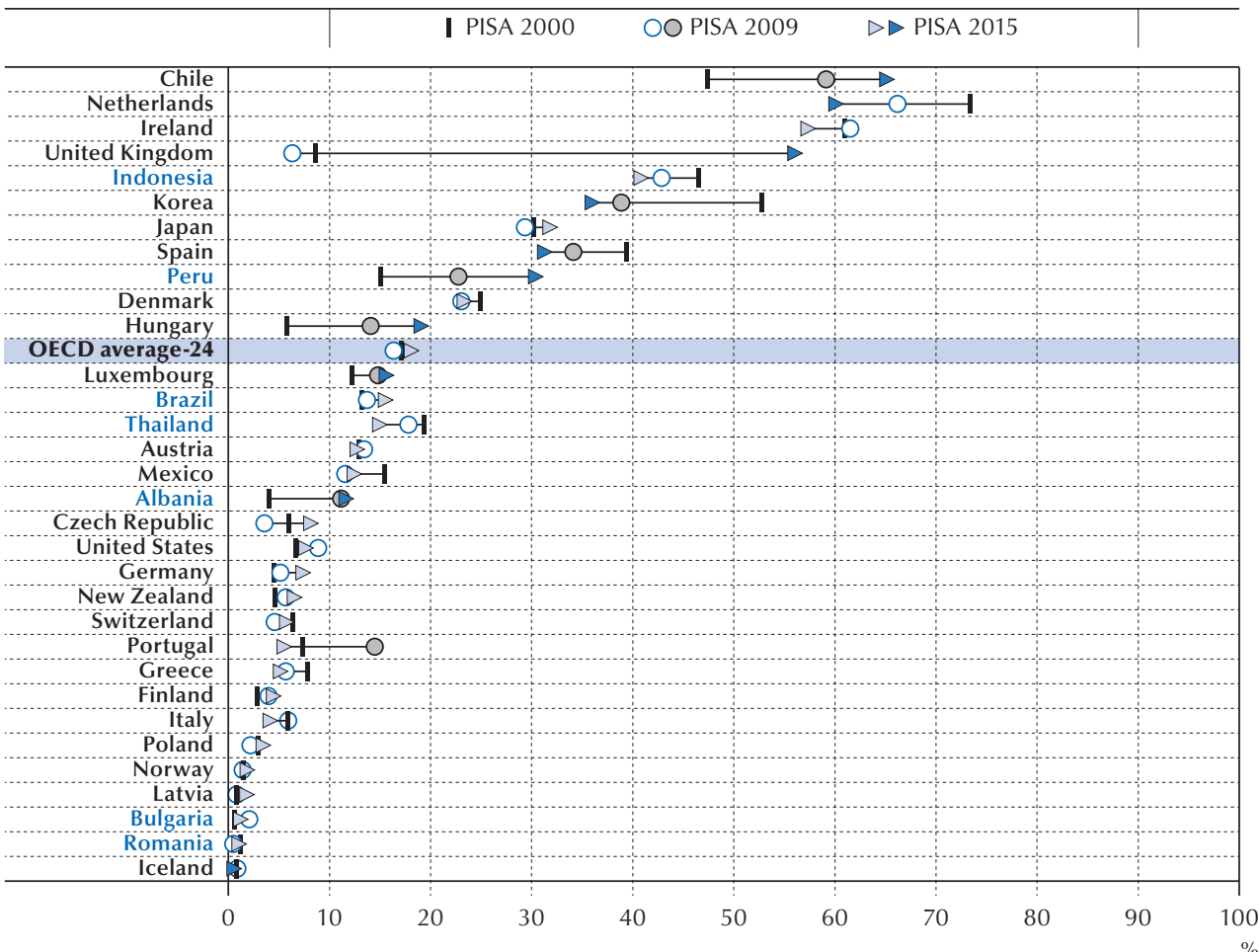

Notes: All analyses are restricted to schools with the modal ISCED level for 15-year-old students.

Public schools are those managed by the local government. Private schools are private independent schools and those funded by government but managed by not-for profit charitable trusts, including academies and free schools.

Only countries with available data in 2000, 2009 and 2015 are shown in the figure.

Statistically significant differences between 2000 and 2009 are shown in dark grey.

Statistically significant differences between 2000 and 2015 are shown in dark blue.

OECD average-24 refers to the arithmetic mean across all OECD countries with available data from 2000 to 2015

Countries and economies are ranked in descending order of the percentage of students enrolled in private schools in 2015.

Source: OECD, PISA 2000, PISA 2009 and PISA 2015 Databases, Table 2.2.

StatLink 需可 https://doi.org/10.1787/888933971404

Apart from the United Kingdom, the proportion of students enrolled in private schools did not change significantly between 2000 and 2015 in two-thirds of the 32 countries with comparable data from 2000, 2009 and 2015 (Figure 2.1). That proportion increased significantly over the period in five other countries (Albania, Chile, Hungary, Luxembourg and Peru), while it decreased in four countries (Iceland, Korea, the Netherlands and Spain). However, actual changes in school choice may not be evident because of differences in the definition of private schools. PISA classifies school type based on the principal's reports. In some instances, the principal may consider a privately managed school public if the funding comes mainly from the government. 
For instance, charter schools in the United States are commonly defined as public schools. While the proportion of charter schools increased by more than $50 \%$ over the past two decades, ${ }^{3}$ the proportion of students enrolled in private schools, as reported by school principals in PISA, appears almost stable. This is another argument for examining the existence of choice amongst public schools, notably by measuring whether families report that several schools compete in the neighbourhood, and by analysing the enrolment practices of schools.

Private schools are not the only choice for parents. In 2009, in 35 out of 46 countries with available data, "there is free choice of other public schools if there were places available"; in 26 of these countries "families were given a general right to enrol in any traditional public school they wish" (Table 2.1). ${ }^{4}$

\section{MORE COMPETITION FOR SCHOOL PRINCIPALS DOES NOT ALWAYS TRANSLATE INTO MORE CHOICE FOR FAMILIES}

The general right of families to choose amongst private or different public schools is expected to create, at the local level, more competition between schools. Regulations in and of themselves do not necessarily correspond to the degree of choice - or competition, as perceived by parents on the one hand and school leaders on the other. The reality on the ground may differ from the regulatory environment for a variety of reasons, including the affordability and accessibility of schools.

In some cycles of PISA, context questionnaires contained questions for school principals about local competition amongst schools. In 2012, on average across OECD countries, 77\% of students were enrolled in schools whose principal reported that the school competes with at least one other school for enrolment (Figure 2.2). ${ }^{5}$ This proportion ranged from 35\% in Norway to $99 \%$ in Singapore. These variations may be explained by differences in school systems, such as the importance of private schooling or distinct regulations concerning open enrolment. In a country with open enrolment, for instance, schools are expected to compete with all other schools in the area. These variations may also be explained simply by population density. The number of local schools is obviously related to the potential number of students in an area. One should therefore expect to observe more competition between schools in urban areas than in rural areas.

School principals' perceptions may also differ from parents' reports on school choice. School principals usually consider as "competitors" all schools - and all types of schools - that may potentially enrol the students in their area. Parents may consider only the actual options that they have reviewed as affordable or desirable for their child.

In 2012, in some PISA-participating countries and economies, parents' perceptions could be compared with school principals' perceptions. In nine countries (Belgium, Chile, Croatia, Germany, Hungary, Italy, Korea, Mexico and Portugal) and two economies (Hong Kong [China] and Macao [China]) parents of the students who participated in PISA were asked the same question as principals about local competition amongst schools. Parents perceived less local competition amongst schools than school principals did. However, in most cases, the proportion of students in schools where at least half of parents reported that there is at least one competing school in the area was only slightly smaller than the proportion of students in schools whose principals so reported (Figure 2.3). 


\section{Table 2.1 - Freedom for parents to choose a public school for their children, 2009}

\begin{tabular}{|c|c|c|c|c|c|c|}
\hline$O E C D$ & $\begin{array}{c}\text { Initial } \\
\text { assignment } \\
\text { based on } \\
\text { geographical } \\
\text { area } \\
\text { schools } \\
\end{array}$ & $\begin{array}{l}\text { Families are given } \\
\text { a general right } \\
\text { to enrol in any } \\
\text { traditional public } \\
\text { school they wish }\end{array}$ & $\begin{array}{l}\text { Choice of other } \\
\text { public schools } \\
\text { is restricted to } \\
\text { the district or } \\
\text { municipality }\end{array}$ & $\begin{array}{l}\text { Choice of } \\
\text { other public } \\
\text { schools is } \\
\text { restricted by } \\
\text { region }\end{array}$ & $\begin{array}{l}\text { Families must } \\
\text { apply to enrol in } \\
\text { a public school } \\
\text { other than the } \\
\text { one assigned to } \\
\text { their child(ren) }\end{array}$ & $\begin{array}{l}\text { There is free } \\
\text { choice of other } \\
\text { public schools if } \\
\text { there are places } \\
\text { available }\end{array}$ \\
\hline Austria & Yes & Yes & No & No & Yes & Yes \\
\hline Belgium (Fl.) & No & Yes & No & No & No & Yes \\
\hline Belgium (Fr.) & No & Yes & No & No & No & Yes \\
\hline Chile & No & Yes & No & No & No & No \\
\hline Czech Republic & Yes & Yes & No & No & No & Yes \\
\hline Denmark & Yes & Yes & No & No & Yes & Yes \\
\hline Estonia & Yes & Yes & No & No & Yes & Yes \\
\hline Finland & Yes & No & No & No & Yes & No \\
\hline France & Yes & No & No & No & Yes & Yes \\
\hline Germany & Yes & No & No & No & Yes & Yes \\
\hline Greece & Yes & No & No & No & No & No \\
\hline Hungary & Yes & Yes & No & No & Yes & Yes \\
\hline Iceland & Yes & No & Yes & Yes & Yes & Yes \\
\hline Ireland & Yes & Yes & No & No & Yes & Yes \\
\hline Israel & Yes & Yes & Yes & Yes & No & Yes \\
\hline Italy & Yes & Yes & No & No & Yes & Yes \\
\hline Japan & Yes & No & No & Yes & Yes & No \\
\hline Korea & Yes & No & No & No & No & No \\
\hline Latvia & Yes & No & Yes & No & No & Yes \\
\hline Luxembourg & Yes & Yes & No & No & Yes & Yes \\
\hline Mexico & Yes & Yes & No & No & Yes & Yes \\
\hline Netherlands & No & No & No & No & No & No \\
\hline New Zealand & No & Yes & No & No & Yes & Yes \\
\hline Norway & Yes & No & Yes & Yes & Yes & No \\
\hline Poland & Yes & No & Yes & Yes & Yes & Yes \\
\hline Portugal & Yes & Yes & No & No & Yes & Yes \\
\hline Slovak Republic & Yes & Yes & No & No & No & Yes \\
\hline Slovenia & Yes & No & No & No & Yes & Yes \\
\hline Spain & Yes & Yes & No & No & Yes & Yes \\
\hline Sweden & Yes & No & No & No & No & Yes \\
\hline Switzerland & Yes & No & Yes & Yes & Yes & No \\
\hline United States & Yes & $\mathrm{m}$ & Yes & Yes & Yes & No \\
\hline \multicolumn{7}{|l|}{ Partners } \\
\hline Argentina & Yes & Yes & No & Yes & No & Yes \\
\hline Brazil & Yes & Yes & Yes & Yes & Yes & Yes \\
\hline Bulgaria & No & Yes & No & No & No & Yes \\
\hline Colombia & Yes & No & No & No & Yes & Yes \\
\hline Croatia & Yes & No & Yes & Yes & Yes & Yes \\
\hline Hong Kong (China) & Yes & Yes & No & No & Yes & Yes \\
\hline Lithuania & Yes & No & No & No & No & No \\
\hline Macao (China) & No & Yes & No & No & No & Yes \\
\hline Montenegro & Yes & Yes & No & No & Yes & Yes \\
\hline Peru & No & Yes & No & No & No & Yes \\
\hline Qatar & Yes & No & No & No & Yes & Yes \\
\hline Singapore & No & Yes & No & No & No & Yes \\
\hline Chinese Taipei & Yes & No & Yes & Yes & Yes & No \\
\hline Thailand & Yes & Yes & Yes & Yes & Yes & Yes \\
\hline $\begin{array}{l}\text { Number of countries/ } \\
\text { economies with a "Yes" }\end{array}$ & 37 & 26 & 11 & 12 & 29 & 35 \\
\hline $\begin{array}{l}\text { Total number of } \\
\text { countries/economies } \\
\text { with available data } \\
\end{array}$ & 46 & 45 & 46 & 46 & 46 & 46 \\
\hline
\end{tabular}

Note: Only countries and economies with available data are included.

Source: OECD (2010), PISA 2009 Results: What Makes a School Successful?: Resources, Policies and Practices (Volume IV), PISA, OECD Publishing, Paris, https://doi.org/10.1787/9789264091559-en, Table IV.3.7

StatLink הiाs https://doi.org/10.1787/888933971803 
Figure 2.2 - School competition, 2012

Percentage of students in schools that compete with at least one other local school; based on school principals' reports

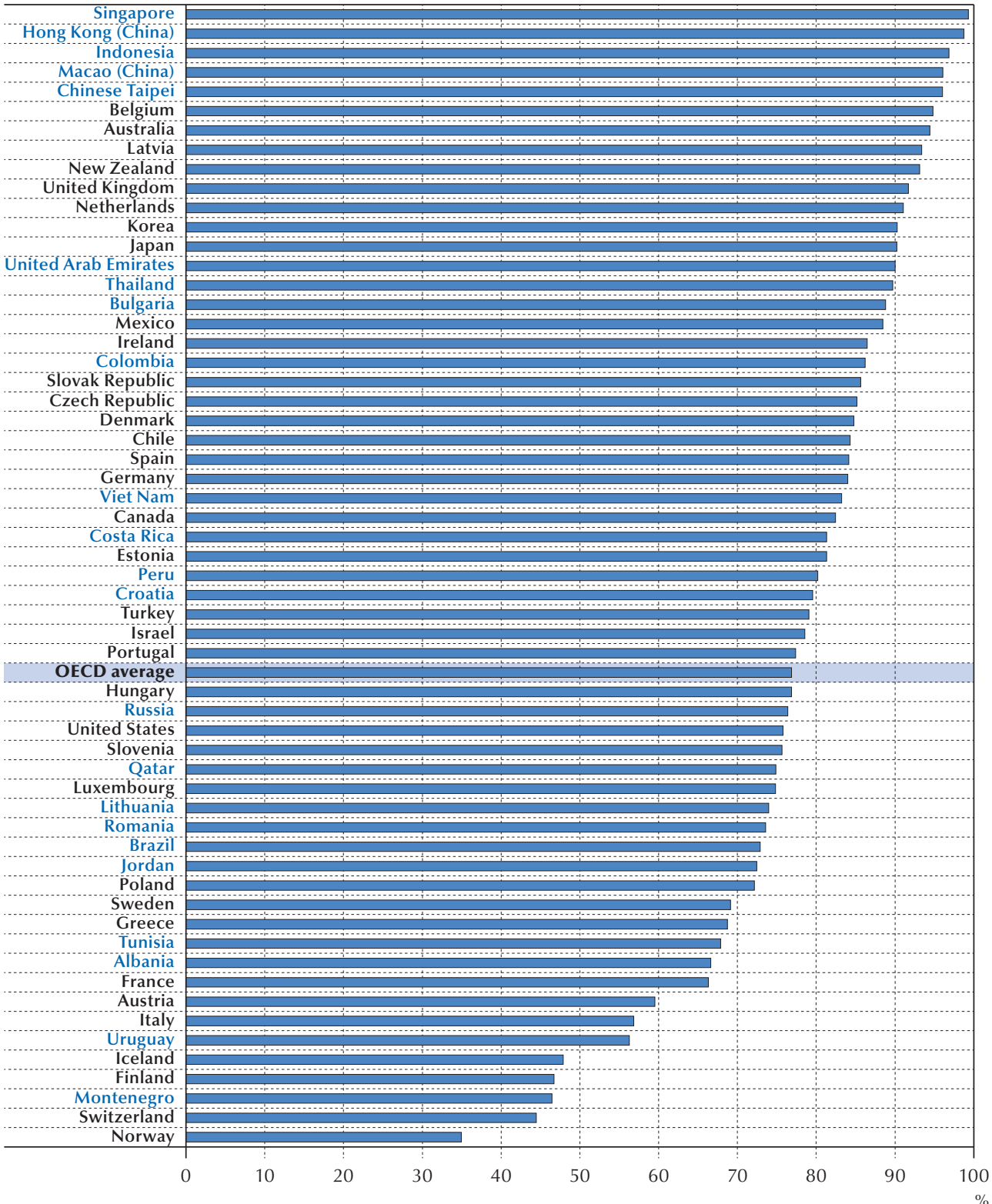

Note: All analyses are restricted to schools with the modal ISCED level for 15-year-old students.

Countries and economies are ranked in descending order of the percentage of students in schools that compete with at least one other local school, according to school principals.

Source: OECD, PISA 2015 Database, Table 2.3.

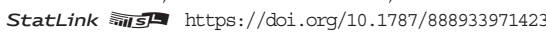




\section{Figure 2.3 - Percentage of students in schools that compete with at least one} other local school, 2012

Based on school principals' and parents' reports

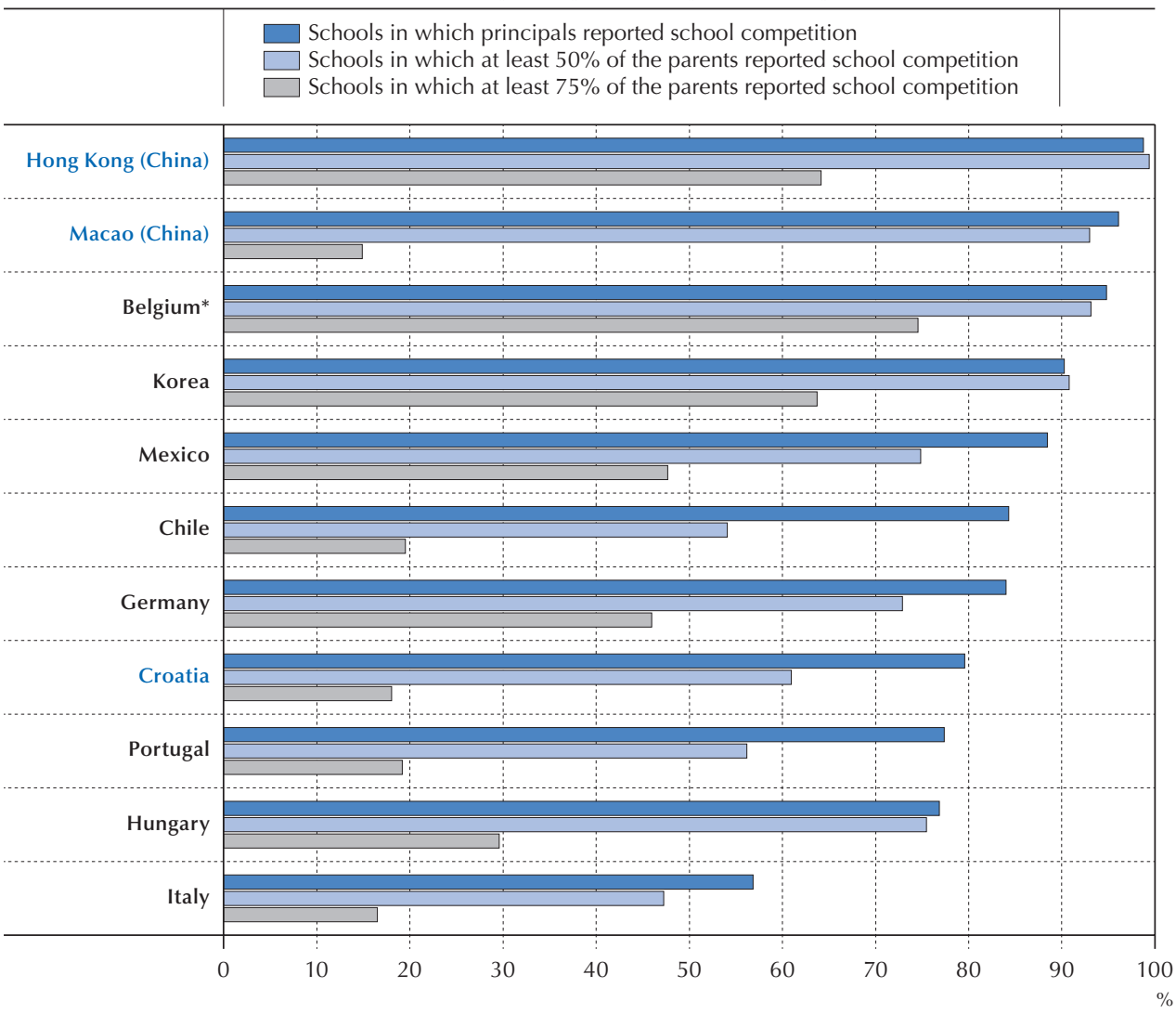

*Parents' reports for Flemish Community only.

Notes: All analyses are restricted to schools with the modal ISCED level for 15-year-old students.

Only countries and economies with available data are shown.

Countries and economies are ranked in descending order of the percentage of students in schools that compete with at least one other school in the area, according to school principals.

Source: OECD, PISA 2012 Database, Table 2.3.

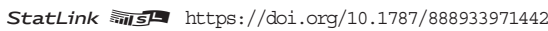

But in many instances, even though the principal reported that his or her school competes with other schools, at least a quarter of parents whose children attend that school didn't feel that way. The proportion of students in schools where at least $75 \%$ of parents reported that the school has at least one local competitor was always much smaller than the proportion of students in schools whose principal reported local competition. For instance, in Chile, Germany and Macao (China), more than $80 \%$ of school principals reported that their school competes with at least one other school, while in less than $20 \%$ of schools did a majority of parents so report.

These differences in perception suggest that local competition does not always translate into more options for parents. A set of factors may limit those options. For instance, tuition fees may make it 
impossible for some families to choose private or independent schools, or a lack of transportation might make access to public schools difficult or impossible. Parents and school principals may also differ in their perception of the size of the "area" to consider. ${ }^{6}$ Some parents are likely to consider only schools in close proximity to their home in order to avoid long commutes. In 2015, a majority of parents, and particularly those in disadvantaged families, reported that distance is an important consideration when choosing a school (OECD, 2016 $\left.6_{[1]}\right)$.

Moreover, the actual choice may be restricted if all schools do not propose the same curriculum. For instance, in vocational education, some specialities may be proposed only by a limited number of schools because they require specific equipment. When choosing a school, parents may consider the fact that the schools "belong to a certain community or ethnic group", or propose pedagogical approaches that may be more appealing to some families than to others. For instance, some families may be reluctant to enrol their children in a religious school because they themselves are not religious or they practice a different religion.

Students' previous school achievement may also affect the degree of choice. Because of local competition, schools may be tempted to skim off the most affluent or highest-achieving students. Restricting enrolment to the most able students makes it easier for a school to rank high in public evaluations, thus maintaining its attractiveness to parents. Indeed, parents have reported that a good reputation and a safe environment are the main considerations when choosing a school for their child (OECD, 2015 $5_{[2]}$ ). Low-achieving students may have little opportunity to choose schools if schools base their admissions on prior academic performance.

\section{IN MANY PISA-PARTICIPATING COUNTRIES, THE ALLOCATION OF STUDENTS TO SCHOOLS DEPENDED LESS ON RESIDENCE IN 2015 THAN IN 2000, AND SCHOOLS BECAME MORE SELECTIVE OVER THE PERIOD}

In almost all school systems, students are assigned to schools based, at least partly, on their home address. Through this policy, students are typically assigned to the school closest to their home. The main objective may be to avoid long and costly commutes to and from school. In 2009, only eight PISA countries and economies reported that students' initial assignment to lower secondary school was not based on geographical location: Belgium, Bulgaria, Chile, Macao (China), the Netherlands, New Zealand, Peru and Singapore (Table 2.1). ${ }^{7}$ In other countries and economies, residence-based rules rarely translate into a rigid assignment to one particular local school.

PISA also asked school principals to cite the criteria used for admissions. In 2009, around 40\% of students, on average across OECD countries, attended a school whose principal reported that "residence is always considered when students are admitted to [their] school" (Table 2.4a). This proportion was especially large in some countries, though. For instance, it was close to or larger than $75 \%$ in Canada, Finland, Norway, Poland, Switzerland, Tunisia and the United States. Lower population density in some areas, or limited access to transportation or schools, may lead to a stronger link between residence and school.

In the majority of countries and economies that participated in PISA in 2000, 2009 and 2015, the proportion of students attending schools that always consider residence for admissions shrank (Figure 2.4). This decline is significant in 11 out of 38 countries and economies. The proportion increased significantly in only five countries: Hungary, Israel, Luxembourg, Poland 
and the Russian Federation. ${ }^{8}$ The dramatic increase observed in Poland may be explained by the 1999 education reform in that country. This reform extended the period of general education by one year. In 2000, 15-year-old students in Poland were still allocated across various kinds of secondary schools; but in subsequent cycles of PISA, they were enrolled in the same types of lower secondary schools. For those schools, admissions were mainly residence-based. ${ }^{9}$ Separate analyses of the students in lower secondary (ISCED 2) and upper secondary (ISCED 3) education suggest that the change affected lower secondary schools more than upper secondary schools (Tables 2.4b and 2.4c) since residence-based admissions had been more widely used in the former. In all countries where 15-year-old students could have been enrolled at either level, in 2000, fewer upper secondary than lower secondary schools based their admissions on residence.

As discussed above, a highly debated issue is whether school choice has resulted in more sorting of students, as highly attractive schools are not always able or willing to increase their intakes to enrol all applicants and may be tempted to select the highest achievers - "cream skim" the best students. Introducing school choice may thus indirectly increase school selectivity in the absence of specific regulations aimed to reduce these sorting effects.

In 2015, on average across OECD countries, around 40\% of students were enrolled in schools whose principal reported that "Students' records of academic performance (including placement tests) are always considered when students are admitted to [their] schools" (Table 2.5a). However, the selectivity of schools varied strikingly across countries. In 2015, less than $10 \%$ of students in Denmark, Finland, Greece, Norway, Spain and Sweden were enrolled in selective schools; by contrast, at least $90 \%$ of students in Croatia, Hong Kong (China), Japan and Thailand were.

These figures are not necessarily related to school-choice programmes. School selectivity may depend on several factors. Differentiated school systems, where students are streamed into distinct education programmes (some with mostly academic curricula, others mostly vocational), are usually more selective than comprehensive school systems, in which all 15-year-old students follow the same programme. Academic criteria are also expected to be more often considered in upper secondary than in lower secondary schools in systems where these two levels of education are not provided in the same schools $\left(\mathrm{OECD}, 2013_{[3]}\right)$. As discussed above, as a result of the 1999 education reform, most 15-year-old students in Poland are now enrolled in lower secondary schools with residence-based admissions policies. This is expected to translate into a sharp drop in the proportion of selective schools.

More generally, one may want to analyse changes by looking separately at students in lower secondary (ISCED 2) and upper secondary (ISCED 3) schools.

School principals in many countries reported that, since 2000, prior academic performance has become increasingly important, and residence less important, when considering students for admission to their schools. Across the 37 countries and economies that participated in PISA in both the early 2000s and 2015, the proportion of students in selective schools increased significantly in 15 countries and economies (Brazil, Canada, Denmark, Finland, France, Germany, Hong Kong [China], Luxembourg, Iceland, Ireland, Israel, New Zealand, Portugal, Spain and Thailand) and decreased significantly in 8 countries (Chile, the Czech Republic, Korea, Latvia, the Republic of North Macedonia, Poland, Romania and the Russian Federation) (Table 2.5a). 
Figure 2.4 - Change between 2000 and 2015 in school admissions based on residence

Percentage of students enrolled in schools in which residence is always considered for admission

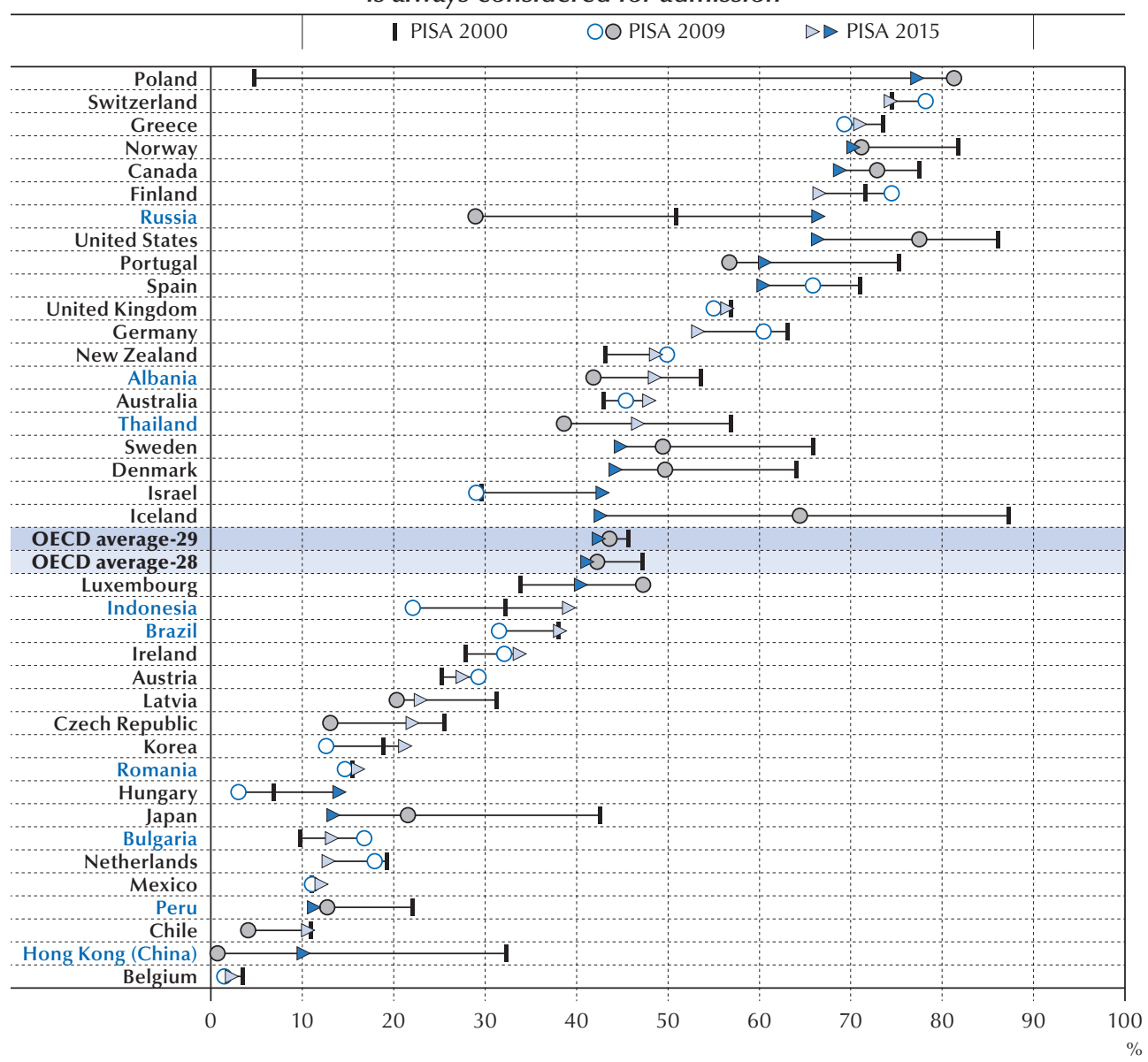

Notes: All analyses are restricted to schools with the modal ISCED level for 15-year-old students.

Only countries with available data in 2000, 2009 and 2015 are shown in the figure.

Statistically significant differences between 2000 and 2009 are shown in dark grey.

Statistically significant differences between 2000 and 2015 are shown in dark blue.

OECD average-29 refers to the arithmetic mean across all OECD countries with available data from 2000 to 2015.

OECD average-28 refers to the arithmetic mean across all OECD countries with available data from 2000 to 2015, except Poland.

Countries and economies are ranked in descending order of the percentage of students enrolled in schools in which residence was always considered for admission in 2015.

Source: OECD, PISA 2000, PISA 2009 and PISA 2015 Databases, Table 2.4a.

StatLink तins https://doi.org/10.1787/888933971461 
Figure 2.5 - Change between 2000 and 2015 in school admissions based on academic performance

Percentage of students enrolled in schools in which academic performance (including placement tests) is always considered for admission

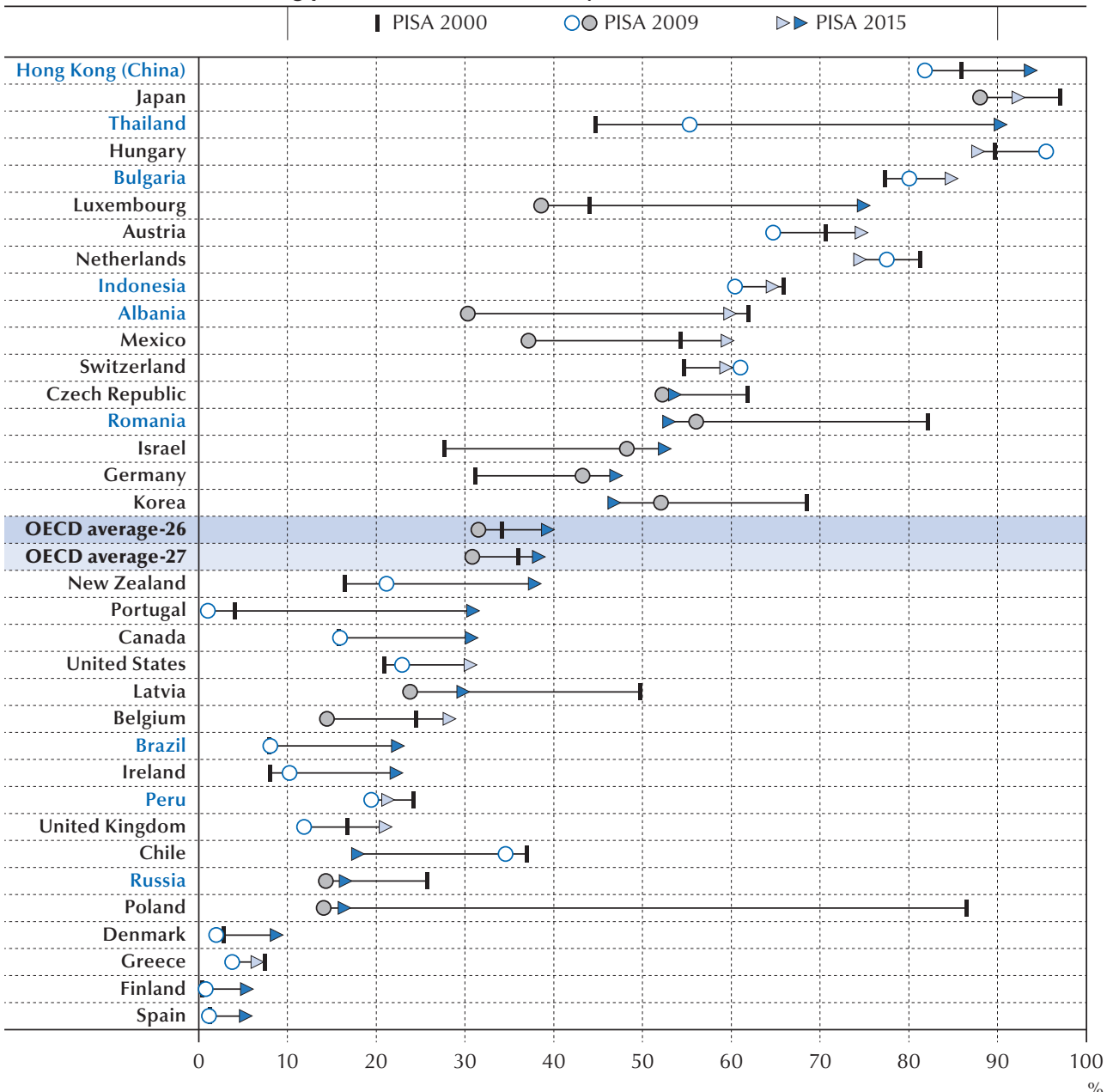

Notes: All analyses are restricted to schools with the modal ISCED level for 15-year-old students.

Only countries with available data in 2000, 2009 and 2015 are shown in the figure.

Statistically significant differences between 2000 and 2009 are shown in dark grey.

Statistically significant differences between 2000 and 2015 are shown in dark blue.

OECD average-27 refers to the arithmetic mean across all OECD countries with available data from 2000 to 2015.

OECD average-26 refers to the arithmetic mean across all OECD countries with available data from 2000 to 2015, except Poland.

Countries and economies are ranked in descending order of the percentage of students enrolled in schools in which academic performance was always considered for admission in 2015.

Source: OECD, PISA 2000, PISA 2009 and PISA 2015 Databases, Table 2.5a.

StatLink 需s ht htps://doi.org/10.1787/888933971480 
Figure 2.6 - School admissions based on academic performance, by school type Percentage of students enrolled in schools in which academic performance (including placement tests) is always considered for admission

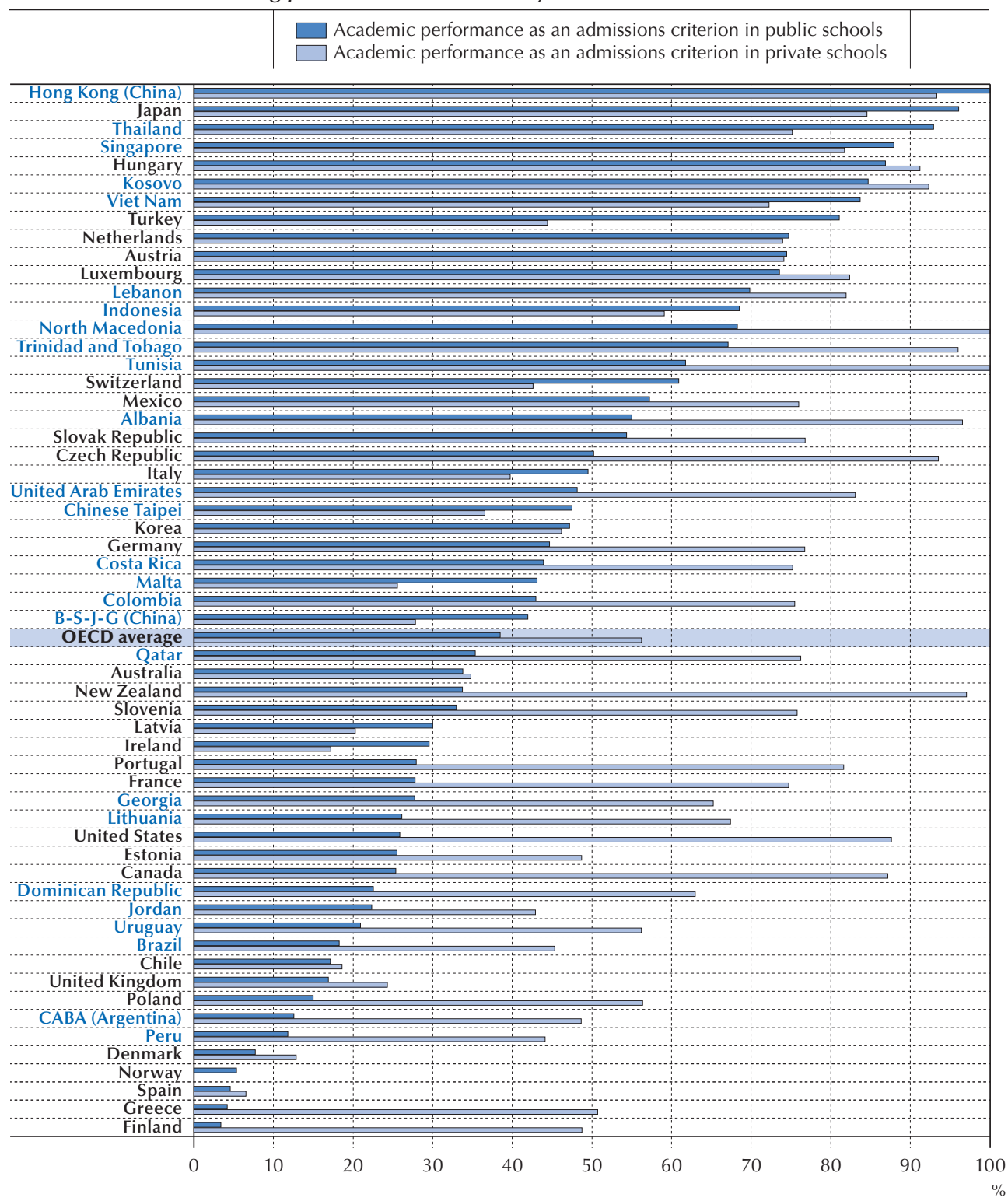

Notes: All analyses are restricted to schools with the modal ISCED level for 15-year-old students.

Public schools are those managed by the local government. Private schools are private independent schools and those funded by government but managed by not-for profit charitable trusts, including academies and free schools.

Countries and economies are ranked in descending order of the percentage of students enrolled in public schools in which academic performance is always considered for admission.

Source: OECD, PISA 2015 Database, Table 2.6.

StatLink 需s https://doi.org/10.1787/888933971499 
The trend towards greater school selectivity was reinforced during the 2010s. When compared to the level that prevailed in 2009, ${ }^{10}$ the proportion of school admissions based on academic performance increased significantly in 34 of the 59 countries and economies that participated in PISA in both 2009 and 2015 (Table 2.5a); in 24 of these countries, the increase was more than 10 percentage points. It decreased significantly in only three countries: Chile, by 16 percentage points, Hungary, by 8 percentage points and Malta, by 14 percentage points. The consistent decrease in school selectivity in Chile over the period may be explained by a major reform introduced in 2008 and extended in 2011. The reform aimed to reduce socio-economic segregation across schools by providing financial incentives to schools that enrol disadvantaged students. ${ }^{11}$

When considering students separately, depending on the level of education in which they are enrolled, the trend towards more selectivity is observed between 2009 and 2015 in both lower and upper secondary schools in many countries, except Chile, Hungary and Luxembourg where school selectivity at the upper secondary level has decreased (Tables 2.5b and 2.5c).

In 2015, more private schools (56\%) than public schools (39\%), on average across OECD countries, based their selection of students on academic criteria (Figure 2.6). However, in nearly one in four countries with available data, public schools were at least as likely as private schools to consider academic performance in their admissions process, or even, as in Ireland, Italy, Japan, Switzerland, Turkey and Thailand, much more likely to be selective than private schools. This reflects the variety of regulatory frameworks, notably for government-dependent private schools (see Box 2.1).

\section{Box 2.1 Public school, government-dependent and government-independent, privately managed schools}

Public schools, as defined in PISA, are those managed by a public education authority, government agency, or governing board appointed by a government or elected by public franchise. Private schools refer to schools managed directly or indirectly by a non-governmental organisation, such as a church, trade union, business or other private institution. Privately managed schools are classified as government-independent when at least $50 \%$ of the funding comes from private sources or as government-dependent when at least $50 \%$ of the funding comes from the government (OECD, 2016 $6_{[1]}$ ). As in many countries, the number of students/schools in the private government-dependent or private independent categories is insufficient to be used for the estimates. For this reason, in this analysis, government-dependent and government-independent private schools are analysed jointly.

Government-dependent private schools are usually required to comply with government regulations to a greater extent than independent private schools. Nevertheless, conditions under which private providers are eligible for public funding vary considerably among OECD countries. In some countries, publicly funded private schools do not only enjoy greater pedagogical freedom than their publicly managed counterparts, but also greater autonomy in their admissions and tuition policies. Other systems impose strict eligibility criteria on private schools seeking to qualify for public funding, for instance, obliging them 
to follow national curricula and assessment procedures, prohibiting for-profit operators, or restricting their ability to charge add-on fees and engage in selective admissions (Boeskens, $\left.2016_{[4]}\right)$. In Belgium, for example, subsidised private schools are not permitted to select students on the basis of their academic achievement in order to guarantee parents' right to exercise free school choice (see Box 6.1). In the Netherlands, government-dependent private schools need to comply with the same regulations governing the school admissions and tuition fees as public schools. Other systems use targeted-funding schemes designed exclusively to benefit or provide additional support to disadvantaged students in private schools (Musset, 2012 $2_{[5]}$ ). While it is relatively common for oversubscribed public schools to take into account non-academic factors, such as the proximity of a student's home or the presence of their siblings, in some countries publicly funded private schools are permitted to select students on the basis of academic achievement, aptitude tests and parent interviews. These differential selection practices can restrict the exercise of school choice and risk increasing student segregation across providers.

Source: OECD (2017), The Funding of School Education: Connecting Resources and Learning, OECD Reviews of School Resources, OECD Publishing, Paris, https://doi.org/10.1787/9789264276147-en. 


\section{Notes}

1. This could be either by "creating new autonomous public or government-dependant private schools, to offer new options from which parents can choose", "expanding the opportunities for families to choose a government-dependent private school", "reducing restrictions to school choice among existing public schools" or "including new funding mechanisms that promote school choice". See Table IV.3.7 in PISA 2009 Results: What Makes a School Successful?: Resources, Policies and Practices (OECD, 2010 $\left.0_{[6]}\right)$.

2. According to the Academies Annual Report 2010/11 (UK Government Department of Education, 2012 ${ }_{[10]}$ ) and the Academy schools sector in England: consolidated annual report and accounts - year ended 31 August 2016 (UK Government Department of Education, 2017 $\left.{ }_{[11]}\right) 133$ primary or secondary schools operated as academies in the school year 2008/2009, while in 2002/2003 only 3 did.

\section{See https://nces.ed.gov/programs/digest/d17/tables/dt17 216.20.asp?current=yes}

4. Based on the system-level questionnaire.

5. This question was not asked in the school questionnaire in PISA 2015.

6. This may specifically depend on the distribution of schools and their degree of dispersion. For instance, depending on their geographical location in the centre or on the contrary at the boundary of cities or school districts, parents and school principals are expected to respectively consider more or less options and perceive more or less intense competitive pressure.

7. This does not mean that the allocation of students in schools does not depend at all on home residence. For instance, in New Zealand, parents must adhere to school-enrolment schemes that are used by some school boards to avoid overcrowding in schools. In state schools, enrolment schemes define a home zone as lying within specific geographic boundaries; establish pre-enrolment procedures for students who live outside of home zones; and identify any special programmes offered by the school and related criteria for student acceptance to these programmes (Education Act 1989, part 2, section 11c). Enrolment schemes for stateintegrated schools must comply with the same requirements outlined above, but may prioritise enrolment of students of a particular religious faith to preserve the school's special character.

8. For the Russian Federation, since 2005 preference was given to those who live in proximity of a school (Põder et al., 2016 $\left.6_{[7]}\right)$. The observed pattern (a decrease from 2000 to 2009, then an increase from 2009 to 2015 ) is not consistent, however, except in the case of a delayed application of this rule.

9. For an evaluation of the impact of the reform of the Polish school system on social equity in education, see (Le Donné, 2014 $\left.4_{[8]}\right)$.

10. The question was also asked in 2003 and 2006, but the formulation was not exactly identical, making comparisons difficult.

11. In 2008, the Law on Preferential Subsidies (Subvención Escolar Preferencial, SEP) provided additional funding to primary schools (extended in 2011 to secondary schools) for the enrolment of socio-economically disadvantaged students. See, for instance, (Santiago et al., 2017 $7_{[9]}$ ) and for an evaluation of the impact of the SEP on segregation (Valenzuela, Allende and Trivelli, 2015 $\left.{ }_{[12]}\right)$. This law was complemented in 2015 by the Inclusion Law,that forbids schools to select students based on social, cultural or academic criteria, and also forbids schools that receive public funding to ask for additional fees from parents. This is unlikely to be observed in the data from PISA 2015, though. 


\section{References}

Boeskens, L. (2016), "Regulating Publicly Funded Private Schools: A Literature Review on Equity and Effectiveness", OECD Education Working Papers, No. 147, OECD Publishing, Paris, https://dx.doi.org/10.1787/5jln6jcg80r4-en.

Le Donné, N. (2014), "La réforme de 1999 du système éducatif polonais Effets sur les inégalités sociales de compétences scolaires", Revue française de sociologie, Vol. 55/1, p. 127,

http://dx.doi.org/10.3917/rfs.551.0127.

Musset, P. (2012), "School Choice and Equity: Current Policies in OECD Countries and a Literature Review", OECD Education Working Papers, No. 66, OECD Publishing, Paris, https://dx.doi.org/10.1787/5k9fq23507vc-en.

OECD (2016), PISA 2015 Results (Volume II): Policies and Practices for Successful Schools, PISA, OECD Publishing, Paris, https://dx.doi.org/10.1787/9789264267510-en.

OECD (2015), "What do parents look for in their child's school?", PISA in Focus, Vol. 51, http://dx.doi.org/10.1787/888932957498.

OECD (2013), PISA 2012 Results: What Makes Schools Successful (Volume IV): Resources, Policies and Practices, PISA, OECD Publishing, Paris, https://dx.doi.org/10.1787/9789264201156-en.

OECD (2010), PISA 2009 Results: What Makes a School Successful?: Resources, Policies and Practices (Volume IV), PISA, OECD Publishing, Paris, https://dx.doi.org/10.1787/9789264091559-en.

Põder, K. et al. (2016), "Family Background and School Choice in Cities of Russia and Estonia: Selective Agenda of the Soviet Past and Present", Studies of Transition States and Societies, Vol. 8/3, http://publications.tlu.ee/index.php/stss/article/view/292 (accessed on 14 December 2018).

Santiago, P. et al. (2017), OECD Reviews of School Resources: Chile 2017, OECD Reviews of School Resources, OECD Publishing, Paris, https://dx.doi.org/10.1787/9789264285637-en.

UK Government Department of Education (2017), Academy Schools Sector in England, Consolidated Annual Report and Accounts 2015/16, http://www.gov.uk/government/publications/academies-consolidated-annual-report-and-accounts2015-to-2016.

UK Government Department of Education (2012), Academies Annual Report 2010/11, [10] http://www.gov.uk/government/publications/academies-annual-report-201011.

Valenzuela, J., C. Allende and G. Trivelli (2015), El efecto de la SEP en la reducción de la segregación socioeconómica del sistema escolar chileno. Primeros Resultados [The impact of the SEP on the reduction of socio-economic segregation in the Chilean school system], Fondo de investigation y Desarrollo en Education,

https://centroestudios.mineduc.cl/wp-content/uploads/sites/100/2017/07/F811333-Informe-FinalValenzuela-UCHILE.pdf (accessed on 17 January 2019). 


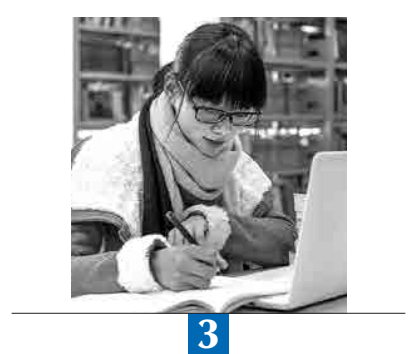

\section{The level of social and academic segregation across schools}

This chapter analyses the sorting of students across schools by socioeconomic status and ability. The degree of both social and academic segregation across schools is measured by several indicators, illustrating the various ways segregation is manifested in a school system.

\section{A note regarding Israel}

The statistical data for Israel are supplied by and under the responsibility of the relevant Israeli authorities. The use of such data by the OECD is without prejudice to the status of the Golan Heights, East Jerusalem and Israeli settlements in the West Bank under the terms of international law.

\section{A note regarding Lithuania}

Lithuania became a member of the OECD on 5 July 2018. However, consistent with other publications based on PISA 2015 data, Lithuania is shown as a partner country and is not included in the OECD average.

This document, as well as any data and map included herein, are without prejudice to the status of or sovereignty over any territory, to the delimitation of international frontiers and boundaries and to the name of any territory, city or area. 


\section{ACADEMIC SEGREGATION IS OFTEN MORE WIDESPREAD ACROSS SCHOOLS THAN SOCIAL SEGREGATION}

Segregation is a complex notion that cannot be fully captured by one single indicator or index (an extensive discussion is provided in Annex A). A common way of analysing school segregation is to see the extent to which students are evenly (or unevenly) distributed across schools, whatever their individual characteristics. The dissimilarity index is one of the indices most commonly used for this purpose. It is usually measured by considering two groups, for example, socio-economically disadvantaged students and students with average or advantaged status. It corresponds to the average proportions of students from both groups (e.g. disadvantaged and notdisadvantaged students) that would need to be reallocated in order to obtain an even distribution of students from these groups across all schools. This index ranges from 0 (no segregation) to 1 (full segregation). A high dissimilarity index means that the distribution of disadvantaged students across schools is different from that of students who are not considered to be disadvantaged, and thus an indication of the processes of sorting students across schools.

Using the dissimilarity index to compare academic segregation (for instance, the lowest achievers in the country compared with those who score higher in PISA) and social segregation (disadvantaged students compared with average or advantaged students), ${ }^{1}$ results show that in almost all countries and economies, there is a higher incidence of academic segregation than social segregation (Figure 3.1). This may be due to several characteristics of the school system (such as the use of grade repetition, the age at first tracking, etc.) and not only to school practices.

For instance, Belgium and the Netherlands are amongst the few countries where a prospective student's home address is not considered at all for admission to a particular school (see Table 2.1 in Chapter 2) - and where a high level of social or academic segregation is observed. However, the correlation may also be due to the young age at first tracking. In both countries, the age at first tracking is only 12 (it is 14.2 on average across OECD countries). Because students are usually streamed according to their academic performance, and advantaged students are often over-represented amongst higher achievers, the level of social segregation across schools is high in both countries - and the level of academic segregation is even higher. In addition, as lower secondary schools are usually less selective than upper secondary schools, the level of academic segregation across schools may also depend on the country's grade-retention rate, since repeaters are more likely to be still enrolled in lower secondary school at age 15, when the PISA test is conducted. 


\section{Figure 3.1 - Dissimilarity index for low-achieving students in reading} and for disadvantaged students

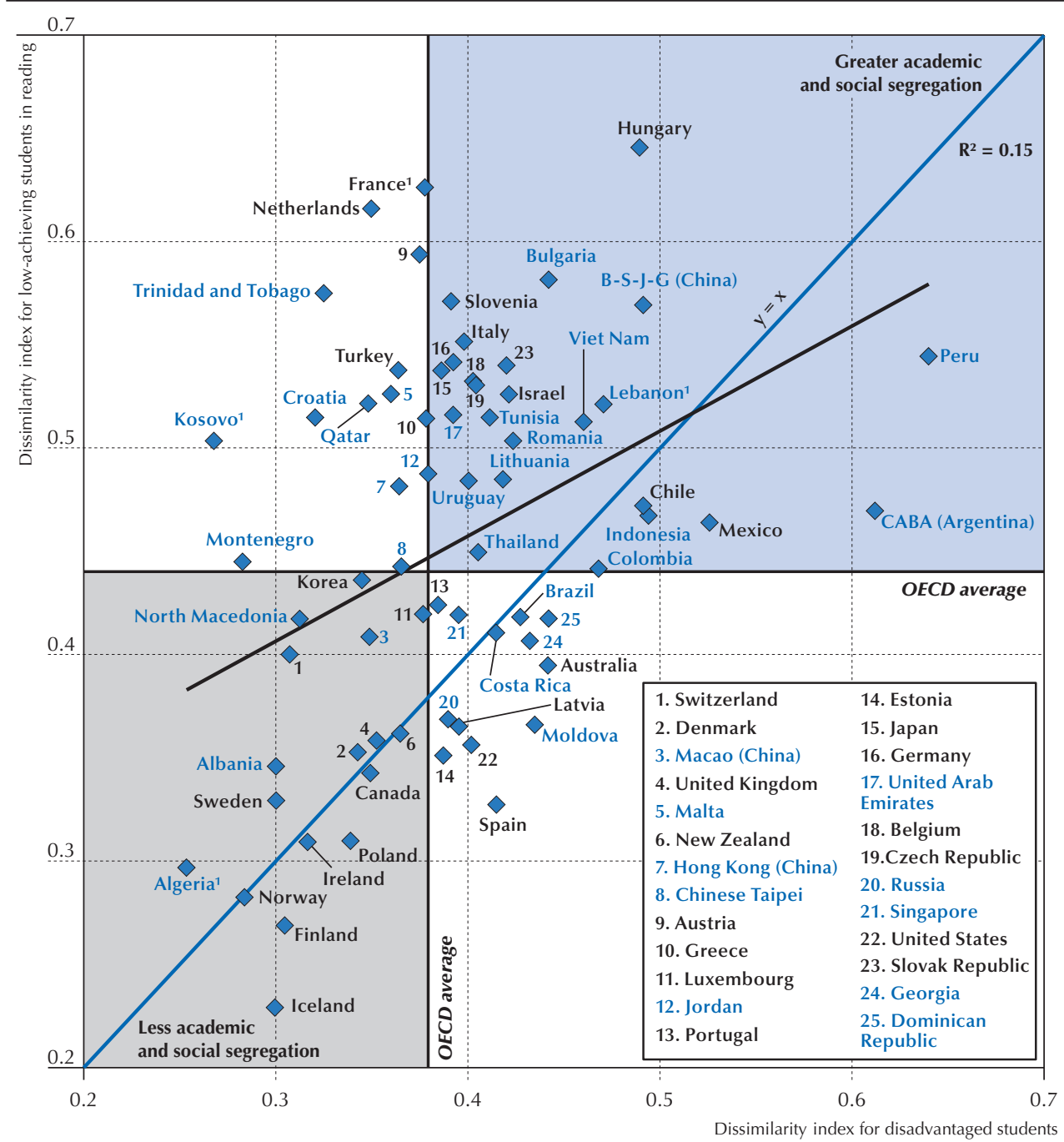

1. In Algeria, France, Kosovo and Lebanon, the proportion of 15-year-old students in modal grade schools is lower than $80 \%$ (see Table B.3), and one should interpret with caution the comparison with other countries.

Notes: All analyses are restricted to schools with the modal ISCED level for 15-year-old students.

Disadvantaged students are students in the bottom quarter of the PISA index of economic, social and cultural status (ESCS) in their own country.

The $\mathrm{R}^{2}$ value indicates the proportion of the dissimilarity index for low-achieving students in reading that is accounted for by differences in the dissimilarity index for disadvantaged students across education systems. It is a measure of the strength of the relationship between the dissimilarity index for low-achieving students in reading and the dissimilarity index for disadvantaged students at the country level.

Source: OECD, PISA 2015 Database, Table 3.1.

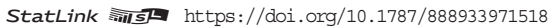




\section{IN MOST COUNTRIES, A HIGH CONCENTRATION OF LOW ACHIEVERS IN CERTAIN SCHOOLS IS MORE COMMON THAN A HIGH CONCENTRATION OF HIGH ACHIEVERS}

Students' performance is influenced by their personal characteristics, but also by those of their schoolmates. Schoolmates can motivate other students and help each other overcome learning difficulties; but they can also disrupt instruction, require disproportionate attention from teachers, and be a source of anxiety. Some students may be more sensitive than others to the composition of their classes. Many recent empirical contributions emphasise the non-linearity of peer effects on student achievement (Burke and Sass, 2013 [1]; Lavy, Silva and Weinhardt, $2012_{[2] \text {; }}$ Mendolia, Paloyo and Walker, 2018 ${ }_{[3]}$ ). The concentration of low achievers usually has negative consequences on student performance, and this is especially the case for students who are themselves low achievers. By contrast, high-ability students are usually less sensitive than their low-achieving peers to the composition of their classes. ${ }^{2}$

If high- and low-ability students are not affected in the same way by the composition of their classes, whether schools are stratified by academic performance may have consequences on both equity and average achievement at the country level. High stratification may increase the achievement gap between students. Moreover, if the negative consequences of having lowachieving schoolmates is not balanced by the positive impact of having high-achieving peers, it may lower the average performance at the macro level.

However, the allocation of students across schools may result in very different segregation patterns. In some cases, academic segregation is mainly due to the sorting of the best students into a limited number of schools; but it could also be the result of allocating the lowest achievers to disadvantaged schools.

In order to examine peer effects, an indicator that more directly focuses on the concentration of some types of students in certain schools may be more useful than the dissimilarity index (for a visualisation of the measure provided by segregation indices, see Annex A). The isolation index, which also ranges from 0 to 1 , allows for an analysis of whether school systems create "clusters" of students, depending on their characteristics. It is negatively correlated with the probability that a "typical" student from a certain group (for instance, a disadvantaged student) would be in contact at school with students who do not belong to his or her group (students with average or advantaged status). One may also estimate the isolation of low achievers (meaning their concentration in a few specific schools) or the isolation of high achievers (their concentration in a few specific schools).

The indicators of isolation of low and high achievers (low achievers are those who score in the bottom quarter of the PISA performance distribution at the country level; high achievers those who score in the top quarter) were, as expected, strongly correlated in 2015 (Figure 3.2). In some countries, such as Hungary and the Netherlands, both indices were especially high, while in others, such as Albania, Finland, Iceland and Norway, both were low. These indicators did not always coincide, however. Only in a few cases was the concentration of bright students in "good" schools much higher than the concentration of low achievers. This was notably the case in Brazil, the Dominican Republic, Lebanon, Singapore and Turkey. By contrast, in Austria, France, Greece and Malta, the concentration of low achievers is much higher than that of high achievers. ${ }^{3}$ 
Figure 3.2 - Isolation of low-achieving and high-achieving students in reading

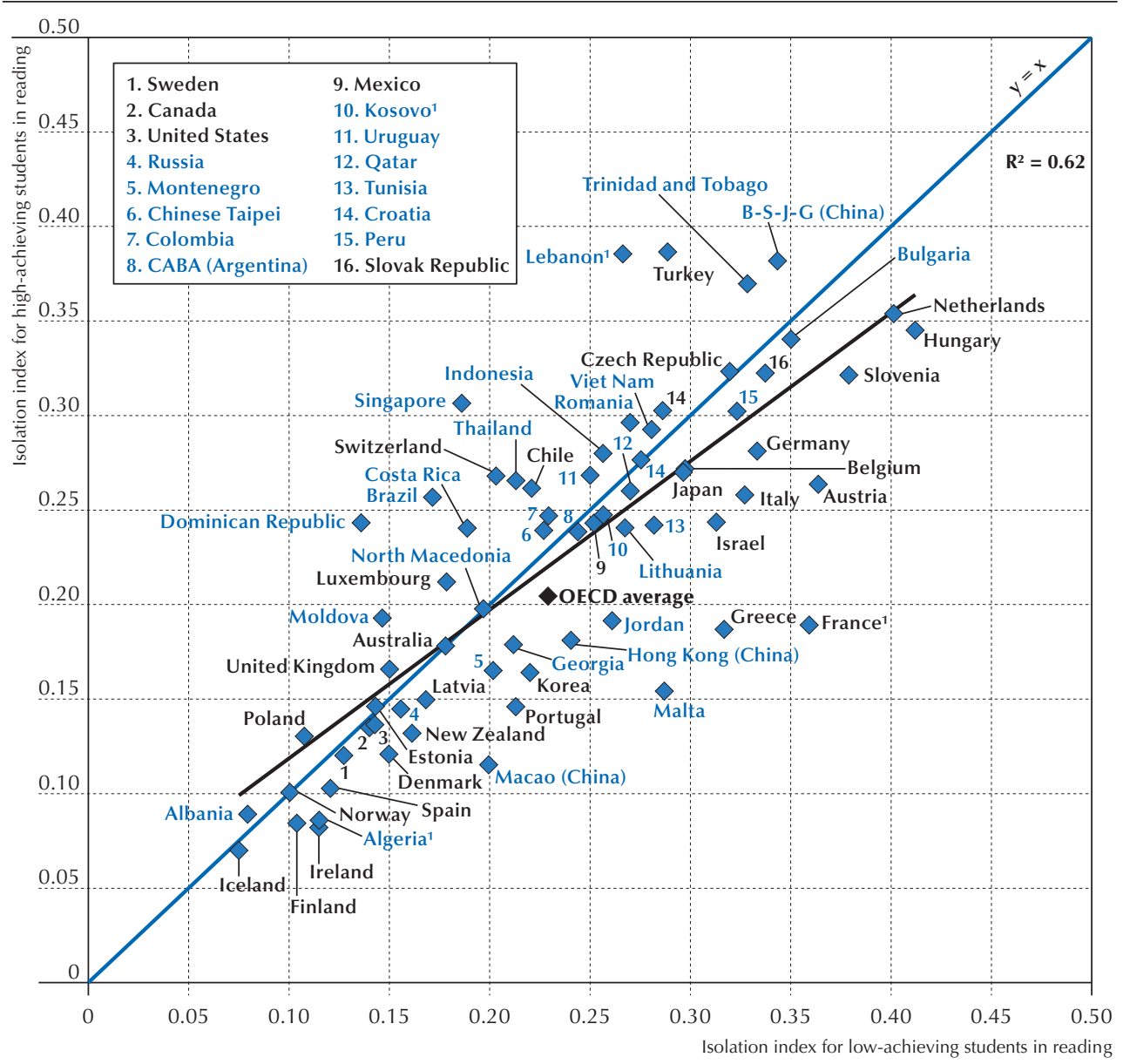

1. In Algeria, France, Kosovo and Lebanon, the proportion of 15-year-old students in modal grade schools is lower than $80 \%$ (see Table B.3), and one should interpret with caution the comparison with other countries.

Notes: All analyses are restricted to schools with the modal ISCED level for 15-year-old students.

The $\mathrm{R}^{2}$ value indicates the variance of the isolation of high-achieving students in reading that is accounted for by

differences in the isolation of low-achieving students in reading across education systems. It is a measure of the strength of the relationship between the isolation of high-achieving students in reading and the isolation of low-achieving students in reading at the country level.

Source: OECD, PISA 2015 Database, Table 3.2.

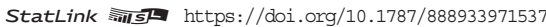




\section{IN MOST COUNTRIES, THERE ARE MORE SCHOOLS WITH A HIGH CONCENTRATION OF ADVANTAGED STUDENTS THAN WITH A HIGH CONCENTRATION OF DISADVANTAGED STUDENTS}

Disadvantaged students usually face specific obstacles to success in their education. They may not, for example, benefit from the same parental support to monitor their school progress as students with more educated parents; and sorting students by socio-economic status across schools may reinforce this deficit. For instance, disadvantaged schools may have less financial resources or may attract less-qualified teachers. One may thus compare whether the degree of segregation across schools in a country/economy stems mostly from the isolation of disadvantaged students from more advantaged students or from the isolation of advantaged students, or both.

Generally, in almost all countries and economies that participated in PISA 2015, the isolation index for disadvantaged students was lower than that for advantaged students. This means that disadvantaged students were more likely, on average, to be in the same schools as more advantaged students than advantaged students were to be in the same school as average or disadvantaged students (Figure 3.3). This situation was especially marked in Chile, Colombia, Costa Rica, Macao (China), Thailand and Uruguay. In some countries, the pattern may be even more pronounced. For example, amongst countries with a concentration of disadvantaged students at the same level as the OECD average (0.16), in Japan, the concentration of advantaged students is relatively low (the isolation index is 0.15), while in Uruguay this same index is relatively high (0.29) as it is in Portugal and Singapore (both 0.23).

In a few countries and economies, however, such as Ciudad Autónoma de Buenos Aires (Argentina), Israel, Peru, Mexico and the Russian Federation, social segregation across schools mainly reflected the fact that disadvantaged students were often "clustered" in some schools, and were thus less likely to interact with students from other socio-economic backgrounds. Such patterns may reflect patterns of residential segregation or arise if middle-class parents are more apt to avoid disadvantaged schools and choose to enroll their children in more advantaged schools, if possible, thus "leaving behind" the most disadvantaged students in low quality schools (OECD, 2018 $\left.8_{[4]}\right)$.

As observed above, social segregation across schools was slightly less prevalent than academic segregation in 2015. The isolation index of disadvantaged students (those with a socio-economic status below the first quartile of the distribution at the country level) was 0.16 , on average across OECD countries (Figure 3.3), while the isolation index for low achievers was 0.23 (Figure 3.2).

One may also question the extent to which disadvantaged students in a country are exposed, at school, to students who are high achievers in PISA (defined as students who score higher than the top quartile of performance). Figure 3.4 illustrates the extent to which a typical disadvantaged student in a country is unlikely to be in a school that enrols high- achieving students. The index has a value close to one when disadvantaged students are clustered in schools that do not enrol high-achieving students, while it has medium values when disadvantaged students or high achievers are spread across schools (for a detailed discussion, see Annex A).

Figure 3.4 shows large disparities across countries. Countries and economies where disadvantaged students are more often concentrated in schools without high achievers are Beijing-ShanghaiJiangsu-Guangdong (China), Bulgaria, Ciudad Autónoma de Buenos Aires (Argentina), Chile, 
the Czech Republic, Hungary, Peru, Mexico, Singapore and Slovenia. By contrast, countries and economies where disadvantaged students are evenly distributed across schools, including schools that enrol high achievers, are Algeria, Canada, Denmark, Finland, Iceland, Ireland, Jordan, Macao (China), Norway and Sweden.

Figure 3.3 - Isolation of disadvantaged and advantaged students

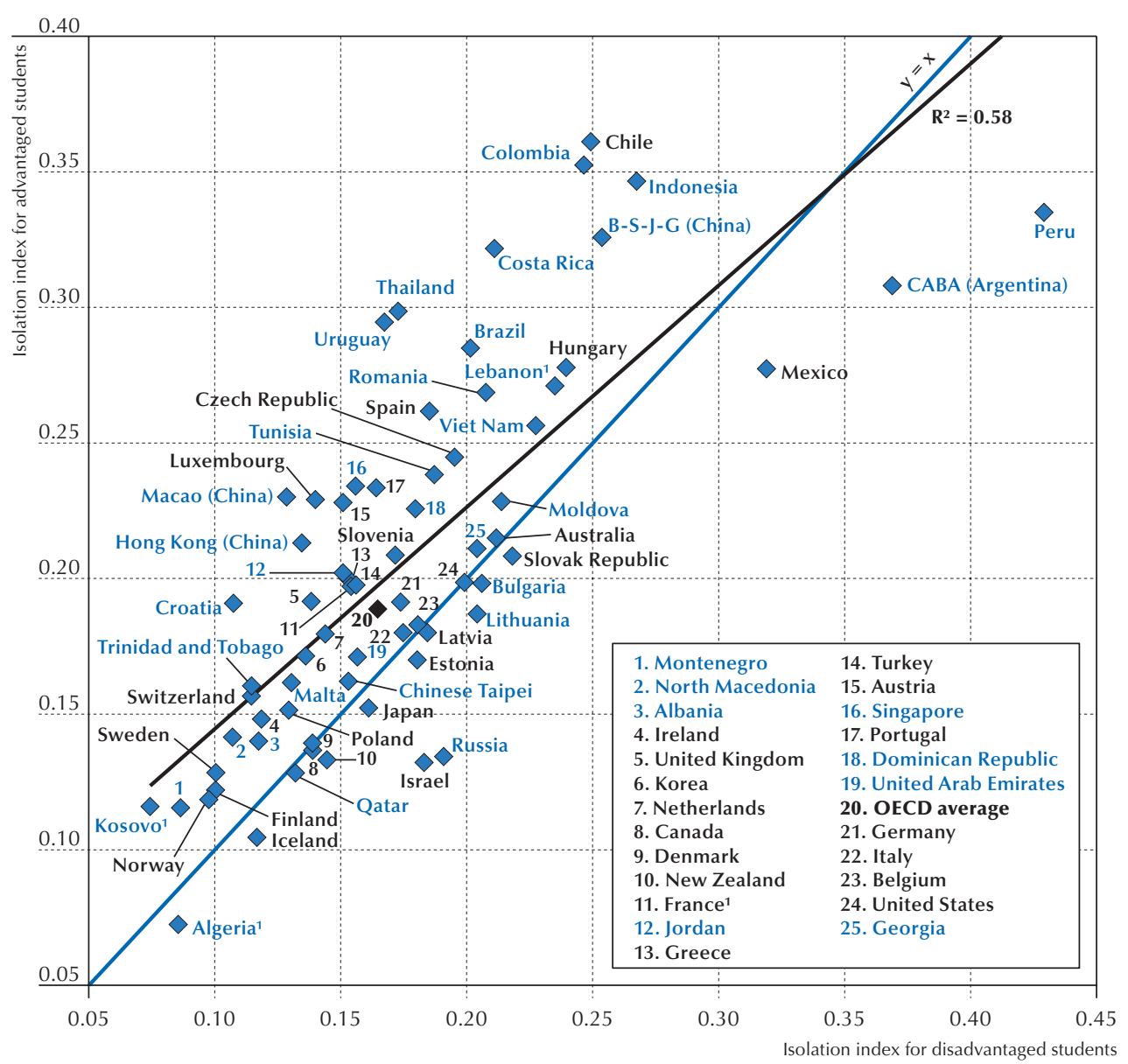

1. In Algeria, France, Kosovo and Lebanon, the proportion of 15-year-old students in modal grade schools is lower than $80 \%$ (see Table B.3), and one should interpret with caution the comparison with other countries.

Notes: All analyses are restricted to schools with the modal ISCED level for 15-year-old students.

Disadvantaged students are students in the bottom quarter of the PISA index of economic, social and cultural status (ESCS) in their own country.

Advantaged students are students in the top quarter of the PISA index of economic, social and cultural status (ESCS) in their own country.

The $\mathrm{R}^{2}$ value indicates the variance of the isolation of advantaged students that is accounted for by differences in the isolation of disadvantaged students across education systems. It is a measure of the strength of the relationship between the isolation of advantaged and the isolation of disadvantaged students at the country level.

Source: OECD, PISA 2015 Database, Table 3.3.

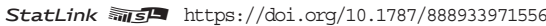




\section{Figure 3.4 - Isolation of disadvantaged students from national} high achievers in reading

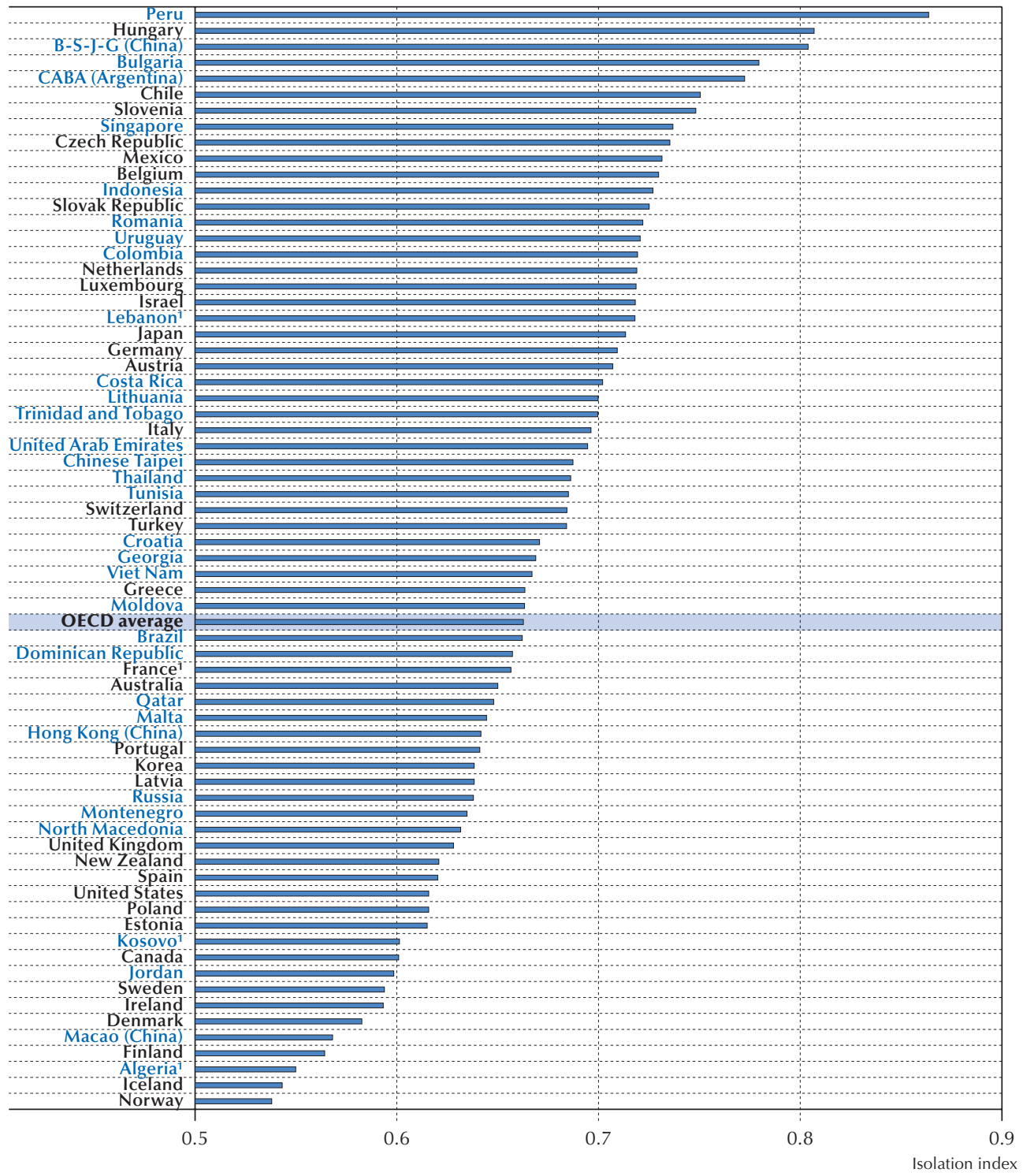

1. In Algeria, France, Kosovo and Lebanon, the proportion of 15-year-old students in modal grade schools is lower than $80 \%$ (see Table B.3), and one should interpret with caution the comparison with other countries.

Notes: All analyses are restricted to schools with the modal ISCED level for 15-year-old students.

Disadvantaged students are students in the bottom quarter of the PISA index of economic, social and cultural status (ESCS) in their own country.

Countries and economies are ranked in descending order of the isolation of disadvantaged students from national high achievers in reading.

Source: OECD, PISA 2015 Database, Table 3.4.

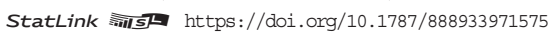


This measure is also expected to be negatively correlated with the proportion of resilient students in countries. In school systems where socio-economic status is weakly associated with performance, disadvantaged students are more likely to overcome their initial difficulty and perform well at school (the definition of resilience). Given the same level of concentration of disadvantaged students in schools, the index may be lower in countries and economies with a high proportion of resilient students. This is especially the case when admission to school depends on proven ability, as resilient disadvantaged students are more likely to be enrolled in "good" schools. ${ }^{4}$ 


\section{Notes}

1. Low achievers are defined here as students who perform below the first quartile of the distribution of PISA performance in their country; disadvantaged students are those whose value in the PISA index of economic, social and cultural status (ESCS) is below the first quartile of the distribution in their country.

2. This is illustrated, for instance, by the results obtained by comparing the achievement of students just below or just above a threshold of admissions in Boston and New York high schools (Abdulkadiroğlu, Angrist and Pathak, 2014 $\left.4_{[5]}\right)$. The achievement outcomes of those who had attended these so-called "elite" schools do not differ from those who just failed the entrance exam. Similar results have also been observed by (Dobbie and Fryer, 2014 $\left.4_{[6]}\right)$ and in Kenyan high schools (Lucas and Mbiti, 2014 $4_{[7]}$.

3. In France and Lebanon, less than $80 \%$ of 15 -year-old students are enrolled in schools with the modal grade (see Table B.3); therefore, comparisons should be interpreted with caution.

4. For the sake of comparison, on average across OECD countries, $11.3 \%$ of disadvantaged students scored in the first quarter of the PISA performance distribution in their own country/economy in 2015.

\section{References}

Abdulkadiroğlu, A., J. Angrist and P. Pathak (2014), "The Elite Illusion: Achievement Effects at Boston and New York Exam Schools", Econometrica, Vol. 82/1, pp. 137-196, http://dx.doi.org/10.3982/ECTA10266.

Burke, M. and T. Sass (2013), "Classroom Peer Effects and Student Achievement", Journal of Labor Economics, Vol. 31/1, pp. 51-82, http://dx.doi.org/10.1086/666653.

Dobbie, W. and R. Fryer (2014), "The Impact of Attending a School with High-Achieving Peers: Evidence from the New York City Exam Schools", American Economic Journal: Applied Economics, Vol. 6/3, pp. 58-75, http://dx.doi.org/10.1257/app.6.3.58.

Lavy, V., O. Silva and F. Weinhardt (2012), "The Good, the Bad, and the Average: Evidence on Ability Peer Effects in Schools", Journal of Labor Economics, Vol. 30/2, pp. 367-414, http://dx.doi.org/10.1086/663592.

Lucas, A. and I. Mbiti (2014), "Effects of School Quality on Student Achievement: Discontinuity Evidence from Kenya", American Economic Journal: Applied Economics, Vol. 6/3, pp. 234-263, http://dx.doi.org/10.1257/app.6.3.234.

Mendolia, S., A. Paloyo and I. Walker (2018), "Heterogeneous effects of high school peers on educational outcomes", Oxford Economic Papers, http://dx.doi.org/10.1093/oep/gpy008.

OECD (2018), Responsive School Systems: Connecting Facilities, Sectors and Programmes for Student Success, OECD Reviews of School Resources, OECD Publishing, Paris, https://dx.doi.org/10.1787/9789264306707-en. 


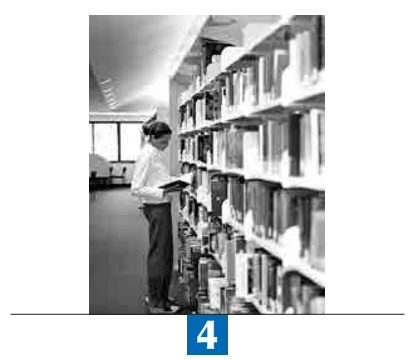

\section{How social and academic segregation are related to school-choice policies}

This chapter investigates whether school choice may affect social and academic diversity within the schools. It compares the degree of social diversity between public and private schools, and examines whether the changes in social and academic segregation may be related to schools' admissions policies.

\section{A note regarding Israel}

The statistical data for Israel are supplied by and under the responsibility of the relevant Israeli authorities. The use of such data by the OECD is without prejudice to the status of the Golan Heights, East Jerusalem and Israeli settlements in the West Bank under the terms of international law.

\section{A note regarding Lithuania}

Lithuania became a member of the OECD on 5 July 2018. However, consistent with other publications based on PISA 2015 data, Lithuania is shown as a partner country and is not included in the OECD average.

This document, as well as any data and map included herein, are without prejudice to the status of or sovereignty over any territory, to the delimitation of international frontiers and boundaries and to the name of any territory, city or area. 


\section{PRIVATE SCHOOLS ARE USUALLY MORE SOCIALLY STRATIFIED THAN PUBLIC SCHOOLS}

How is school choice related to sorting students across schools? One may analyse first whether the coexistence of the private sector with the public sector is related to the degree of school segregation at the national level. This can be done using the diversity index. ${ }^{1}$ This index measures how social diversity, as observed at the country level, is or is not reproduced within schools. Diversity within schools ensures that students from different backgrounds may interact with each other. It is expected to have a positive impact on social cohesion (Borgonovi and Pokropek, $2017_{[1]}$ ). The mutual information index (hereafter called the no diversity index) allows for a consideration of more than two groups of students. In the following, four groups are defined using the quartiles of the socio-economic index at the country level (see Annex A for details). The nodiversity index $\mathrm{H}$ goes from 0 (no segregation) to 1 (full segregation). ${ }^{2}$

The highest levels of social segregation according to this indicator (meaning the lowest degree of social diversity within schools) are observed in several Latin American countries and economies (Chile, Ciudad Autónoma de Buenos Aires [Argentina], Colombia, Mexico and Peru), in the four provinces and municipalities of China that participated in PISA 2015 (Beijing, Shanghai, Jiangsu and Guangdong) and in Indonesia (Figure 4.1). In these countries and economies, the no-diversity index is at least 0.20 , meaning twice as high as the level of segregation that prevails in Finland, Kosovo, the Republic of North Macedonia and Norway, for instance.

One of the advantages of the no-diversity index is that it is decomposable (Frankel and Volij, $\left.2011_{[2]}\right)$. This property is useful for measuring segregation within the public and private sectors, as well as the discrepancies in school enrolment between these two sectors. Formally, the decomposition can be written as the sum of three components: ${ }^{3}$

- A first component measures the social segregation observed between public and private schools. It compares the social composition of the enrolment (taken as a whole) of private schools with the social composition of enrolment (taken as a whole) of public schools. One expects to observe a positive contribution to the overall level of social segregation if, for instance, private schools tend to select more affluent students because of tuition fees. This contribution is represented by the dark blue segment of the bars in Figure 4.1. In a few countries, the difference in the social composition of public and private schools has a marked impact on the level of social diversity within schools at the aggregated level. For instance, in Brazil, Ciudad Autónoma de Buenos Aires (Argentina), Colombia, the Dominican Republic, Lebanon, Peru, Malta, Spain and Uruguay, this difference accounts for more than a quarter of the overall level of segregation. In the vast majority of countries, however, the difference in the composition of private and public schools alone does not account for more than $10 \%$ of the degree of segregation. In these cases, the level of social segregation depends not only on the social difference between private and public schools, but because social sorting may occur amongst public schools - or amongst private schools.

- Two components measure the degree of segregation across private and public schools separately, weighted by the proportions of 15-year-old students enrolled in these sectors in the country/economy. At the country level, intra-sector segregation may be due to the fact that 
grade repetition and streaming into different education tracks are often related to the socioeconomic status of students. One thus also expects to find segregation within both private and public schools. Competition between schools within the same sector, i.e. public or private, may also create segregation. For instance, schools may choose to limit their offer to specific conditions (for instance, provide remedial education for low achievers who struggle in the traditional school system, or propose an education for "gifted" children). Even in the absence of competition, enrolment is expected to reflect residential segregation, and this may be reinforced over time, as parents' decisions about where to live are partly driven by the profile of the schools - and the schools' student population - that are available to them.

After taking into account the respective weights of the private and public sectors within a country/ economy, the segregation observed in private schools does not contribute much to the overall segregation in the country/economy. Since students in most countries were more often enrolled in public schools than in private schools, the contribution of public schools to overall segregation is usually greater (the grey segments of the bars in Figure 4.1) than that of private schools. Exceptions are countries where the share of private schools is very large. It is, for instance, the case in Chile, Ireland and the Netherlands (the light blue segments of the bars).

However, in a large majority of countries, the degree of segregation is greater in private schools than in public schools. Differences are especially striking in Brazil, Chile, Colombia, Italy, Jordan, Mexico, Poland, Portugal, Tunisia and Turkey (Figure 4.2). The segregation in private schools is measured by considering only the students enrolled in private institutions. In many countries, private schools are expected to offer a more differentiated education (for instance, distinct curriculum or pedagogical practices) than public education does - and thus may attract different types of students. ${ }^{4}$ This is especially true when families are offered financial support - either directly or indirectly through public funding to schools - to send their child to private school. Middle- or even low-income students may enrol in some private schools, but not necessarily the same private schools as those attended by the most advantaged students.

In 9 countries, however, segregation is greater in public schools than in private schools. These differences are especially wide in Costa Rica, the Republic of North Macedonia, Slovenia and Viet Nam. This may reflect either school selectivity or the large differences in the social composition of schools related to where they are located. 
Figure 4.1 - Contributions of public and private schools to social segregation amongst schools

Decomposition of the no-diversity index based on the contributions of public and private schools

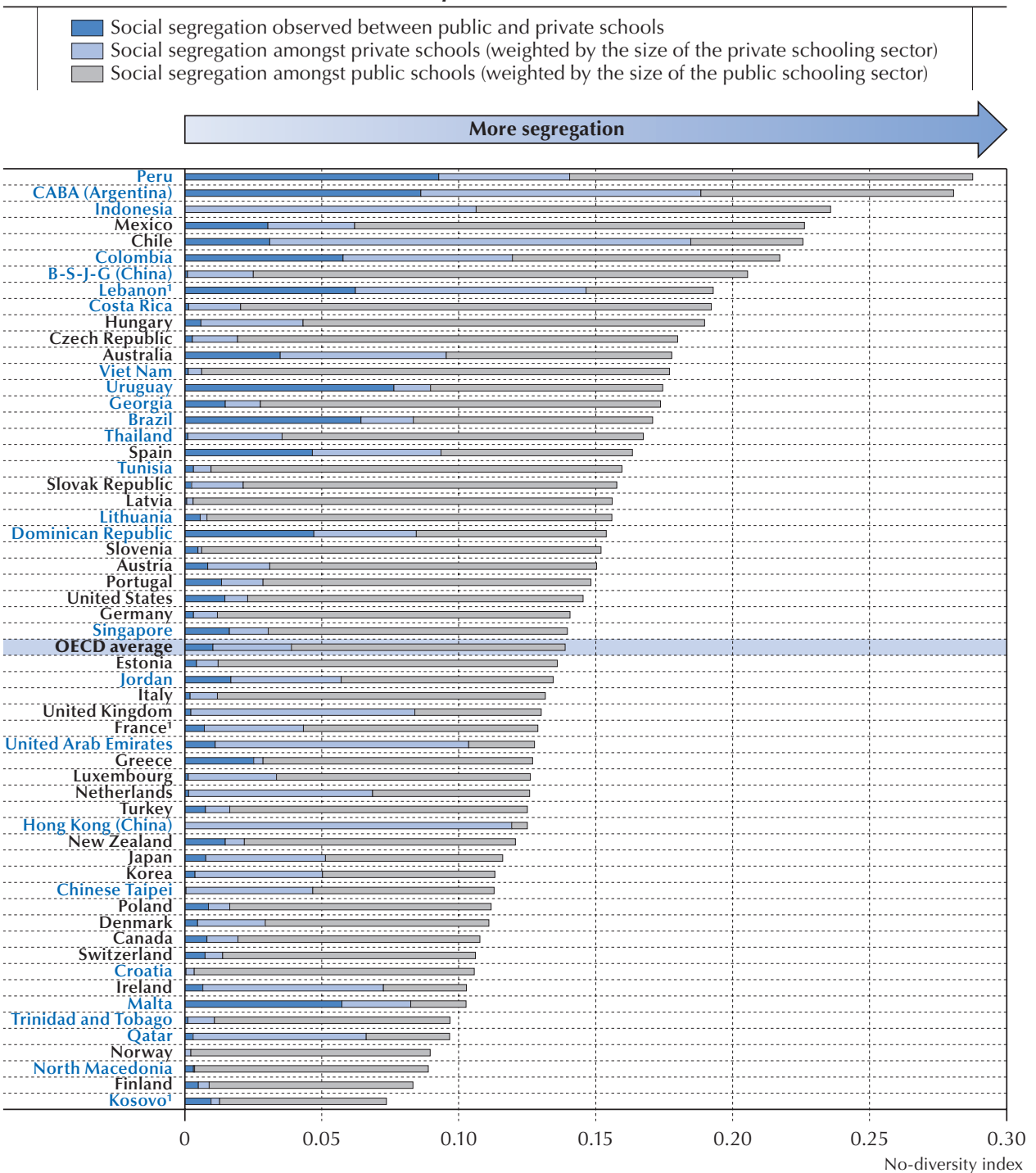

1. In France, Kosovo and Lebanon, the proportion of 15 -year-old students in modal grade schools is lower than $80 \%$ (see Table B.3), and one should interpret with caution the comparison with other countries.

Notes: All analyses are restricted to schools with the modal ISCED level for 15-year-old students.

Public schools are those managed by the local government. Private schools are private independent schools and those

funded by government but managed by not-for profit charitable trusts, including academies and free schools.

OECD average refers to the arithmetic mean across all OECD countries for which data are available.

Countries and economies are ranked in descending order of the overall level of segregation.

Source: OECD, PISA 2015 Database, Table 4.2.

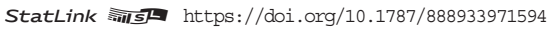




\section{Figure 4.2 - Social segregation, by type of school No-diversity index}

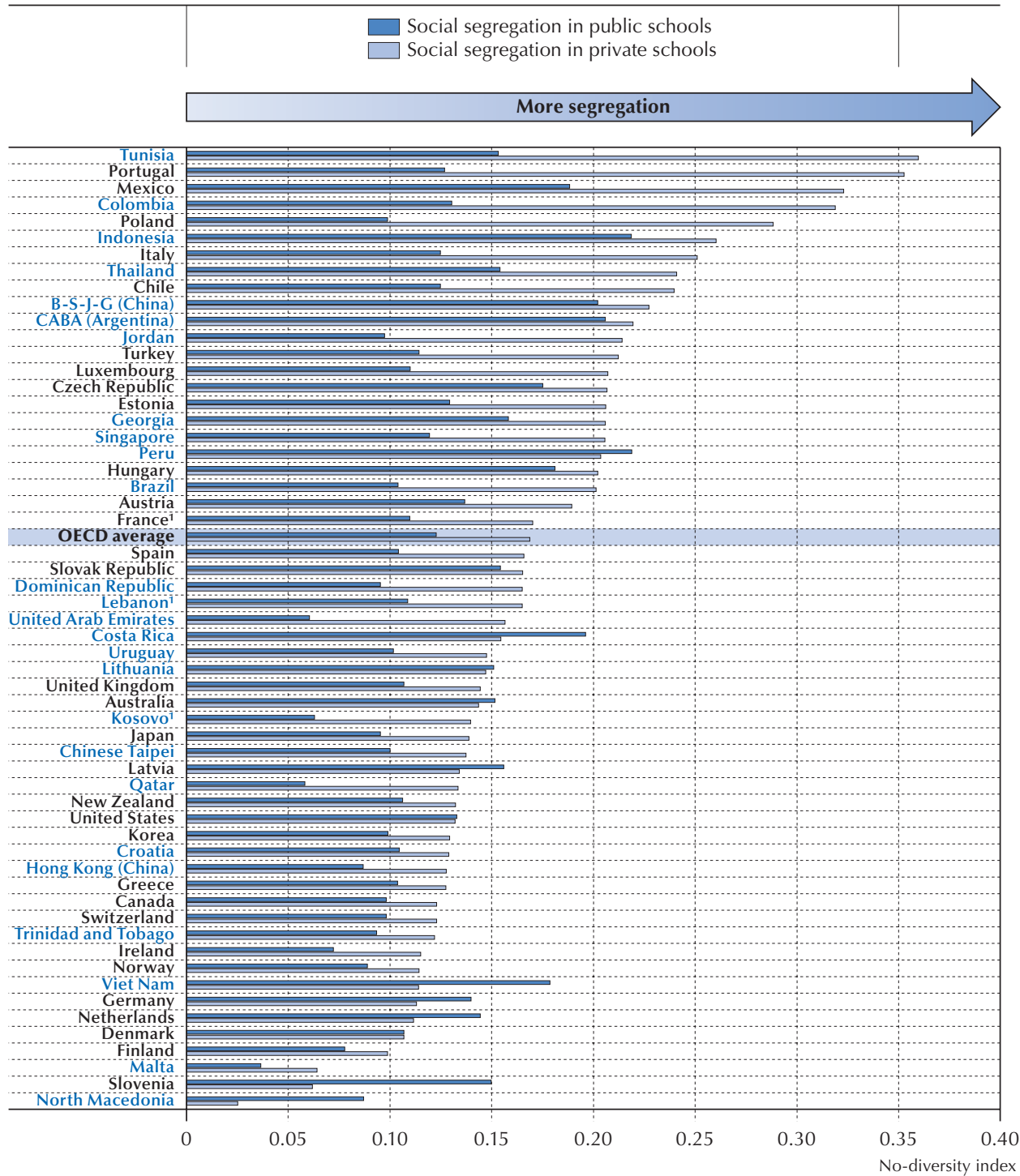

1. In France, Kosovo and Lebanon, the proportion of 15-year students in modal grade schools is lower than $80 \%$ (see Table B.3), and one should interpret with caution the comparison with other countries.

Notes: All analyses are restricted to schools with the modal ISCED level for 15-year-old students.

Public schools are those managed by the local government. Private schools are private independent schools and those funded by government but managed by not-for profit charitable trusts, including academies and free schools.

Countries and economies are ranked in descending order of the no-diversity index in private schools.

Source: OECD, PISA 2015 Database, Table 4.3.

StatLink त्राज़ https://doi.org/10.1787/888933971613 


\section{THE RELATIONSHIP BETWEEN SEGREGATION ACROSS SCHOOLS AND SCHOOL ENROLIMENT PRACTICES IS AMBIGUOUS}

How are academic and social segregation related to school-choice policies? School-choice enrolment practices provide two proxies of the degree of actual choice families can exercise: academic selectivity, as a measure of possible "cream skimming" by schools, and residencebased criteria, as a measure of the degree choice is limited by home location. Cross-country comparisons suggest that, in 2015, the countries where more schools selected their students based on prior academic performance were characterised by greater academic stratification, as expected (Figure 4.3). The degree of segregation of disadvantaged students across schools at the country level was negatively correlated with the proportion of students in schools whose principals always consider residence as a criterion for admission to school. But this correlation is weak, and large variations between countries are observed (Figure 4.4). Several other country specificities, notably the degree of residential segregation, are expected to affect school segregation - and for this reason it may be difficult to observe direct relations.

This finding may be explained more by school practices than by school choice. Indeed, academic and social segregation across schools are not only due to schools' enrolment practices. Academic segregation, for instance, is expected to be linked with the coexistence of different streams: vocational and general schools usually select students with different academic backgrounds. In addition, the school segregation indices may depend on grade repetition, especially if the repeaters are expected to be still in lower secondary education while the "modal grade" corresponds to upper secondary education. Upper secondary education is commonly more selective than lower secondary education. This means that the correlation observed at the country level may be due to the fact that countries with the largest proportions of selective schools are also countries where students are streamed into different education tracks at a young age, or where larger proportions of students repeat a grade in primary or lower secondary school. Moreover, a change in grade repetition policy that would result in changes in the proportion of repeaters amongst 15-year students is expected to be reflected in segregation indices.

By observing country-level trends in PISA results over several cycles, one may compare how segregation indicators have evolved within countries when school selectivity has changed, using a series of fixed-effect regressions. Formally, it corresponds to the following equation at the country level:

$$
Y_{c t}=\alpha_{c}+\alpha_{t}+X_{c t}+\varepsilon_{c t}
$$

where $Y_{c t}$ corresponds to the outcomes observed at the country level (social or academic segregation), $X_{c t}$ the characteristics of schools based on aggregated school-level data (such as the proportion of academically selective schools in the country, the proportion of grade repeaters, etc.) observed in cycle t of PISA. The value $\left(\alpha_{t}\right)_{t=(2009,2012,2015)}$ is a set of cycle-specific dummies that capture potential changes that are common to all countries in PISA, and $\left(\alpha_{c}\right)$ is a set of country-specific fixed effects that capture the characteristics of the school systems that are stable over time. Because of these country-specific fixed effects, the estimation of the 
variables (such as school-enrolment practices) on the dependant variable (such as the level of segregation) depends on the changes in these variables over time within the same country. Controlling by change in the proportion of grade repeaters or students in vocational training is intended to account for other institutional changes, such as policies aimed at reducing graderepetition rates.

\section{Figure 4.3 - Dissimilarity index for low-achieving students in reading and school admissions based on academic performance}

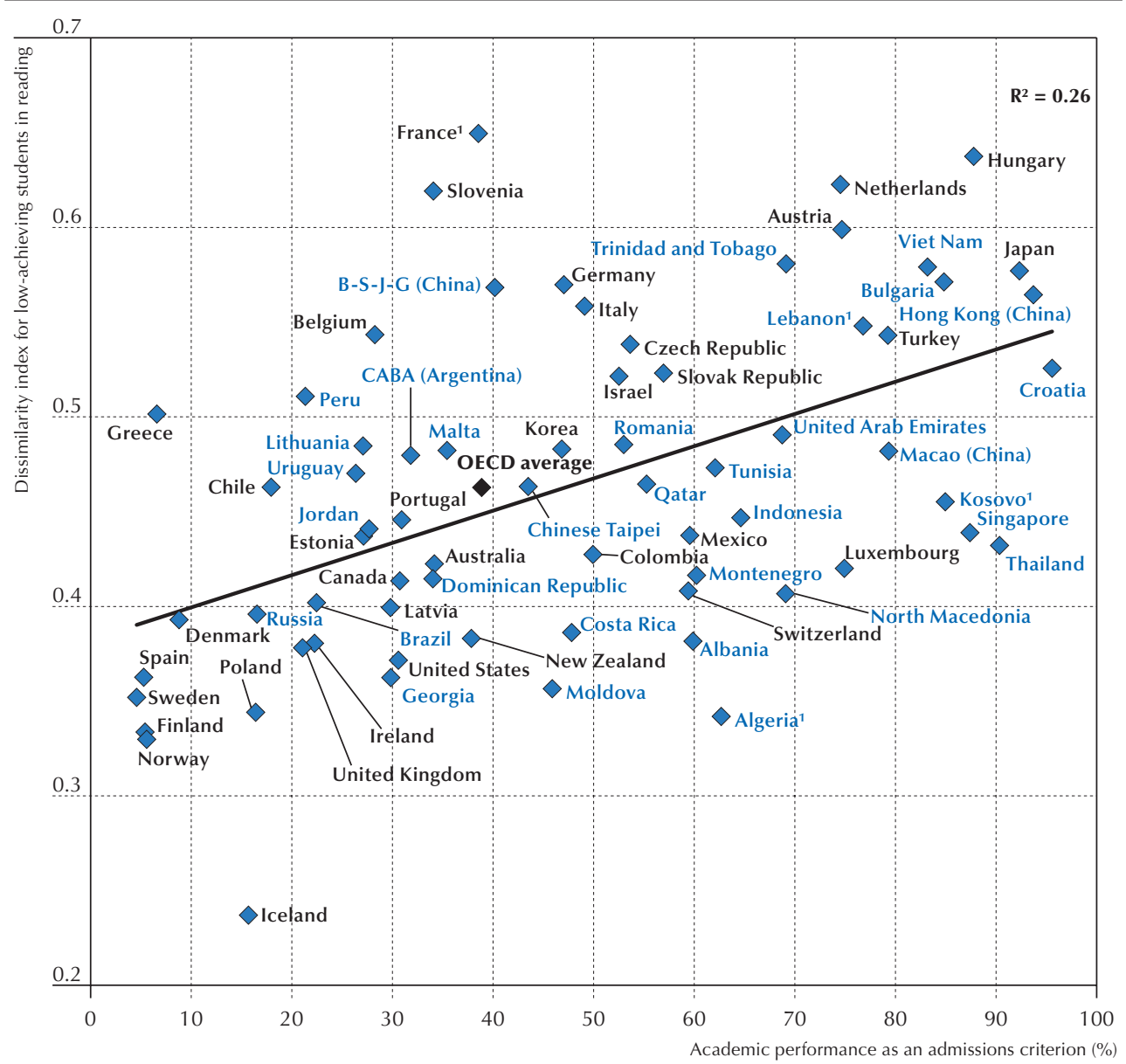

1. In Algeria, France, Kosovo and Lebanon, the proportion of 15-year-old students in modal grade schools is lower than $80 \%$ (see Table B.3), and one should interpret with caution the comparison with other countries.

Notes: All analyses are restricted to schools with the modal ISCED level for 15-year-old students.

The $\mathrm{R}^{2}$ value indicates the proportion of the dissimilarity index for low-achieving students in reading that is accounted for by school selectivity based on academic performance across education systems. It is a measure of the strength of the relationship between the dissimilarity index for low-achieving students in reading and school selectivity based on academic performance at the country level.

Source: OECD, PISA 2015 Database, Table 4.4

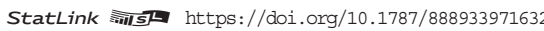


Figure 4.4 - Dissimilarity index for disadvantaged students and school admissions based on residence

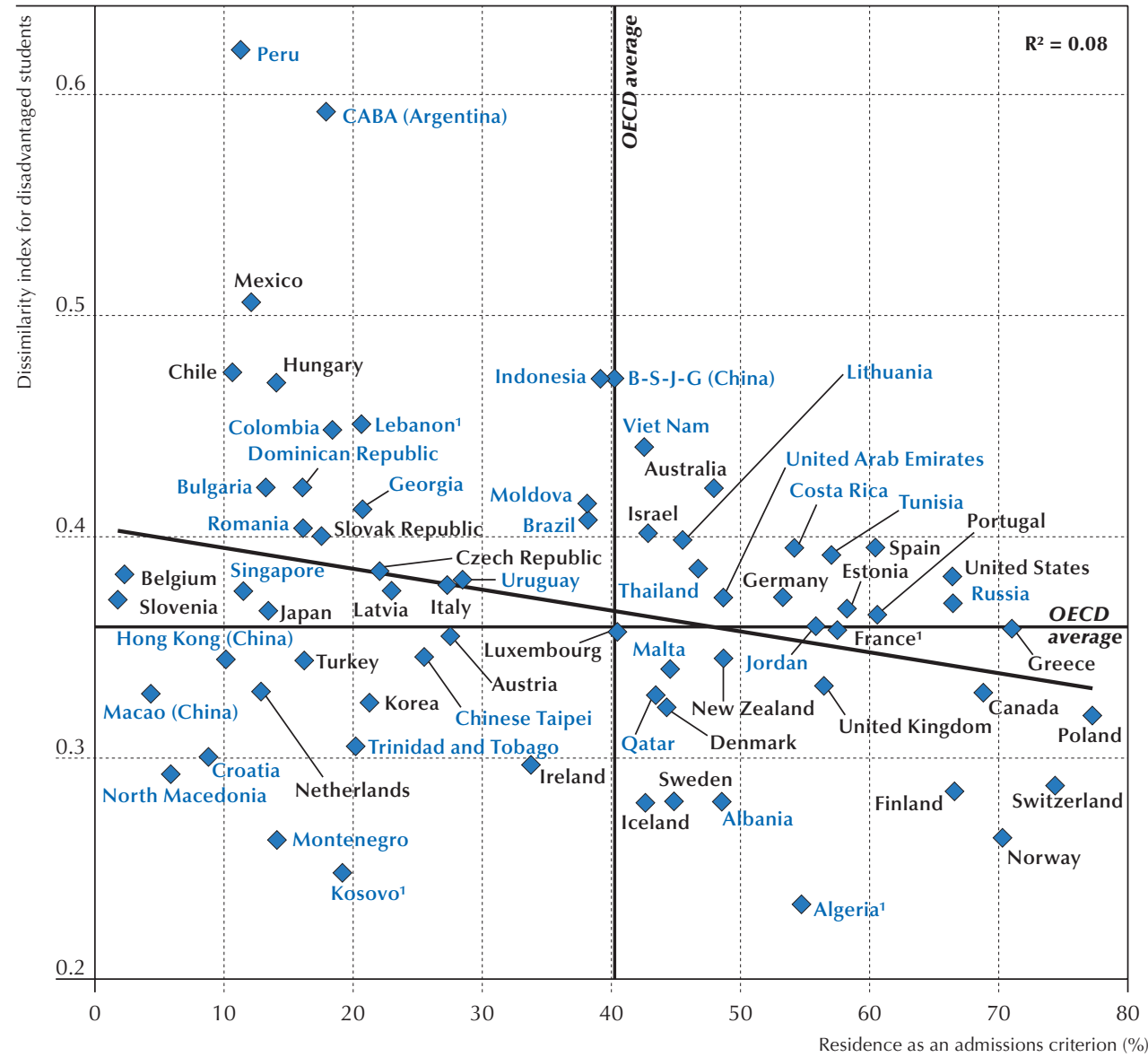

1. In Algeria, France, Kosovo and Lebanon, the proportion of 15-year-old students in modal grade schools is lower than $80 \%$ (see Table B.3), and one should interpret with caution the comparison with other countries.

Notes: All analyses are restricted to schools with the modal ISCED level for 15-year-old students.

Disadvantaged students are students in the bottom quarter of the PISA index of economic, social and cultural status (ESCS) in their own country.

The $\mathrm{R}^{2}$ value indicates the variance of the dissimilarity index for disadvantaged students that is accounted for by differences in school selectivity based on residence across education systems. It is a measure of the strength of the relationship between the dissimilarity index for disadvantaged students and school selectivity based on residence at the country level.

Source: OECD, PISA 2015 Database, Table 4.5

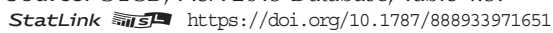

The 2009, 2012 and 2015 cycles of PISA are used for estimations as they provide consistent measures of the criteria applied for enrolment. When taking into account the unobserved characteristics of countries and economies (such as urban segregation, commuting facilities, etc.), empirical evidence does not support the claim that residence-based enrolment policies always increase social segregation (i.e. that catchment areas would trap disadvantaged students in 
low-performing schools). A decrease in the proportion of students in schools that use residencebased selection has no significant impact on the social diversity of schools or on the isolation of disadvantaged students (Figure 4.1). Relaxing residence-based regulations is even related to a tiny increase in the concentration of advantaged students in certain schools. A 10 percentage-point increase in the proportion of students in residence-based schools would result in a decrease in the isolation index from 0.26 to 0.25 . Moreover, the negative correlation between residencebased rules and the concentration of advantaged students reflects a short-term impact. Strict school-zoning laws may affect families' choice of where they live and thus, in the long term, may reinforce residential segregation. The short-term correlation measured here may be reversed over the long term if relaxing the link between residence and school admissions prompts middle-class families to consider residing in mixed neighbourhoods.

On the other hand, an increase in the proportion of schools that always use academic criteria for enrolment is associated with a slight decrease in the level of social segregation amongst schools, as measured by the no-diversity index (Table 4.1, column 1). This may be explained by the fact that when schools rely more on academic criteria, they may enrol resilient disadvantaged students, i.e. those disadvantaged students who perform well at school. ${ }^{5}$ The impact is small, though: an increase of 10 percentage points in the proportion of students in selective schools shifts by only 0.003 the level of social segregation (from a baseline of 0.17 ).

\section{Table 4.1 . Social and academic segregation, and school-stratification policies, 2009-15}

Panel estimates, country-level regressions

\begin{tabular}{|c|c|c|c|c|c|c|c|c|c|c|}
\hline \multirow[b]{2}{*}{$\begin{array}{l}\text { School admissions } \\
\text { based on academic } \\
\text { performance }(\%)\end{array}$} & \multicolumn{2}{|c|}{$\begin{array}{l}\text { No-diversity index } \\
\text { (multigroup ESCS) }\end{array}$} & \multicolumn{2}{|c|}{$\begin{array}{c}\text { Isolation index } \\
\text { for disadvantaged } \\
\text { students }\end{array}$} & \multicolumn{2}{|c|}{$\begin{array}{l}\text { Isolation index } \\
\text { for socio- } \\
\text { economically } \\
\text { advantaged } \\
\text { students }\end{array}$} & \multicolumn{2}{|c|}{$\begin{array}{c}\text { Isolation index } \\
\text { for low-achieving } \\
\text { students } \\
\text { in reading }\end{array}$} & \multicolumn{2}{|c|}{$\begin{array}{c}\text { Isolation index } \\
\text { for high-achieving } \\
\text { students } \\
\text { in reading }\end{array}$} \\
\hline & -0.034 & $(0.017)$ & -0.029 & $(0.026)$ & -0.062 & $(0.029)$ & -0.038 & $(0.038)$ & -0.087 & $(0.038)$ \\
\hline $\begin{array}{l}\text { School admissions } \\
\text { based on residence (\%) }\end{array}$ & -0.028 & $(0.024)$ & -0.003 & $(0.035)$ & -0.089 & $(0.039)$ & -0.067 & $(0.053)$ & -0.107 & $(0.052)$ \\
\hline $\begin{array}{l}\text { Vocational programmes } \\
(\%)\end{array}$ & -0.090 & $(0.040)$ & -0.131 & $(0.060)$ & -0.142 & $(0.066)$ & 0.046 & $(0.089)$ & 0.050 & $(0.088)$ \\
\hline Grade repetition (\%) & -0.003 & $(0.005)$ & -0.011 & $(0.008)$ & -0.002 & $(0.008)$ & 0.005 & $(0.011)$ & 0.008 & $(0.011)$ \\
\hline Private schools (\%) & 0.043 & $(0.032)$ & 0.018 & $(0.048)$ & 0.073 & $(0.053)$ & 0.070 & $(0.071)$ & -0.004 & $(0.070)$ \\
\hline Intercept & 17.607 & $(1.433)$ & 20.426 & $(2.157)$ & 27.304 & $(2.386)$ & 27.181 & (3.203) & 31.685 & $(3.154)$ \\
\hline Country fixed effect & \multicolumn{2}{|c|}{ yes } & \multicolumn{2}{|c|}{ yes } & \multicolumn{2}{|c|}{ yes } & \multicolumn{2}{|c|}{ yes } & \multicolumn{2}{|c|}{ yes } \\
\hline Number of observations & \multicolumn{2}{|c|}{177} & \multicolumn{2}{|c|}{188} & \multicolumn{2}{|c|}{188} & \multicolumn{2}{|c|}{188} & \multicolumn{2}{|c|}{188} \\
\hline $\mathbf{R}^{2}$ & \multicolumn{2}{|c|}{0.11} & \multicolumn{2}{|c|}{0.07} & \multicolumn{2}{|c|}{0.13} & \multicolumn{2}{|c|}{0.03} & \multicolumn{2}{|c|}{0.09} \\
\hline
\end{tabular}

Notes: All analyses are restricted to schools with the modal ISCED level. The results above may thus differ from those estimated on the entire sample of 15 -year-old students.

Disadvantaged students are students in the bottom quarter of the PISA index of economic, social and cultural status (ESCS) in their own country.

Data are aggregated at the country/cycle level.

Segregation indices are rescaled from 0 to 100 .

Standard errors are indicated in parentheses.

Values that are statistically significant at the $10 \%$ level are indicated in italics and those at the $5 \%$ level are indicated in bold.

Source: OECD, PISA 2009, PISA 2012 and PISA 2015 Databases.

StatLink त्ताls https://doi.org/10.1787/888933971822 
The result is also observed when taking into account the proportion of students in private schools at the country level. Private schools are often more academically selective but may also be less accessible to disadvantaged students if they charge fees and in the absence of financial support for low-income families. Using both the proportion of students enrolled in private schools and those attending selective schools helps to disentangle the two effects. While an increase in academic selectivity tends to be related to a decrease in social segregation, a larger share of private schools in a country/economy tends to be positively related to social segregation (although not significantly). The estimated impact is weak, however. School-enrolment practices, and the share of private schools in an education system, are only proxies of the intensity of school choice in one country/economy. The estimates are thus attenuated measures of the impact of these policies.

Regarding academic segregation, once the potential confounding factors and country-specific effects are taken into account, an increase in the proportion of students in schools that always use residence-based criteria for enrolment is related to lower concentrations of high achievers in schools. Again, the impact is weak, and the estimates show no significant effect on the concentration of low achievers in schools. This may be explained by the fact that these correlations correspond to short-term effects, while school enrolment policies may take time to produce their full effects (for instance if it shifts household preferences regarding residential segregation). Moreover, the link between residence-based and academic segregation is only indirect, as it is expected mostly to affect the social composition of schools.

Surprisingly, while a positive cross-country correlation is observed between the selectivity of schools and the academic segregation index (Figure 4.3), panel estimates suggest a negative correlation with a change in the concentration of high achievers in certain schools (Figure 4.1). While this result may appear counterintuitive, it may be because a larger number of schools with similar enrolment practices dilutes the effects of those practices. If $10 \%$ of schools select their students based on their academic records, then they might end up with the highest-performing students. However, if $80 \%$ of schools attempt to select their students based on their academic performance, then the high-performing students in the system may be distributed across more schools. Moreover, even if schools use academic performance as a criterion for enrolment that does not mean that they always select only the top-performing students or that they do not use other admissions criteria as well. For instance, in some countries, regulations may encourage, if not require, schools to accept students with a mix of abilities and socio-economic backgrounds.

However, once other confounding factors are taken into account, an increase in the proportion of students in private schools is positively related to the isolation of low achievers in some schools.

The relationship between the proportions of grade repeaters and students in vocational tracks, and the academic segregation indices appears negligible, once country fixed effects are taken into account. 


\section{Notes}

1. This is a common property with the square roots index proposed by Hutchens for binary variable (see $\left(\mathrm{OECD}, 2017_{[3]}\right)$ ). The $\mathrm{H}$ indicator used here has the advantage of dealing with more than two groups (here, the four groups defined by the quartiles). It corresponds to a measure of relative social diversity within schools. It can be compared to the social inclusion index commonly used in PISA publications, which relies on the continuous measure of socio-economic status; but this estimator cannot be decomposed additively.

2. The index is sometimes called the Theil index or Mutual Information Index (Frankel and Volij, $2011_{[2]}$ ). In practice, it is usually much lower than 1, except when a very small proportion of some groups in some schools is observed.

3. Formally $H=H^{\text {Priv/Pub }}+\theta^{\text {Public }} H^{\text {Public }}+\theta^{\text {Private }} H^{\text {Private }}$ with $H^{\text {Priv/Pub }}$ is the no-diversity index, measured by comparing the populations of 15-year-old students in private and public schools (taken as only two big entities); $H^{\text {Public }}$ and $H^{\text {Private }}$ the no-diversity indices estimated amongst respectively public and private schools; $\theta^{\text {Private }}$ and $\theta^{\text {Public }}$ the proportion of 15 -year-old students in public and private schools.

4. This has been observed, for instance, in France (Tavan, 2004 $4_{[4]}$; Givord et al., 2016 $6_{[5]}$ ).

5. This may also explain why the proportion of students in vocational tracks has the strongest negative correlation with social segregation according to the results shown in Table 4.1.

\section{References}

Borgonovi, F. and A. Pokropek (2017), "Birthplace diversity, income inequality and education gradients in generalised trust: The relevance of cognitive skills in 29 countries", OECD Education Working Papers, No. 164, OECD Publishing, Paris, https://dx.doi.org/10.1787/f16a8bae-en.

Frankel, D. and O. Volij (2011), "Measuring school segregation", Journal of Economic Theory, http://dx.doi.org/10.1016/j.jet.2010.10.008.

Givord, P. et al. (2016), "La ségrégation sociale entre les collèges. Quelles différences entre public et privé, aux niveaux national, académique et local ?", Education et Formations, Vol. 91, http://media.education.gouv.fr/file/revue 91/05/4/depp-2016-EF-91 635054.pdf.

OECD (2017), PISA 2015 Results (Volume III): Students' Well-Being, PISA, OECD Publishing, Paris, [3] https://dx.doi.org/10.1787/9789264273856-en.

Tavan, C. (2004), "Public, privé - Trajectoires scolaires et inégalités sociales", Education et Formations, [4] Vol. 69, http://media.education.gouv.fr/file/07/6/5076.pdf (accessed on 3 January 2019). 



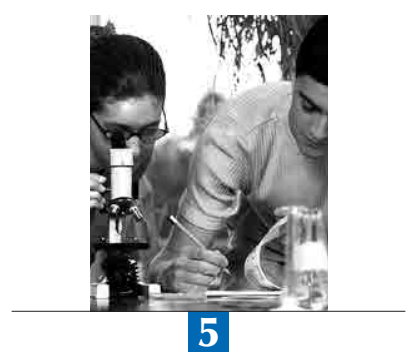

\section{How school-choice policies are related to quality and equity in education}

This chapter analyses how changes observed in the degree of social and academic segregation across schools is related to the link between socioeconomic status and performance in PISA. The chapter also examines whether the criteria used for admissions to school have a direct impact on performance and equity, as measured by PISA.

\section{A note regarding Israel}

The statistical data for Israel are supplied by and under the responsibility of the relevant Israeli authorities. The use of such data by the OECD is without prejudice to the status of the Golan Heights, East Jerusalem and Israeli settlements in the West Bank under the terms of international law.

\section{A note regarding Lithuania}

Lithuania became a member of the OECD on 5 July 2018. However, consistent with other publications based on PISA 2015 data, Lithuania is shown as a partner country and is not included in the OECD average.

This document, as well as any data and map included herein, are without prejudice to the status of or sovereignty over any territory, to the delimitation of international frontiers and boundaries and to the name of any territory, city or area. 
The relationships between school-choice policies and the outcomes of an education system are equivocal. On the one hand, more competition may improve the efficiency of schools: greater freedom to choose the school that best matches the needs of every student may improve the overall performance of the school system. Greater competition could also improve equity if students from disadvantaged families have access to the best schools - even if these schools are not located in their neighbourhoods. On the other hand, school-choice policies may reduce equity in education if only the best-informed and most-advantaged students benefit from the opportunity of opting out of their neighbourhood schools to enrol in higher-performing schools.

These effects may also be indirectly amplified - or mitigated - if the performance of students is affected by the socio-economic status of their peers in school, as school choice policies may affect social and academic segregation between schools. The consequences of school segregation is unclear, as they depend on the magnitude and the nature of peer effects at school. The effect of sorting students based on performance or social status may be positive for some students and negative for others; it is thus an open question whether greater segregation will have a positive or negative impact on education outcomes.

While the previous section analyses the link between school-choice policies, and social and academic segregation, this section analyses the link with academic outcomes, as illustrated in the following figure. It analyses whether school segregation is related to education outcomes, and then examines the direct relationship with certain proxies of school choice, such as school admissions practices and the proportion of private schools in a system.

Figure 5.1 - School-choice policies, segregation in schools and education outcomes

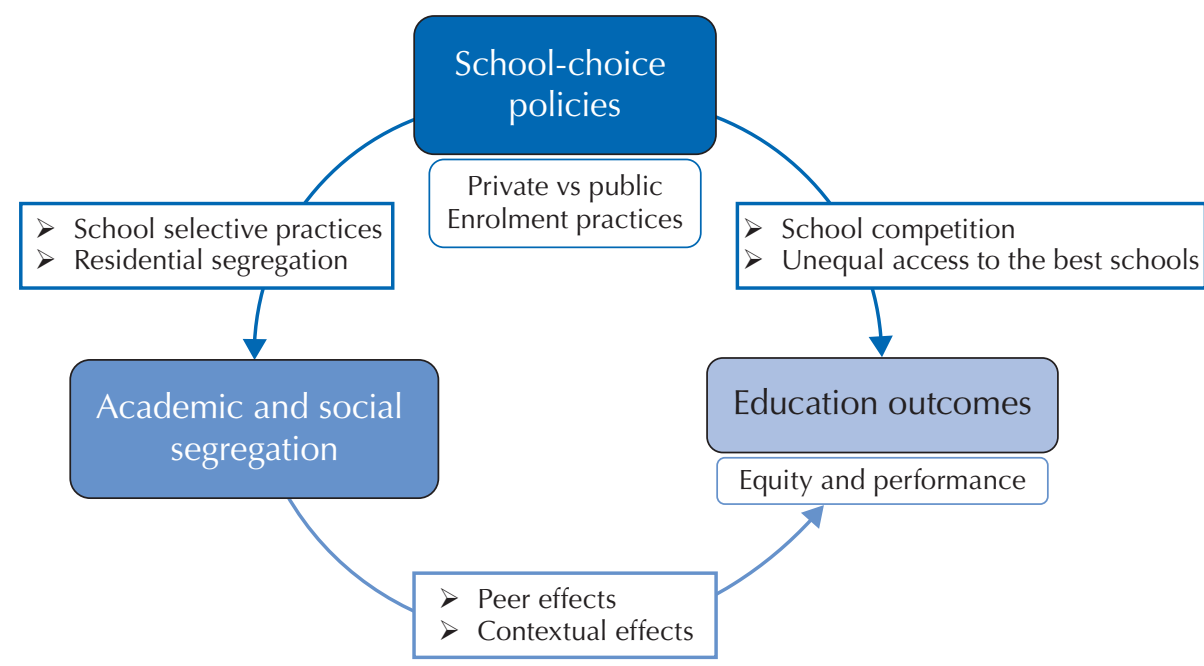




\section{SORTING BY SOCIO-ECONOMIC STATUS ACROSS SCHOOLS IS NEGATIVELY RELATED TO EQUITY IN EDUCATION}

In 2015, countries where schools were less socially diverse also had less-equitable education systems (Figure 5.2). For instance, Peru has one of the highest levels of social segregation amongst all the countries and economies that participated in PISA in 2015; it is also one of the countries where the link between performance in reading and students' socio-economic status is the strongest. ${ }^{1}$ At the other extreme, in Algeria, where students' reading performance is weakly related to their socio-economic status, schools are more socially diverse, on average, than those in other countries and economies.

Figure 5.2 - Equity in reading performance and no-diversity index for disadvantaged students

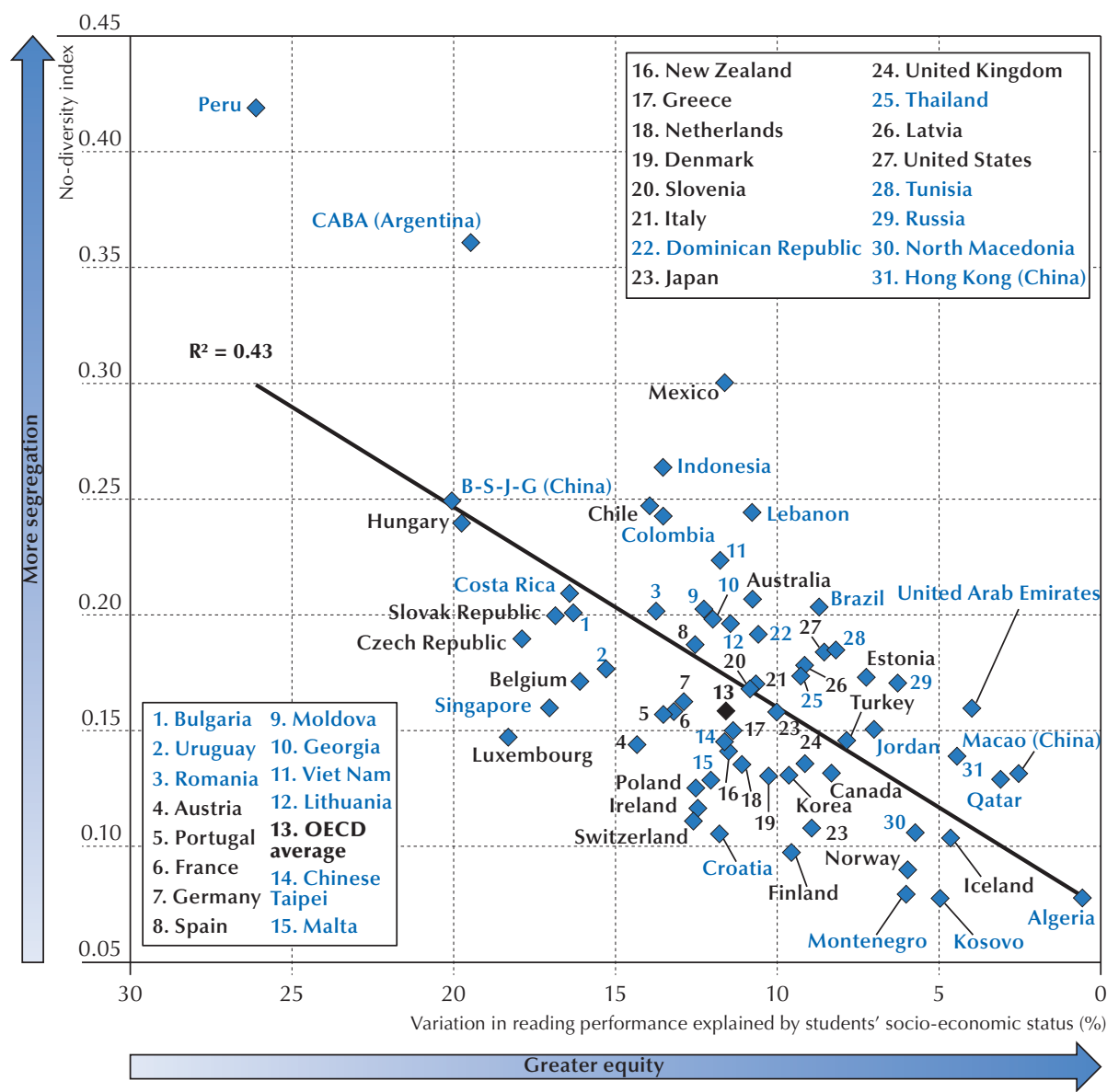

Notes: All analyses are restricted to schools with the modal ISCED level for 15-year-old students.

The $\mathrm{R}^{2}$ value indicates the proportion of the variance in the no-diversity index that is accounted for by differences in equity in reading performance across education systems. It is a measure of the strength of the relationship between the no-diversity index and equity in reading performance at the country level.

Source: OECD, PISA 2015 Database, Table 5.4.

StatLink क्ता Sh https://doi.org/10.1787/888933971670 
As described above, several confounding factors (some observed, such as early tracking or grade repetition, some unobserved, such as differentiated financial support for disadvantaged families) may affect both performance and equity. Again, examining the data from several cycles of PISA and introducing country-fixed effects help disentangle these effects. Specificities of individual school systems that may have an impact on student performance should be taken into account, as that impact may otherwise be spuriously attributed to school segregation.

Both average performance and the socio-economic gradient (both the strength and the slope ${ }^{2}$ ) at the country/economy level are examined to determine how they are related to indicators of both academic and social segregation. A specification similar to the one provided in equation (1) in Chapter 4 is used. To get a more accurate picture, one may rely on panel estimates at the student level (Hanushek and Woessmann, 2006 [1] ), as shown in Table 5.2. One may take into account students' individual characteristics, such as gender, immigrant background and socio-economic status, and measure the relationship with country-level segregation indices.

As seen below, the econometric specification includes country-specific effects, meaning that the effect is identified by comparing changes in the level of segregation within countries. ${ }^{3}$ The interaction of the country-level segregation indices with dummies of advantaged and disadvantaged students is a proxy for the impact on equity (the reference is students of average socio-economic status). One may thus determine whether or not school segregation has a different impact on students, depending on their socio-economic status (if these interacted dummies are significantly different from zero) and, when this is the case, whether school segregation tends to favour or penalise disadvantaged students more than advantaged students. As emphasised above, the estimated relations correspond to short-term effects - and thus may underestimate the final results.

Empirical evidence suggests that social segregation across schools is negatively correlated with equity in education, with a weak but positive relationship with performance (Table 5.1 and Table 5.2). An increase in the no-diversity index results in an increase in both the strength and the slope of the social gradient (how much student performance in PISA changes with a one-unit increase in the PISA index of economic, social and cultural status), as measured at the country level (Table 5.1). Less diversity in schools tends to favour advantaged students (column [2] of Table 5.2). It has a weak, positive relationship with performance, but one that is insufficient to counteract the negative relationship for disadvantaged students. This is partly because social segregation is often related to academic segregation, which appears to be harmful for all types of students. Academic segregation is negatively correlated with both the average performance and the equity of education systems (Table 5.2, columns [3] and [4]).

When academic segregation is taken into account, estimates suggest that social segregation may be slightly positive, even for disadvantaged students. However, these correlations should be interpreted with caution, first, because disadvantaged students are over-represented among low achievers, and advantaged students are over-represented among high achievers. Social and academic segregation are largely intertwined, and it would be difficult to shift social segregation without changing academic segregation. Second, if students' performance depends on that of their peers, academic segregation may have a self-reinforcing effect. Even limited sorting by ability in admissions may result in larger differences in achievement among the students enrolled in these schools. In addition, academic segregation across schools will be observed if some schools are more effective than others in improving their students' academic achievement. The magnitude of 
the estimates is shown in Table 5.3. A 10-point increase in the no-diversity index (on a scale of 0 to 100) results in an increase of 5 score points in the average reading performance of students enrolled in schools of the modal grade, assuming that all specificities of the education system, including academic segregation, remain unchanged. However, disadvantaged students would not benefit as much as other students - the change in their performance would be significantly smaller than the change in average performance - and not more than 3 score points. ${ }^{4}$

\section{Table 5.1 - Social gradient and reading performance related to social and academic segregation, 2009-15 \\ Panel estimates, country-level regressions}

\begin{tabular}{|c|c|c|c|c|c|c|c|c|c|c|}
\hline \multirow[b]{2}{*}{ No-diversity index } & \multicolumn{2}{|c|}{$\begin{array}{l}\text { Strength } \\
\text { (1) }\end{array}$} & \multicolumn{2}{|c|}{$\begin{array}{l}\text { Strength } \\
\text { (2) }\end{array}$} & \multicolumn{2}{|c|}{$\begin{array}{l}\text { Strength } \\
\text { (3) }\end{array}$} & \multicolumn{2}{|c|}{$\begin{array}{l}\text { Slope } \\
\text { (3) }\end{array}$} & \multicolumn{2}{|c|}{$\begin{array}{c}\text { Reading } \\
\text { performance } \\
\text { (3) }\end{array}$} \\
\hline & 0.733 & $(0.105)$ & & & 0.671 & $(0.112)$ & 1.066 & $(0.214)$ & 0.939 & $(0.715)$ \\
\hline $\begin{array}{l}\text { Isolation index for high- } \\
\text { achieving students in reading }\end{array}$ & & & 0.184 & $(0.054)$ & 0.079 & $(0.050)$ & 0.060 & $(0.096)$ & -0.345 & $(0.320)$ \\
\hline Grade repetition (\%) & 0.021 & $(0.005)$ & 0.017 & $(0.006)$ & 0.019 & $(0.005)$ & 0.012 & $(0.010)$ & -0.037 & $(0.033)$ \\
\hline Vocational programmes $(\%)$ & -0.064 & $(0.044)$ & -0.142 & $(0.049)$ & -0.073 & $(0.044)$ & -0.077 & $(0.085)$ & 0.130 & $(0.285)$ \\
\hline Private schools (\%) & -0.064 & $(0.035)$ & -0.034 & $(0.040)$ & -0.062 & $(0.035)$ & -0.136 & $(0.067)$ & 0.198 & $(0.223)$ \\
\hline Intercept & 2.889 & $(1.857)$ & 9.732 & $(1.663)$ & 1.958 & $(1.935)$ & 19.947 & (3.708) & 457.094 & (12.308) \\
\hline Number of observations & \multicolumn{2}{|c|}{176} & \multicolumn{2}{|c|}{176} & \multicolumn{2}{|c|}{176} & \multicolumn{2}{|c|}{176} & \multicolumn{2}{|c|}{177} \\
\hline $\mathbf{R}^{2}$ & \multicolumn{2}{|c|}{0.42} & \multicolumn{2}{|c|}{0.23} & \multicolumn{2}{|c|}{0.43} & \multicolumn{2}{|c|}{0.28} & \multicolumn{2}{|c|}{0.05} \\
\hline
\end{tabular}

Notes: All analyses are restricted to schools with the modal ISCED level. The results above may thus differ from those estimated on the entire sample of 15 -year-old students.

Data are aggregated at the country/cycle level.

The strength of the social gradient corresponds to the variation in student performance in one country that is explained by socio-economic status; the slope refers to the score-point difference in performance associated with one-unit increase in ESCS (the $\mathrm{R}^{2}$ and coefficient, respectively, of a regression of individual performance on socio-economic status).

For the sake of readability, the strength of the social gradient and the segregation indices have been rescaled from 0 to 100. Standard errors are indicated in parentheses.

Values that are statistically significant at the $10 \%$ level are indicated in italics and those at the $5 \%$ level are indicated in bold. Source: OECD, PISA 2009, PISA 2012 and PISA 2015 Databases.

StatLink *iाst https://doi.org/10.1787/888933971841

By contrast, advantaged students would benefit to a much larger extent from greater social stratification between schools, as their performance would improve by 16 score points. According to these estimates, increasing social segregation amongst schools would widen the gap between disadvantaged and advantaged students. That is consistent with the positive correlation observed at the aggregated level (Table 5.1) between the no-diversity index and the slope of the social gradient. In the sample, the range observed between the lowest and highest levels of the no-diversity index in 2009, 2012 and 2015 (see Table B.2 in Annex B) is around 20 (on a scale of 100), but the changes in social diversity observed within countries are much smaller than this range.

While greater social segregation is positively related to the average performance of a school system, this may be offset by greater academic segregation. According to the estimates, a 10-point increase (on a scale of 100) in the isolation of high achievers would result in a decrease of around 6 score points in the reading performance of advantaged students and those of average socio-economic status, while the reading performance of disadvantaged students would decline by 10 score points. All in all, greater segregation of higher achievers would thus amplify social inequity in education.

Figure 5.2 illustrates the negative relationship between social segregation and equity in a cross-country comparison. 


\section{Table 5.2 - Reading performance, by school practices, academic and social segregation, 2009-15}

\section{Panel estimates, student-level regressions}

\begin{tabular}{|c|c|c|c|c|c|c|c|c|c|c|}
\hline \multirow[b]{2}{*}{ Boy } & \multicolumn{2}{|c|}{ Benchmark (1) } & \multicolumn{2}{|c|}{$\begin{array}{l}\text { Social segregation } \\
\text { (2) }\end{array}$} & \multicolumn{2}{|c|}{$\begin{array}{c}\text { Academic } \\
\text { segregation (3) }\end{array}$} & \multicolumn{2}{|c|}{$\begin{array}{c}\text { Social and } \\
\text { academic } \\
\text { segregation (4) }\end{array}$} & \multicolumn{2}{|c|}{$\begin{array}{l}\text { School enrolment } \\
\text { criteria (5) }\end{array}$} \\
\hline & -35.086 & $(0.258)$ & -35.121 & $(0.257)$ & -35.103 & $(0.257)$ & -35.120 & $(0.256)$ & -35.094 & $(0.259)$ \\
\hline Immigrant & -5.026 & $(0.516)$ & -5.231 & $(0.518)$ & -5.179 & (0.519) & -5.251 & $(0.520)$ & -5.214 & $(0.520)$ \\
\hline Disadvantaged & -38.773 & $(0.570)$ & -31.740 & (1.303) & -31.424 & (0.894) & -29.873 & $(1.315)$ & -46.575 & $(1.132)$ \\
\hline Advantaged & 45.527 & $(0.568)$ & 27.391 & (1.263) & 37.761 & (0.886) & 26.926 & $(1.280)$ & 53.704 & $(1.370)$ \\
\hline No-diversity index & & & 0.095 & $(0.165)$ & & & 0.469 & $(0.179)$ & & \\
\hline x Disadvantaged & & & -0.484 & $(0.078)$ & & & -0.170 & $(0.090)$ & & \\
\hline x Advantaged & & & 1.245 & $(0.083)$ & & & 1.163 & $(0.093)$ & & \\
\hline $\begin{array}{l}\text { Isolation index for high- } \\
\text { achieving students }\end{array}$ & & & & & -0.562 & (0.118) & -0.637 & $(0.128)$ & & \\
\hline x Disadvantaged & & & & & -0.355 & (0.035) & -0.311 & $(0.040)$ & & \\
\hline x Advantaged & & & & & 0.376 & $(0.040)$ & 0.081 & $(0.045)$ & & \\
\hline $\begin{array}{l}\text { School admissions based on } \\
\text { academic performance }(\%)\end{array}$ & & & & & & & & & -0.252 & $(0.035)$ \\
\hline x Disadvantaged & & & & & & & & & 0.023 & $(0.014)$ \\
\hline x Advantaged & & & & & & & & & -0.050 & $(0.013)$ \\
\hline $\begin{array}{l}\text { School admissions based on } \\
\text { residence }(\%)\end{array}$ & & & & & & & & & 0.204 & $(0.042)$ \\
\hline x Disadvantaged & & & & & & & & & 0.137 & $(0.016)$ \\
\hline x Advantaged & & & & & & & & & -0.127 & $(0.021)$ \\
\hline Private schools (\%) & 0.206 & $(0.051)$ & 0.196 & $(0.051)$ & 0.223 & $(0.050)$ & 0.198 & $(0.051)$ & 0.237 & $(0.051)$ \\
\hline x Disadvantaged & 0.093 & $(0.013)$ & 0.095 & $(0.013)$ & 0.098 & $(0.013)$ & 0.099 & $(0.013)$ & 0.136 & $(0.014)$ \\
\hline x Advantaged & -0.167 & $(0.012)$ & -0.173 & $(0.012)$ & -0.174 & $(0.012)$ & -0.174 & $(0.012)$ & -0.199 & $(0.014)$ \\
\hline Vocational programmes (\%) & 0.084 & $(0.076)$ & 0.115 & $(0.075)$ & 0.088 & $(0.075)$ & 0.155 & $(0.075)$ & 0.179 & $(0.079)$ \\
\hline x Disadvantaged & 0.011 & $(0.017)$ & 0.003 & (0.018) & 0.083 & (0.019) & 0.071 & $(0.021)$ & 0.080 & $(0.020)$ \\
\hline x Advantaged & 0.087 & $(0.017)$ & 0.107 & $(0.016)$ & 0.011 & $(0.020)$ & 0.089 & $(0.019)$ & 0.039 & $(0.022)$ \\
\hline Grade repetition (\%) & -0.005 & $(0.014)$ & -0.001 & $(0.013)$ & -0.002 & $(0.013)$ & 0.003 & $(0.013)$ & -0.013 & $(0.015)$ \\
\hline x Disadvantaged & -0.019 & $(0.010)$ & -0.015 & $(0.010)$ & -0.013 & $(0.010)$ & -0.012 & $(0.010)$ & -0.020 & $(0.010)$ \\
\hline x Advantaged & 0.030 & $(0.010)$ & 0.017 & $(0.009)$ & 0.023 & $(0.010)$ & 0.016 & $(0.009)$ & 0.026 & $(0.009)$ \\
\hline Intercept & 403.806 & $(2.388)$ & 402.838 & $(2.912)$ & 410.342 & $(2.644)$ & 404.560 & $(2.928)$ & 405.906 & $(3.270)$ \\
\hline Number of observations & \multicolumn{2}{|c|}{$1,175,972$} & \multicolumn{2}{|c|}{$1,175,972$} & \multicolumn{2}{|c|}{$1,175,972$} & \multicolumn{2}{|c|}{$1,175,972$} & \multicolumn{2}{|c|}{$1,175,972$} \\
\hline $\mathbf{R}^{2}$ & \multicolumn{2}{|c|}{0.283} & \multicolumn{2}{|c|}{0.284} & \multicolumn{2}{|c|}{0.284} & \multicolumn{2}{|c|}{0.284} & \multicolumn{2}{|c|}{0.284} \\
\hline Country fixed effect & \multicolumn{2}{|c|}{ yes } & \multicolumn{2}{|c|}{ yes } & \multicolumn{2}{|c|}{ yes } & \multicolumn{2}{|c|}{ yes } & \multicolumn{2}{|c|}{ yes } \\
\hline Cycle fixed effect & \multicolumn{2}{|c|}{ yes } & \multicolumn{2}{|c|}{ yes } & \multicolumn{2}{|c|}{ yes } & \multicolumn{2}{|c|}{ yes } & \multicolumn{2}{|c|}{ yes } \\
\hline
\end{tabular}

Notes: All analyses are restricted to schools with the modal ISCED level. The results above may thus differ from those estimated on the entire sample of 15-year-old students.

Disadvantaged students are students in the bottom quarter of the PISA index of economic, social and cultural status (ESCS) in their own country.

Advantaged students are students in the top quarter of the PISA index of economic, social and cultural status (ESCS) in their own country.

Individual student weights are normalised in such a way that the contributions of all countries are equal, regardless of the size of their population (senate weights). The benchmark specification does not include segregation variables nor schoolenrolment criteria included in the following ones.

The strength of the social gradient corresponds to the variation in student performance in one country that is explained by socio-economic status; the slope refers to the score-point difference in performance associated with one-unit increase in ESCS (the $\mathrm{R}^{2}$ and coefficient, respectively, of a regression of individual performance on socio-economic status).

For the sake of readability, the strength of the social gradient and the segregation indices have been rescaled from 0 to 100. Standard errors are indicated in parentheses.

Values that are statistically significant at the $10 \%$ level are indicated in italics and those at the $5 \%$ level are indicated in bold. Source: OECD, PISA 2009, PISA 2012 and PISA 2015 Databases.

StatLink 需s https://doi.org/10.1787/888933971860 
Figure 5.3 - Estimated impact of segregation and school type on reading performance, by socio-economic status

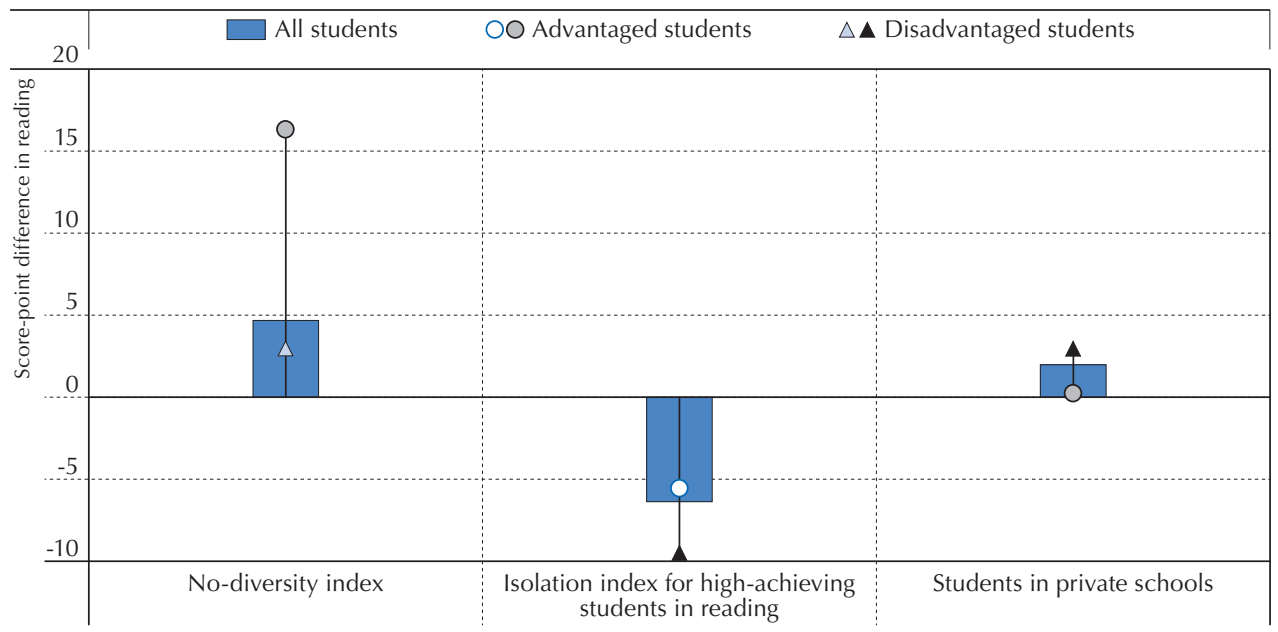

Notes: All analyses are restricted to schools with the modal ISCED level for 15-year-old students.

Disadvantaged students are students in the bottom quarter of the PISA index of economic, social and cultural status (ESCS) in their own country.

Advantaged students are students in the top quarter of the PISA index of economic, social and cultural status (ESCS) in their own country.

Estimated impact of an increase of 10 points in the no-diversity index or the isolation index, and 10 percentage points in the percentage of students in private schools, using specification (3) in Table 5.2. In the sample, the observed maximum range (highest - lowest level) is 21.1 for the no-diversity index, 43.6 for the isolation index of high achievers, and 97.4 percentage points for the proportion of students in private schools (see Table B.2 in Annex B).

Dark blue bars correspond to an effect that is statistically significantly different from the null for average students; dark grey and black symbols correspond to a significant additional impact for advantaged or disadvantaged students.

Source: OECD, PISA 2009, PISA 2012 and PISA 2015 Databases, Table 5.2.

StatLink त्ताs https://doi.org/10.1787/888933971689

When taking the level of academic segregation into account, the share of private schools in a country/economy tends to be positively related to both equity and performance, although this relationship is not statistically significant (Table 5.1). The difference is small, though. As illustrated in Figure 5.3, a 10 percentage-point increase in the proportion of students in private schools would improve average student performance by 2 score points. After accounting for academic and social segregation, it would narrow the performance gap between advantaged and disadvantaged students by three score points. One may conclude from this estimation that the availability of private schools, as it induces greater competition, may result in better school performance. However, this conclusion should be regarded with caution, as such a positive effect may be undermined by sorting effects, as private schools are also usually more academically selective than public schools (see Figure 2.6 in Chapter 2).

\section{THE DIRECT IMPACT OF SCHOOL ADMISSIONS POLICIES ON PERFORMANCE AND SOCIAL EQUITY IN EDUCATION IS SMALL}

While the previous section suggests that segregation may be related to both equity and performance, one may measure the direct impact of school enrolment practices on education outcomes. Specifically, the same analyses are performed using the proportions of students in 
schools using academically selective admissions practices and those relying on residence-based admissions policies, at both the student (Table 5.2) and country levels (Table 5.3). Table 5.2 shows the impact on equity of the interaction of these proportions with dummies of disadvantaged and advantaged students.

\section{Table 5.3 - Social gradient and reading performance related to admissions criteria, 2009-15}

Panel estimates, country-level regressions

\begin{tabular}{|c|c|c|c|c|c|c|c|c|c|c|}
\hline \multirow[b]{2}{*}{$\begin{array}{l}\text { School admissions based on } \\
\text { academic performance }(\%)\end{array}$} & \multicolumn{2}{|c|}{$\begin{array}{l}\text { Strength } \\
\text { (1) }\end{array}$} & \multicolumn{2}{|c|}{$\begin{array}{l}\text { Strength } \\
\text { (2) }\end{array}$} & \multicolumn{2}{|c|}{$\begin{array}{l}\text { Slope } \\
(1)\end{array}$} & \multicolumn{2}{|c|}{$\begin{array}{c}\text { Reading } \\
\text { performance } \\
\text { (1) }\end{array}$} & \multicolumn{2}{|c|}{$\begin{array}{c}\text { Reading } \\
\text { performance } \\
(2)\end{array}$} \\
\hline & -0.059 & $(0.022)$ & -0.038 & (0.019) & -0.041 & $(0.037)$ & -0.125 & $(0.117)$ & -0.088 & $(0.121)$ \\
\hline $\begin{array}{l}\text { School admissions based on } \\
\text { residence }(\%)\end{array}$ & -0.029 & $(0.031)$ & -0.012 & $(0.026)$ & -0.020 & $(0.050)$ & 0.245 & $(0.161)$ & 0.294 & $(0.165)$ \\
\hline No-diversity index & & & 0.697 & $(0.106)$ & 1.072 & $(0.204)$ & & & 0.675 & $(0.676)$ \\
\hline Grade repetition (\%) & 0.014 & $(0.007)$ & 0.017 & $(0.006)$ & 0.009 & $(0.011)$ & -0.075 & $(0.034)$ & -0.065 & $(0.036)$ \\
\hline Vocational programmes (\%) & -0.123 & $(0.051)$ & -0.060 & $(0.044)$ & -0.065 & $(0.085)$ & 0.039 & $(0.272)$ & 0.103 & $(0.281)$ \\
\hline Private schools (\%) & -0.027 & $(0.041)$ & -0.058 & $(0.035)$ & -0.131 & $(0.067)$ & 0.251 & $(0.218)$ & 0.239 & $(0.222)$ \\
\hline Intercept & 17.461 & $(1.870)$ & 5.369 & $(2.429)$ & 23.613 & $(4.665)$ & 459.579 & (9.809) & 446.014 & (15.488) \\
\hline Number of observations & \multicolumn{2}{|c|}{176} & \multicolumn{2}{|c|}{176} & \multicolumn{2}{|c|}{176} & \multicolumn{2}{|c|}{188} & \multicolumn{2}{|c|}{177} \\
\hline $\mathbf{R}^{2}$ & \multicolumn{2}{|c|}{0.20} & \multicolumn{2}{|c|}{0.44} & \multicolumn{2}{|c|}{0.28} & \multicolumn{2}{|c|}{0.07} & \multicolumn{2}{|c|}{0.08} \\
\hline
\end{tabular}

Notes: All analyses are restricted to schools with the modal ISCED level. The results above may thus differ from those estimated on the entire sample of 15 -year-old students.

Data are aggregated at the country/cycle level.

The strength of the social gradient corresponds to the variation in student performance in one country that is explained by socio-economic status; the slope refers to the score-point difference in performance associated with one-unit increase in ESCS (the $\mathrm{R}^{2}$ and coefficient, respectively, of a regression of individual performance on socio-economic status).

For the sake of readability, the strength of the social gradient and the segregation indices have been rescaled from 0 to 100 . Standard errors are indicated in parentheses.

Values that are statistically significant at the $10 \%$ level are indicated in italics and those at the $5 \%$ level are indicated in bold. Source: OECD, PISA 2009, PISA 2012 and PISA 2015 Databases.

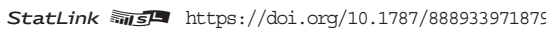

Overall, results estimated at the student level align with those observed at the country level even if the former estimates are usually more statistically significant than the latter, given the much larger sample size. An increase in the proportion of students in schools that base enrolment on residence is related to an improvement in performance, while an increase in the proportion of academically selective schools is related to a deterioration in average performance, although in both cases, the coefficients are small -0.20 and -0.25 , respectively (Table 5.2). For the sake of comparison, an increase of 10 percentage points in the proportion of schools that always rely on residence for enrolment would result in an improvement of two score points, at most, in average performance, while a similar change in the proportion of selective schools would have a similarly small, but negative effect on performance ${ }^{5}$ (Table 5.2).

Estimates also suggest that school-enrolment practices may have a relationship with equity in education, in the sense that an increase in the proportions of both academically selective schools and residence-based schools tend to be associated with a deterioration in performance amongst advantaged students relative to that of students of average or disadvantaged status. This is consistent with results discussed in Chapter 4 that show, first, that an increase in the proportion 
of schools that are academically selective and those that apply residence-based policies for admission is associated with a lower level of social segregation across schools; and, second, that fewer socially diverse schools result in less equity at the country level. However, the impact is again weak, as suggested by cross-country comparisons (Figure 5.4).

Figure 5.4 - Equity in reading performance and school admissions based on academic performance

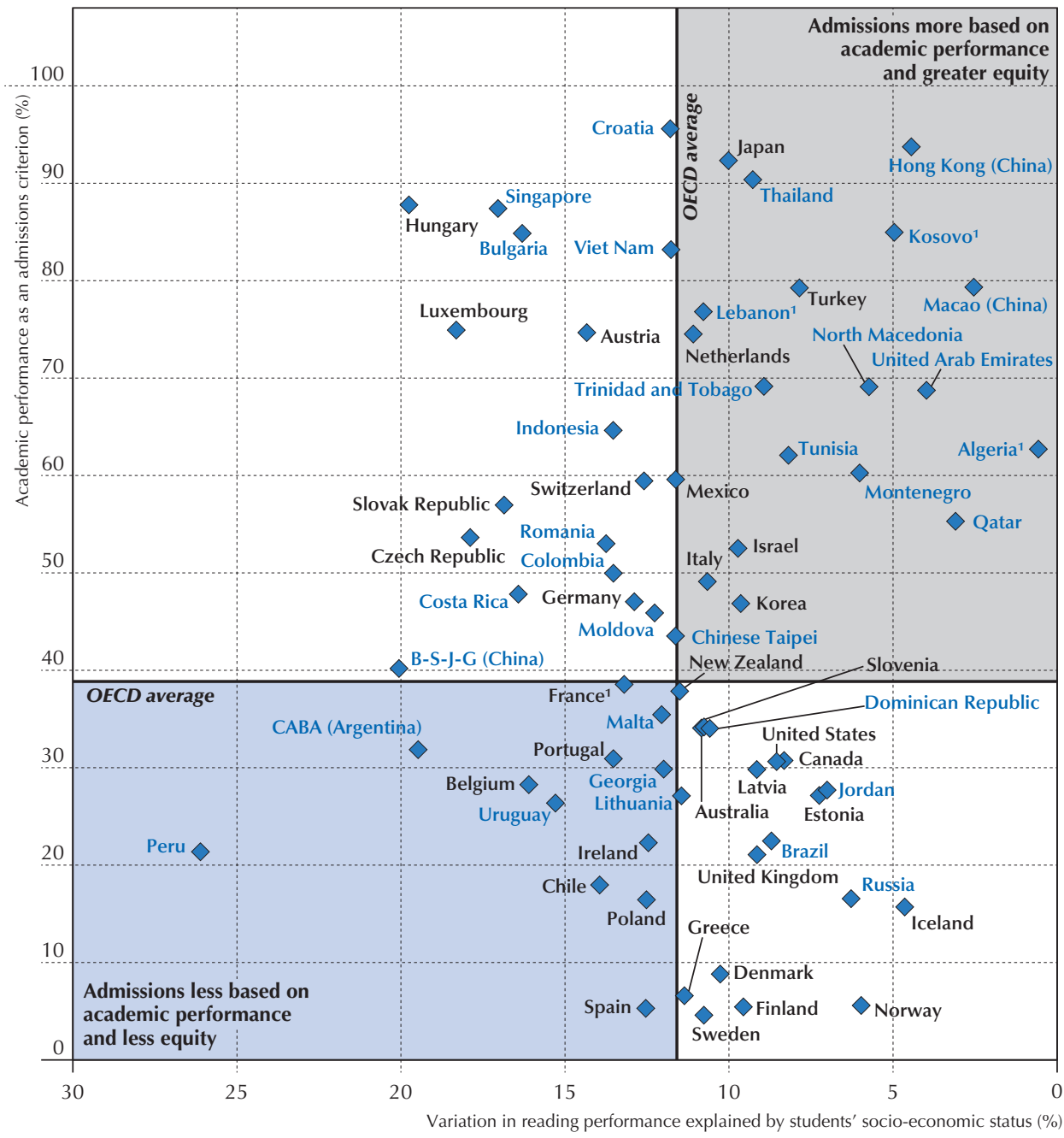

\section{Greater equity}

1. In Algeria, France, Kosovo and Lebanon, the proportion of 15 -year-old students in modal grade schools is lower than $80 \%$ (see Table B.3), and one should interpret with caution the comparison with other countries.

Note: All analyses are restricted to schools with the modal ISCED level for 15-year-old students.

Source: OECD, PISA 2015 Database, Table 5.5.

StatLink 全Is https://doi.org/10.1787/888933971708 
According to the estimates provided in the column (5) in Table 5.2, an increase of 10 percentage points in the proportion of students in academically selective schools would be related to a decrease in the performance gap between advantaged and disadvantaged students by less than one score point, at most. A similar change in the proportion of students in schools that admit students on the basis of residence would reduce that performance gap by three score points. On the other hand, once the level of school selectivity is accounted for, a larger proportion of students in private schools is associated with an improvement in both performance and equity. This is consistent with the results discussed in the section below: that the competition pressures on schools associated with a large share of private schools in a country/economy have a positive impact on student performance; but this is counterbalanced by the negative impact of sorting students by ability. 


\section{Notes}

1. Note that as the sample is restricted to students in modal grade schools, the figures on the social gradient may differ from those estimated on the entire sample of 15 -year-old students.

2. The strength of the social gradient corresponds to the variation in student performance in one country that is explained by socio-economic status; the slope refers to the score-point difference in performance associated with one-unit increase in ESCS (the $\mathrm{R}^{2}$ and coefficient, respectively, of a regression of individual performance on socio-economic status).

3. Individual student weights are normalised in such a way that the contributions of all countries are equal, regardless of the size of their population (senate weights).

4. In order to estimate the impact on disadvantaged students, one should add $0.47+(-0.17)=0.30$.

5. From Table 5.2, $0.20 * 10=2$ and $-0.25 * 10=-2.5$.

\section{References}

Hanushek, E. and L. Woessmann (2006), "Does Educational Tracking Affect Performance and Inequality? Differences-in-Differences Evidence Across Countries", The Economic Journal, Vol. 116/510, pp. C63-C76, http://dx.doi.org/10.1111/j.1468-0297.2006.01076.x. 



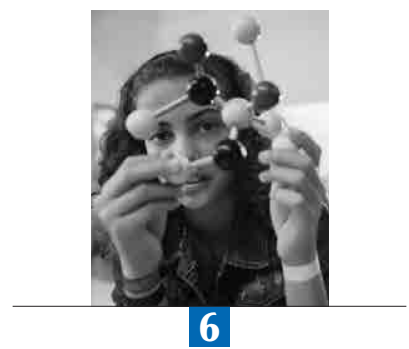

\section{Balancing choice and equity: Considerations for policy and practice}

This chapter summarises the results discussed in the report. It provides a broad perspective on the issue of school choice, and identifies the types of education policies that can help balance school choice and equity.

\section{A note regarding Israel}

The statistical data for Israel are supplied by and under the responsibility of the relevant Israeli authorities. The use of such data by the OECD is without prejudice to the status of the Golan Heights, East Jerusalem and Israeli settlements in the West Bank under the terms of international law.

\section{A note regarding Lithuania}

Lithuania became a member of the OECD on 5 July 2018. However, consistent with other publications based on PISA 2015 data, Lithuania is shown as a partner country and is not included in the OECD average.

This document, as well as any data and map included herein, are without prejudice to the status of or sovereignty over any territory, to the delimitation of international frontiers and boundaries and to the name of any territory, city or area. 
Many countries face the challenge of balancing aspirations for greater flexibility and parents' freedom to choose their child's school with the need to ensure equity in their school systems.

Education systems pursue very different approaches when it comes to linking school autonomy to school choice, and to reconciling choice with equity. For example, England and Shanghai both emphasise market mechanisms, but while public policy in England mainly operates on the demand side of markets, seeking to improve schooling by enhancing parents' choice, in Shanghai, the main emphasis of public policy lies in creating a level playing field at the supply side: providing schools in the most disadvantaged areas with the best education resources. While Finland and Hong Kong both emphasise local autonomy, in Finland that autonomy is exercised within a strong public school system, while most schools in Hong Kong are managed by private entities with relatively loose steering mechanisms.

Some countries have strengthened choice and equity-related mechanisms at the same time. England, for example, has rapidly increased the number of academies, schools funded directly by the Department for Education and independent of local authority control. At the same time, England has established a pupil premium that provides schools with additional resources based on the socio-economic composition of their student body. Some countries have also made it possible for private schools to be integrated into the public education system as governmentdependent schools or as independent schools that receive a certain amount of public funding.

Proponents of school choice defend the right of parents to send their child to the school of their preference - because of quality, pedagogical approaches, religious denomination, affordability or geographical location - regardless of legal restrictions or financial or geographical barriers. The idea is that, given students' diverse needs and interests, a larger number of options in any one school system should lead to better value by reducing the cost of failure and mismatch. More options should stimulate competition and, in doing so, prompt schools to innovate, experiment with new pedagogies, become more efficient and improve the quality of the learning experience. Proponents argue that the increasing social and cultural diversity of modern societies calls for greater diversification in the education landscape, including allowing non-traditional providers and even commercial companies to enter the market.

Critics of school choice argue that, when presented with more options, students from advantaged backgrounds often choose to leave the public system, leading to greater social and cultural segregation in the school system. They are also concerned with over-reliance on theoretical models of rational, price-based economic competition as the basis for the allocation of resources.

At the macro level, such segregation can deprive children of opportunities to learn, play and communicate with children from different social, cultural and ethnic backgrounds; that, in turn, threatens social cohesion. To critics, vouchers and voucher-like systems divert public resources to private and sometimes commercial providers, thereby depriving public schools, which tend to serve large populations of disadvantaged students, of the resources they need to maintain the quality of the education they provide.

A closer look at the evidence shows that the arguments are not so clear-cut. For a start, the term "school choice" can be interpreted, and made manifest, in a variety of ways, depending on the local context (Musset, 2012 $[1]$ ). For instance, school-choice programmes can simply involve 
relaxing the rules on geographic assignment in the public sector or promote general choice amongst both public and private providers, as in Belgium and the Netherlands. In other cases, school-choice programmes are restricted to specific types of schools or student groups, such as those involving the use of income-dependent vouchers. ${ }^{1}$

Greater enrolment in private schools is often referred to as the privatisation of education, and is regarded as a move away from the notion of education as a public good. But that link is not so clear. In many countries where large parts of the school system operate under private legal statutes, such schools are seen as legally private but functionally public. For example, they can partly or completely follow the national curriculum and serve the public mission of education by providing accessible quality education (particularly where they are obliged to apply the same admissions and tuition standards as public schools). There are also many cases in which private schools provide access to education for underserved communities and have equity-related missions.

In addition, the consequences of school choice on education outcomes vary widely. This report provides an international perspective on issues related to school choice, especially how certain aspects of school-choice policies may be associated with sorting students into different schools. It discusses two proxies for school choice: the share of private schools in an education system and the use of residence-based policies in allocating students across schools. Over the past two decades, the number of privately funded secondary educational institutions has increased in only a few countries while residence-based enrolments have decreased in most countries. This suggests that school choice concerns all types of schools, as enrolment in public schools does not depend only on catchment areas.

One concern associated with increased school choice is the impact on the segregation of students by ability or socio-economic status. This report draws a comprehensive picture of school segregation, using a variety of indicators in order to account for the diversity of the sorting processes of students across schools. While in most countries the indices of academic segregation amongst schools are higher than those measuring socio-economic segregation, the opposite is observed in several countries, notably Latin American ones. These are also those countries where socio-economic differences in enrolment between private and public schools contributes, to a large extent, to the overall level of school segregation.

The organisation of the school system also affects the type of segregation. In some countries and economies, the academic segregation of students is mainly due to the isolation of low achievers "left behind" in some schools, while in other systems, it reflects a significant concentration of high achievers in "elite" schools. These specifics may have distinct consequences for student performance.

\section{PROVIDE THE CHECKS AND BALANCES THAT PREVENT CHOICE FROM LEADING TO MORE SEGREGATION}

Whether greater competition between schools results in sorting students by ability or socioeconomic status is a major question in the school-choice debate. Results discussed in this volume suggest that the impact of school-choice policies are ambiguous, and one should look carefully at the effects of the programmes on school diversity. Once the specificities of the school system are 
taken into account, estimates suggest that within a country/economy, relaxed residence-based admissions regulations is related to an increase in social segregation across schools. This does not mean that one should favour strict residence-based regulations; as discussed below, over the long term, such regulations can create additional residential segregation and thus reinforce school segregation. However, without some constraints in place, relaxing residence-based regulations may result in greater sorting of students by both ability and socio-economic status.

The design of catchment areas is an important tool that can be used to advance both equity and the efficient organisation of the school network. Given its sensitive nature, the definition and reform of catchment areas should involve local actors wherever possible. To avoid segregation, the equitable distribution of students should also be considered, such as by combining districts with different socio-demographic characteristics within a single catchment area (OECD, 2018 $\left.8_{[2]}\right)$.

Relaxing residence-based policies may benefit some disadvantaged students who can then attend better-quality schools that may not be located near their home. However, some students may lose out from such policies, namely low-achieving students who are "left behind" in low-quality schools. At the aggregate level, this may have a negative impact on equity but also, in some cases, on the general performance of the school system if low achievers are more harmed when they attend low-quality schools than high achievers benefit from being in better schools (for an illustration, see for instance (Brunello and De Paola, 2017 $\left.7_{[3]}\right)$ ). Panel estimates in this volume suggest that an increase in the isolation of high achievers from other students is associated with lower scores in PISA amongst socio-economically disadvantaged students, without any significant impact on advantaged students.

In practice, providing choice to parents without exacerbating segregation may be achieved by introducing specific criteria to the allocation of students across the set of local schools available. Different forms of "controlled choice" have been used to reduce high levels of student segregation, for example by reserving a given number or share of places in oversubscribed schools to students from different socio-demographic backgrounds to maintain a balanced distribution of students. The use of lottery systems to assign places in oversubscribed schools or formulae aimed to maintain a diverse student composition can also be considered (Musset, $2012_{[1]}$ ). Centralised procedures to match students to schools usually rely on a set of criteria (Abdulkadiroğlu and Sönmez, 2003 $\left.{ }_{[4]}\right)$ that may include socio-economic status. ${ }^{2}$ Engaging school communities in defining these criteria and allowing for local variation can ensure that they are sensitive to local contexts; it can also significantly ease implementation of the criteria. Given their complexity, controlled-choice systems may require a certain degree of centralisation in order to minimise administrative costs and avoid problems, like multiple registrations (OECD, 2018 $8_{[2]}$ ).

In order to mitigate the potential negative effects of school choice and public funding of private schools, particularly segregation and social stratification, various governments have implemented compensatory financing mechanisms. For example the Flemish Community of Belgium (Box 6.1), Chile (Box 6.2) and the Netherlands have instituted weighted student-funding schemes, whereby funding follows the student on a per-student basis, and the amount provided depends on the socio-economic status and education needs of each student. These schemes target disadvantaged students and, in doing so, make these students more attractive to schools competing for enrolment. ${ }^{3}$ 


\section{Box 6.1 Controlled-choice reforms in the Belgian Communities}

Since passing the 2002 Decree on Equal Educational Opportunities, the Flemish Community of Belgium has implemented a series of reforms to its school-choice system. Following a two-year period between 2008 and 2010 that allowed for local experimentation to test different enrolment systems, a 2011 decree took stock of the lessons learnt and introduced a number of reforms to the controlled-choice system. First applied in 2012-13 (and subsequently adjusted) to admissions to all pre-primary, primary and secondary schools, the reform required oversubscribed schools to assign places to disadvantaged and non-disadvantaged students in proportion to the socio-economic composition of each school's neighbourhood.

The reform also defined the criteria that schools could draw on to choose among students within each group when demand for places exceeded supply. Pre-primary and primary schools were allowed to consider the distance between the parents' home or workplace and the school, the position of the school in the student's ranking of preferences, or the results of a lottery. Secondary schools were required to operate on a first-come-first-served basis or to make decisions based on the position of the school in the student's list of preferences. Many elements of the reforms' implementation were decentralised and assigned to local negotiating platforms (locale overlegplatformen, LOPs). These platforms decided on matters such as the definition of neighbourhoods and the quotas for disadvantaged students, which helped reduce local resistance to the new rules. By 2013, there were 72 such platforms covering most of the territory of the Flemish Community, each of which ensured co-operation among schools, stakeholders and a defined local authority or region, bringing together representatives of the main education stakeholder groups in that area.

The French Community of Belgium reformed its parental choice system starting in 2007 and enrolment in the first year of secondary education has been subject to a $20 \%$ quota for disadvantaged students in every school since 2010-11. Enrolment at the pre-primary and primary levels remains largely unregulated. In contrast to that in the Flemish Community, the reform did not provide scope for adjustments at the local level or adaptations to a school's neighbourhood characteristics, which may help to explain the relatively strong resistance by schools and other stakeholders. Identification of disadvantaged students was also imprecise and based on the average socio-economic status of their primary school, which, in turn, was defined on the basis of the residential area in which the school was located.

Sources: OECD (2018), Responsive School Systems: Connecting Facilities, Sectors and Programmes for Student Success, OECD Publishing, Paris, https://dx.doi.org/10.1787/9789264306707-en; Nusche et al. (2015), OECD Reviews of School Resources: Flemish Community of Belgium 2015, OECD Publishing, Paris, http://doi.org/10.1787/9789264247598-en; OECD (2015), OECD Economic Surveys: Belgium 2015, OECD Publishing, Paris, http://doi.org/10.1787/eco surveysbel-2015-en. 


\section{Box 6.2 Regulating publicly funded private schools in Chile: The 2016 Inclusion Law}

The Chilean school system is characterised by a large network of publicly funded private schools, enrolling 53\% of its students in mainstream basic education (year 1 to year 8 ) and $51 \%$ at the upper secondary level (in 2014). Historically, Chile allowed publicly funded private schools to charge tuition fees, operate for profit and select students based on academic achievement, aptitude tests or parent interviews. This practice contributed to the country's high level of socio-economic segregation as middle-class students increasingly left the public school system to enter subsidised private schools with admissions requirements that excluded large parts of the population. In order to address these concerns and facilitate the exercise of free school choice, a new law (Ley de Inclusion, Inclusion Law) was adopted in 2016 that imposes new eligibility criteria for public funding in order to restrict selective admissions, for-profit ownership and top-up fees among subsidised private schools.

The new regulations are enforced by the Education Superintendence. In order to remain eligible for public subsidies, private schools will need to phase out their tuition fees and other obligatory parental contributions (e.g. for school materials) over the coming years. They will also have to stop selecting students based on parent interviews or prior academic achievement. In order to facilitate this transition and compensate schools for the loss of revenues from parents' "co-payment", the law provides a number of additional subsidies (Aporte de Gratuidad). Notably, the law provides for a $20 \%$ increase in the Preferential School Subsidy (Subvención Escolar Preferencial, SEP), which assigns additional resources to schools serving the most vulnerable $40 \%$ of students. In addition, schools that abolish co-payments will be eligible to receive a grant amounting to $50 \%$ of the SEP for students from the third and fourth quintile of the income distribution. The estimated fiscal cost of these transition arrangements are subject to debate, ranging from the official estimate of USD 914 million per year to about USD 1170 million (Santiago et al., 2017 ${ }_{[5]}$ ).

Sources: OECD (2017), The Funding of School Education: Connecting Resources and Learning, OECD Publishing, Paris, https://doi.org/10.1787/9789264276147-en; Santiago et al. (2017), OECD Reviews of School Resources: Chile 2017, OECD Publishing, Paris, https://doi.org/10.1787/9789264285637-en.

\section{WHERE THERE IS FREE SCHOOL CHOICE, ENSURE THAT ALL PARENTS CAN EXERCISE THEIR RIGHT TO CHOOSE THE SCHOOL OF THEIR PREFERENCE}

The international evidence suggests that schools that are selective in their admissions tend to attract students with greater ability and higher socio-economic status, regardless of the quality of the education they provide. Given that high-ability students can be less costly to educate and their presence can make a school more attractive to parents, schools that can control their intake wind up with a competitive advantage. Allowing private schools to select their students thus gives these schools an incentive to compete on the basis of exclusiveness rather than on their intrinsic quality. That, in turn, can undermine the positive effects of competition (Boeskens, 2016 $6_{[6]}$ ). 
Evidence also shows that selective admissions can be a source of greater inequality and stratification within a school system. However, there are few studies that have investigated whether these effects vary, depending on the selection criteria - for example, interviews with parents compared to results of aptitude tests (Boeskens, 2016 $6_{[6]}$ ). It is also important to keep in mind that students are selected not only based on explicit admissions criteria but also because of parents' self-selection, selective exclusion and more subtle barriers to entry. Policies that aim to reduce segregation in a school system should therefore also identify and address overly complex application procedures, expulsion practices, lack of information and other factors that prevent some students and parents from exercising their right to choose a school. To ensure that the advantages of school choice accrue to families across the socio-economic spectrum, the criteria used by oversubscribed schools to select their incoming students should be monitored and regulated to prevent "cream skimming" (OECD, 2018 $\left.8_{[2]}\right)$.

Evidence has repeatedly shown that it is usually the most highly educated and well-off parents who opt out of the assigned public schools. Low-income families may be unable to send their child to the best schools if those schools are privately funded and if the parents cannot afford tuition fees. They may prefer to enrol their child in the schools closest to their home, in order to avoid a long and costly commute. Public and school transport systems are another factor moderating the link between residential segregation and diversity in schools. Weakly developed or prohibitively costly transport networks can limit the extent to which lower-income families benefit from school choice. Effective school transport arrangements can ensure that all students are sufficiently mobile to benefit from the expansion of parental choice (OECD, 2018 $8_{[2]}$ ). Policies should thus provide targeted support to these families, not only by offering financial assistance but also by promoting mobility through adequate public transportation. Pioneered in the United States to overcome the legacy of racial segregation in the 1950s, busing schemes have since been used in multiple countries with the explicit aim to achieve a more socially balanced distribution of students across the school network and reduce the impact of residential segregation (Brunello and De Paola, 2017 $7_{[3]}$ ).

Mobility may also be reinforced through policies aimed at reducing urban segregation. School and urban segregation are two mutually reinforcing phenomena, as the social diversity in schools partly reflects that observed in nearby neighbourhoods, and will also determine where families choose to reside (if they have a choice).

School systems should ensure that all parents are provided with the relevant information. Efficient school choice implies that parents select the best school for their child - the school that can fulfil their education needs and improve their performance. However, a growing body of research suggests that parents have a clear preference for schools with better performance at test scores. ${ }^{4}$ Good test scores may be an indication that a school is doing a very good job of educating its students; they may also reflect the fact that the school teaches only the (already) best students. Absolute performance, as measured by test scores, does not mean that a school has a high "value-added" component. Attending a school with a large proportion of high achievers does not always result in individual improvements in performance (Abdulkadiroğlu et al., 2017 $7_{\text {[7]; }}$ Dobbie and Fryer, 2014 ${ }_{[8]} ;$ Lucas and Mbiti, 2014 $\left.4_{[9]}\right)$. Parents would benefit from a measure of the actual "value-added" of schools, meaning whether those schools succeed in improving the performance 
of all of their students. ${ }^{5}$ Evidence shows that the quality of teachers is the most important element (Hoekstra, Mouganie and Wang, 2018 ${ }_{[10]}$; Pop-Eleches and Urquiola, $2013_{[11]}$ ), suggesting that another way of avoiding additional stratification between schools is to allocate the best teachers across all schools, including disadvantaged ones.

Well-crafted school-choice policies can help school systems deliver education tailored to a diverse student population, while limiting the risk of social segregation. When market mechanisms are introduced or expanded in education systems, the role of public policy needs to shift from overseeing the quality and efficiency of public schools to ensuring that oversight and governance arrangements are in place to guarantee that every child benefits from accessible, high-quality education.

The conditions under which private schools are eligible for public subsidies influence the ways in which school-choice programmes affect the accessibility, quality and equity of the school system. Risk to equity can be mitigated if all publicly funded providers are required to adhere to the same regulations regarding tuition and admissions policies, and compliance with these regulations is monitored. Adequate accountability and transparency requirements are also important to ensure that subsidised private schools serve the public interest in providing high-quality education, and to provide parents with the information they need to evaluate different schools' processes and outcomes (OECD, 2017 $\left.7_{[12]}\right)$. 


\section{Notes}

1. For instance, in the voucher programme implemented in the district of Milwaukee (state of Wisconsin in the United States), eligibility is restricted to students from low-income families.

2. For instance, in the city of Paris (France), the allocation of students to high schools relies on a matching procedure that has, for more than 15 years, integrated criteria favouring students from low-income families. This has resulted in large reductions in academic and social segregation across Parisian high schools (Fack and Grenet, 2014 $[14])$.

3. Specific area-based support schemes, such as the "zones of educational priority" found in France and Greece, are observed in school systems with large between-school variations in performance and a concentration of low-performing schools in certain locations. In the case of France, this scheme has been shown to do more harm than good (Davezies and Garrouste, $2018_{[17]}$ ): the most advantaged families tend to disproportionally opt out from schools labelled as disadvantaged.

4. This is observed, for instance, in China (Hoekstra, Mouganie and Wang, 2018 $8_{[10]}$ ), New York City and Boston (Abdulkadiroğlu, Angrist and Pathak, 2014 ${ }_{[13]}$; Dobbie and Fryer, $\left.2014_{[8]}\right)$, Romania (Pop-Eleches and Urquiola, 2013 ${ }_{[11]}$ ) and Paris (Fack and Grenet, 2014 ${ }_{[14]}$ ).

5. See (OECD, 2008 $\left.{ }_{[15]}\right)$ for a practical guide on how school effects were computed. The evaluation of school or teacher effects per se may be complex (as they are often intertwined with the impact of school composition on achievement); but under certain conditions these indicators may be relevant for parents choosing a school for their child (Raudenbush and Willms, $1995_{[16]}$ ).

\section{References}

Abdulkadiroğlu, A., J. Angrist and P. Pathak (2014), "The Elite Illusion: Achievement Effects at Boston and New York Exam Schools", Econometrica, Vol. 82/1, pp. 137-196, http://dx.doi.org/10.3982/ECTA10266.

Abdulkadiroğlu, A. et al. (2017), "Do Parents Value School Effectiveness?", NBER Working Paper, Vol. 23912, http://dx.doi.org/10.3386/w23912 (accessed on 19 July 2018).

Abdulkadiroğlu, A.andT.Sönmez (2003), "SchoolChoice:AMechanism DesignApproach", American Economic Review, Vol. 93/3, pp. 729-747, http://dx.doi.org/10.1257/000282803322157061.

Boeskens, L. (2016), "Regulating Publicly Funded Private Schools: A Literature Review on Equity and Effectiveness", OECD Education Working Papers, No. 147, OECD Publishing, Paris, https://dx.doi.org/10.1787/5jln6jcg80r4-en.

Brunello, G. and M. De Paola (2017), School segregation of immigrants and its effects on educational outcomes in Europe - Publications Office of the EU, European Commission,

http://dx.doi.org/10.2766/045520.

Davezies, L. and M. Garrouste (2018), "More Harm than Good? Sorting Effects in a Compensatory Education Program", Journal of Human Resources, pp. 0416-7839R1, http://dx.doi.org/10.3368/jhr.55.1.0416-7839R1.

Dobbie, W. and R. Fryer (2014), "The Impact of Attending a School with High-Achieving Peers: Evidence from the New York City Exam Schools", American Economic Journal: Applied Economics, Vol. 6/3, pp. 58-75,

http://dx.doi.org/10.1257/app.6.3.58. 
Fack, G. and J. Grenet (2014), Can we increase the social and academic mix in the education system? Theimpact of allocation procedures on Lycée students in the Paris region, IPP, Paris, http://www.parisschoolofeconomics.eu (accessed on 4 January 2019).

Hoekstra, M., P. Mouganie and Y. Wang (2018), "Peer Quality and the Academic Benefits to Attending Better Schools", Journal of Labor Economics, Vol. 36/4, pp. 841-884, http://dx.doi.org/10.1086/697465.

Lucas, A. and I. Mbiti (2014), "Effects of School Quality on Student Achievement: Discontinuity Evidence from Kenya", American Economic Journal: Applied Economics, Vol. 6/3, pp. 234-263, http://dx.doi.org/10.1257/app.6.3.234.

Musset, P. (2012), "School Choice and Equity: Current Policies in OECD Countries and a Literature Review", OECD Education Working Papers, No. 66, OECD Publishing, Paris, https://dx.doi.org/10.1787/5k9fq23507vc-en.

OECD (2018), Responsive School Systems: Connecting Facilities, Sectors and Programmes for Student Success, OECD Reviews of School Resources, OECD Publishing, Paris, https://dx.doi.org/10.1787/9789264306707-en.

OECD (2017), The Funding of School Education: Connecting Resources and Learning, OECD Reviews of School Resources, OECD Publishing, Paris, https://dx.doi.org/10.1787/9789264276147-en.

OECD (2008), Measuring Improvements in Learning Outcomes: Best Practices to Assess the ValueAdded of Schools, OECD Publishing, Paris, https://dx.doi.org/10.1787/9789264050259-en.

Pop-Eleches, C. and M. Urquiola (2013), "Going to a Better School: Effects and Behavioral Responses", [11] American Economic Review, Vol. 103/4, pp. 1289-1324, http://dx.doi.org/10.1257/aer.103.4.1289.

Raudenbush, S. and J. Willms (1995), "The Estimation of School Effects", Journal of Educational [16] and Behavioral Statistics, Vol. 20/4, pp. 307-335, http://dx.doi.org/10.3102/10769986020004307.

Santiago, P. et al. (2017), OECD Reviews of School Resources: Chile 2017, OECD Reviews of School Resources, OECD Publishing, Paris, https://dx.doi.org/10.1787/9789264285637-en. 


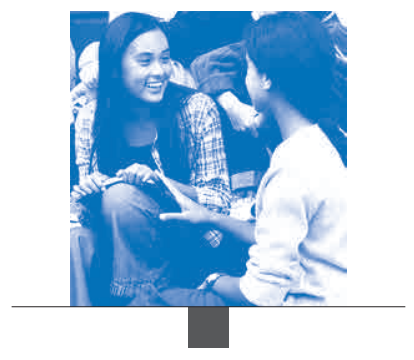

Annex A

MEASURES OF SEGREGATION 
A variety of measures of residential or school segregation have been proposed in the literature (for a review see, for instance, (Frankel and Volij, $2011_{[1]}$ ). These measures may vary by the population groups and geographical areas they consider, as well as by the type of question they try to answer. These measures are always highly correlated. However, they may differ in some cases, as they do not convey exactly the same meaning. A measure taken in isolation provides insights only on one part of the general picture, and the choice of using one or other indicators depends on the particular aspect of segregation one wants to focus on.

The first decision to make is which groups should be considered, answering the question: "Who is segregated from whom?" Historically, a large body of academic research focuses on the segregation by race in the United States, but these notions may be extended to study a wide range of dimensions. One may consider the segregation of socio-economically disadvantaged or advantaged students, or low-achieving students, or those with an immigrant background, etc.

The second decision depends on the aspect of segregation that is the most pertinent to the analysis, answering the question: "Why does segregation matter?" in a specific context. The various measures commonly used by scholars can be classified by the dimension they focus on, such as whether the different groups have any opportunities for social interactions, or whether some groups are concentrated in some schools or are evenly distributed across schools (Massey and Denton, 1988 $8_{[2]}$ ).

\section{Measuring group interactions}

A first family of measures focuses on the interactions between groups of students. This is important if one believes that the interactions of peers of different backgrounds may be beneficial for academic performance or social cohesion. The exposure indicator measures the probability that an average student from a group will be in contact at school with members of another group. Formally, it can be written as:

$E=\sum_{j=1}^{1} \frac{n_{j}^{a}}{N^{a}} \frac{n_{j}^{b}}{n_{j}}$, where $n_{j}^{a}$ (respectively $N^{a}$ ) stands for the number of students of type a (for instance, those with an immigrant background) in school $j$ (respectively, in the country), $n_{j}^{b}$ the number of students of the other type $b$ and $n_{j}$ the total number of students in this school $j$. The value of the exposure indicator decreases with the level of segregation between the two groups, and ranges from 0 (full segregation, when the two groups have no contact at all) to $p^{b}$, with $p^{b}=\frac{n^{b}}{N}$ the proportion of the group $b$ in the population (no segregation). One may also, conversely, compute an indicator that measures the probability for the average student from a group of being in contact with students from the same group. This indicator increases with segregation and ranges from the proportion of the group a in the population $p^{a}$ (no segregation) to 1 (full segregation). The two previous indicators usually rely on a binary decomposition along a sole dimension (for instance ethnic, social or academic groups) and always sum to 1 .

The ranges of these two indices related to interactions depend on the proportion of the group that is studied, which can make comparisons between countries difficult. For instance, consider the hypothetical example of two countries where the isolation indices for immigrant students have the same value, 0.20 , but where the shares of immigrant students are $20 \%$ (country A) and $2 \%$ (country B). In country A, the value of the index corresponds to a no-segregation situation (the typical immigrant student has a chance of being enrolled in the same school as other immigrants, as observed in the entire country population). By contrast, in country B, in theory an immigrant student would be much less frequently enrolled with other immigrants, as there are fewer of them in the population. The same value in the isolation index means in this case that immigrant students should still have been concentrated in the same schools. 
In order to compare segregation across countries, one should thus prefer to use the normalised version of the exposure indicator, which is called the isolation indicator in the document:

$$
N E(a, b)=1-\frac{\sum_{j=1}^{1} \frac{n_{j}^{a}}{N^{a}} \frac{n_{j}^{b}}{n_{j}}}{\frac{N^{b}}{N^{b}+N^{a}}}
$$

This index ranges from 0 (no segregation) to 1 (full segregation).

One may also derive a version of this indicator when the two groups of this indicator do not constitute a division of the population - for example, when measuring the exposure of disadvantaged students to high achievers in the country. In this case, the two groups taken together may not constitute the entire population, and in this example may partially overlap. ${ }^{1}$ The lowest value $(0)$ is observed when the two subgroups are clustered in the same schools; the highest value (1) is observed when they are both clustered in schools, but in different ones. Medium values are observed when the two populations are randomly mixed within the schools.

\section{Measuring departure from unevenness}

Another way of analysing segregation is to look whether the student body in a country's schools resembles the population of the country, in other words whether the distribution of students in schools deviate from what would have been observed if they were distributed randomly across schools (unevenness). The dissimilarity index is commonly used for this purpose. It is related to the proportions of students of the two groups who have to be displaced in order to obtain an identical distribution across all schools. Formally, the dissimilarity index may be written as:

$D=\frac{1}{2} \sum_{j=1}^{1}\left|\frac{n_{j}^{a}}{N^{a}}-\frac{n_{j}^{b}}{N^{b}}\right|$, where $n_{j}^{b}$ (respectively $N^{b}$ ) stands for the number of students in school $j$ with type $b$ (respectively, in the country). This index thus measures the dissimilarity in the distribution of type a students across schools from the distribution of type $b$ students across schools. It may be interpreted as the proportion of one or the other group that has to be displaced in order to achieved unevenness (assuming that school size may be adjusted), or as the average proportions of students of both group $a$ and group $b$ that have to be reallocated in order to achieved unevenness, maintaining equal school size.

Other indicators have been derived from the dissimilarity index. For instance, the indicator proposed by Gorard and Taylor (2002):

$G=\frac{1}{2} \sum_{j=1}^{1}\left|\frac{n_{j}^{\text {disadv }}}{N^{\text {disadv }}}-\frac{n_{j}}{N}\right|$, where $n_{j}$ (respectively, $N$ ) stands for the number of students in school (respectively, in the country). It corresponds to the proportion of students of the considered group that should be displaced in order to obtain evenness, keeping the size of the schools stable. This indicator ranges from 0 (no segregation) to $1-\frac{N^{d i s a d v}}{N}$ (full segregation). The current concentration indicator proposed in PISA 2015, CC $=\sum_{j=1}^{1} \frac{n_{j}}{N}\left|\frac{n_{j}^{\text {disadv }}}{N^{\text {disadv }}}-\frac{N^{\text {disadv }}}{N}\right|$, is also derived from the dissimilarity indicator.

The dissimilarity, Gorard and current concentration indices are closely linked. It can be easily shown that $C C=2 p G=2 p(1-p) D$. However, while the dissimilarity index $\mathrm{D}$ ranges from 0 (no segregation) to 1 (full segregation), the maximum values of the two other indicators depend on the proportion of the 
considered group in the population: $1-p$ for the $\mathrm{G}$ indicator and $2 p(1-p)$ for the CC indicator. One should be thus cautious when comparing the value of these indices when the share of the proportion of interest has a large range amongst countries. For the sake of illustration, consider the two "countries" A and B with $20 \%$ and $40 \%$ of students, respectively, from the minority group. For country A, the indicator will range from 0 to 0.8 . However, by construction, even in the case of full segregation (all students in the category are in some schools without any other students), the $G$ indicator in country B cannot be higher than 0.6 , which thus corresponds to an "intermediate" situation in term of segregation in country A.

Comparability may not be an issue when the analysis focuses on a minority group whose proportions are similar or even identical across countries. This could be the case when considering categories related to the quartiles of the country distribution of a continuous variable, such as socio-economic status or academic performance. Yet, using a common range for different indices make interpretation easier.

\section{Analysing diversity}

The indices described above single out one group of students (for instance, disadvantaged students), compared to all other students (for instance, all non-disadvantaged students, including advantaged students and those of average socio-economic status). However, the two-group analysis may be inadequate for describing more complex patterns of social segregation. In PISA, for instance, the social background of students is defined by a continuous variable. Using binary variables for describing this situation loses a lot of information. For instance, if one focuses on disadvantaged students, a binary outcome will result in contrasting those disadvantaged students (defined as students whose socioeconomic status is below the first quartile of the national distribution of this variable) to all other students (from the second to the fourth quartile). Assume that in some countries the most disadvantaged students (those below the first quartile) are never enrolled in the same schools as the most advantaged students (those above the fourth quartile) but often with the slightly more advantaged students. Contrasting the disadvantaged students with all other students will provide only a partial view of the segregation across social categories, and how social diversity observed in the population is reflected in schools. One could use several distinct indices, but another option is to use multi-group indices. Several ones have been proposed for categorical data in order to obtain a more complete description of the segregation (Reardon and Firebaugh, 2002 ${ }_{[3]}$; Frankel and Volij, $2011_{[1]}$ ).

One may also consider the no-diversity index, which has the advantage of being decomposable. This index is based on a measure of entropy, meaning of the diversity in a group, and for this reason is often referred as the entropy index, or mutual information index. It is based on the Theil index commonly used in inequality analysis. When analysing a distribution of the population in four categories, in proportion $q=\left(q^{1}, q^{2}, q^{3}, q^{4}\right)$, the diversity of the population may be related to the measure:

$$
h(q)=-\sum_{k=1}^{4} q^{k} \ln \left(q^{k}\right)
$$

The no-diversity index compares this measure to the average obtained at the school level:

$$
H=\sum_{j=1}^{\prime} \frac{n_{j}}{N} \frac{h\left(q_{j}\right)-h(q)}{h(q)}
$$

In the equation above, $q_{j}=\left(q_{j}^{1}, q_{j}^{2}, q_{j}^{3}, q_{j}^{4}\right)$ is the proportion of the four categories of the students amongst the $n_{j}$ students in school $j$ (and $N$ the total number of students). 
The no-diversity index goes from 0 (no segregation) to 1 (full segregation). One of its advantages is that it is additively decomposable. ${ }^{2}$ If one aggregates schools at a higher level, typically comparing private schools to public schools, the no-diversity index can be decomposed into three components. One component corresponds to the social segregation within private schools, the second to the segregation within public schools, and the third to the additional segregation that reflects the fact that the social composition in the public sector could be distinct from that of the private sector.

Formally, this can be written as:

$H=H^{\text {Priv/Pub }}+\theta^{\text {Pub }} H^{\text {Pub }}+\theta^{\text {Private }} H^{\text {Private }}$, with $H^{\text {Priv/Pub }}$ interpreted as the segregation due specifically to the coexistence of private and public sectors.

The indicator is based on the same idea as the social inclusion index commonly used in PISA publications, from the ratio of the within- and between-school variances (of the continuous social index or performance). The inclusiveness indicator measure relies on a multilevel model (or hierarchical model) that decomposes the variance (modelled by a normal distribution) with one component corresponding to the schools and another to the students. In multilevel models, the estimator of the variance between schools is corrected in order to take into account the part of this variability that is due to students. However, this estimator cannot be additively decomposed in a direct way.

\section{Why do these indicators differ?}

Consider the hypothetical situation of a population of students who may be of type A $(10 \%$ of the population) or B (90\%). The students are distributed across six schools, each with a capacity of six students. The full segregation situation is observed when all the type A students are in one and only one school. No segregation corresponds to a situation where all schools are equally composed of one type A student and five type B students. In both cases, the dissimilarity index, the isolation index and the diversity index coincide (Figure A.1). However, these indicators may differ in intermediate situations. The first panel in Figure A.1 is a slight departure from the complete segregation case (one type A student is mixed with five type B students) while all others are in the same school (with only one type $B$ student). Both the dissimilarity and the isolation indices are very high $(D=0.80$ and $\mathrm{NE}=0.67$, respectively). In the former, many type A students have to be displaced in order to achieve evenness. In the latter, most of the type A students are concentrated in only one school, and the probability of an average student A to interact with a student B is low (one student A has a very high probability of interacting with a student $B$, but for the remaining five students $B$ the probability is much lower). Now consider the case illustrated in the right panel of Figure A.2. The dissimilarity index has the same value as in the previous case: the same proportion of students has to be displaced to achieve unevenness. However, the isolation index is much lower ( $N E=0.4$ ), as the average type A student is much more likely to interact with type B students (as they constitute two-thirds of the enrolment of any type A student's school). In both cases, the no-diversity index is between these two.

Dissimilarity, no-diversity and isolation indices convey different meanings - and this may be important for analysing real data. For example, Figure A.3 shows the values of these three indices of segregation for students with an immigrant background across schools. Countries and economies are sorted according to the proportion of immigrant students within the 15-year-old student population (represented by diamonds in the figure). In countries where the proportion of immigrants is very small, the dissimilarity index tends to be very high. If the country hosts only a few students with an immigrant background, one cannot expect them to be distributed to all schools. As the dissimilarity index is related to the proportion of the population of immigrant students who have to be displaced, this proportion may quickly become very large if the population is small (as the related population, meaning the denominator, is very small). ${ }^{3}$ 
Figure A.1 - Complete vs no segregation cases (illustrative example)

\begin{tabular}{|c|c|c|c|c|}
\hline \multirow{4}{*}{$\begin{array}{l}6 \text { schools with } \\
6 \text { students } \\
6 \text { students A } \\
30 \text { students B }\end{array}$} & \multirow{6}{*}{$\begin{array}{c}\text { No segregation } \\
\text { Dissimilarity index }=0 \\
\text { Isolation index }=0 \\
\text { Diversity index }=0\end{array}$} & $0_{0}^{0}$ & \multirow{6}{*}{$\begin{array}{r}\text { Complete segregation } \\
\begin{aligned} \text { Dissimilarity index }=1 \\
\text { Isolation index }=1 \\
\text { Diversity index }=1\end{aligned}\end{array}$} & $0^{0}$ \\
\hline & & $0^{\circ}$ & & $0^{\circ} \circ$ \\
\hline & & $0^{\circ}$ & & $0^{\circ}$ \\
\hline & & $0_{0}^{\circ}$ & & 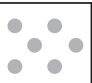 \\
\hline & & $0^{\circ}$ & & $0^{\circ}$ \\
\hline & & $0_{0}^{0}$ & & $0_{0}^{\circ}$ \\
\hline
\end{tabular}

\section{Figure A.2 - High dissimilarity, high vs medium isolation (illustrative example)}

\begin{tabular}{|c|}
\hline (0) \\
\hline $0_{0}^{0}$ \\
\hline $0_{0}^{0}$ \\
\hline $0_{0}^{0}$ \\
\hline $0_{0}^{0}$ \\
\hline $0_{0}^{0}$ \\
\hline
\end{tabular}

\section{Still high concentration of students}

4 over 6 students A $(66 \%)$

4 over 30 students B (13\%) have to

be displaced to achieve evenness

Dissimilarity index $=\mathbf{0 . 8}$

Average student A has little chance to interact with students B

Isolation index $=\mathbf{0 . 7}$

Diversity averaged amongst schools far from the country diversity

Diversity index $=0.7$

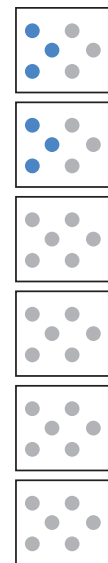

More even situation

... But same proportion of

students have to be displaced to achieve evenness

Dissimilarity index $=\mathbf{0 . 8}$

Average student $A$ is more likely

to interact with students B

Isolation index $=\mathbf{0 . 4}$

Diversity averaged amongst

schools closer to the country level

Diversity index $=0.5$

One may imagine an extreme case where the country hosts fewer immigrant students than the number of schools. In this case, even if these students are distributed across all schools, one will observe numerous schools without any immigrant students. One the other hand, the isolation index is much lower, as the average immigrant student is also more likely to interact with native students at school.

Figure A.3 also illustrates that both isolation and dissimilarity indices may vary widely in countries with similar proportions of immigrant students. For instance, the concentration of these students in some schools is much lower in New Zealand than in Australia and in the United States, while the proportions of non-native students amongst 15-year-old students are similar in these three countries. Isolation of immigrant students is also much higher in Denmark and the Netherlands than in Estonia and Greece, while in most European countries, around $10 \%$ of students are non-native. 


\section{Figure A.3 - Dissimilarity index, no-diversity index and isolation of students with an immigrant background}

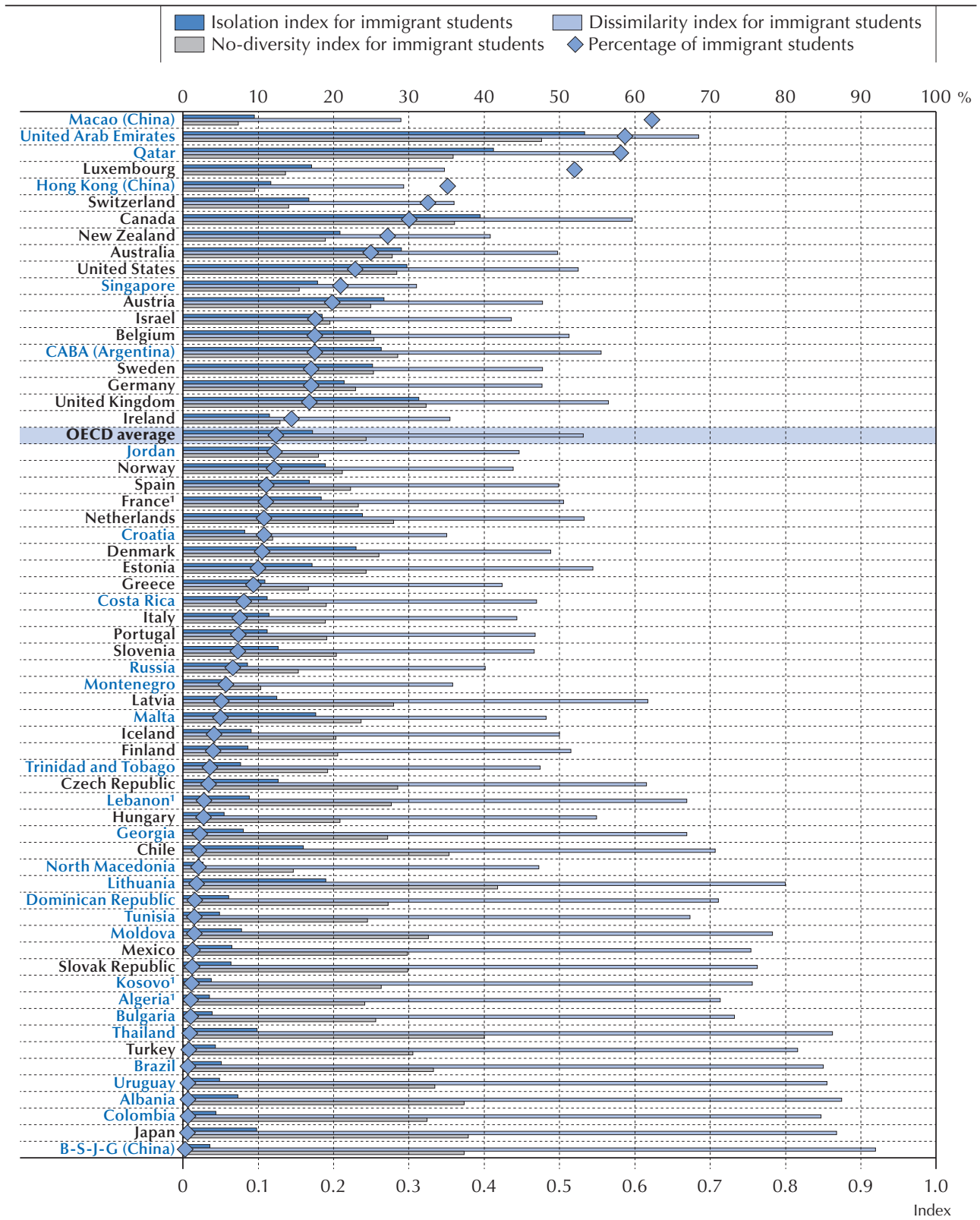

1. In Algeria, France, Kosovo and Lebanon, the proportion of 15 -year-old students in modal grade schools is lower than $80 \%$ (see Table B.3), and one should interpret with caution the comparison with other countries.

Note: All analyses are restricted to schools with the modal ISCED level for 15-year-old students.

Countries and economies are ranked in descending order of the percentage of immigrant students.

Source: OECD, PISA 2015 Database, Table A.1.

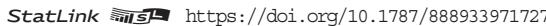




\section{Notes}

1. The index obviously does not make sense when the two populations completely overlap $\left(N^{b}=N^{a}\right.$, or when $\left.N^{b}+N^{a}>N\right)$.

2. This is a common property with the square roots index proposed by Hutchens for binary variables, see PISA 2015 Results Volume IV (OECD, 2017 $\left.7_{[6]}\right)$.

3. This is related to the issue of measuring segregation when units are small ( $\mathrm{D}^{\prime}$ Haultfœuille and Rathelot, $2017_{[4]}$; Carrington and Troske, $\left.1997_{[5]}\right)$.

\section{References}

Carrington, W. and K. Troske (1997), "On Measuring Segregation in Samples with Small Units", Journal of Business \& Economic Statistics, Vol. 15/4, p. 402, http://dx.doi.org/10.2307/1392486.

D'Haultfœuille, X. and R. Rathelot (2017), "Measuring segregation on small units: A partial identification analysis", Quantitative Economics, Vol. 8/1, pp. 39-73, http://dx.doi.org/10.3982/QE501.

Frankel, D. and O. Volij (2011), "Measuring school segregation", Journal of Economic Theory, http:// dx.doi.org/10.1016/j.jet.2010.10.008.

Gorard, S. and C. Taylor (2002), "What is Segregation?: A Comparison of Measures in Terms of 'Strong' and 'Weak' Compositional Invariance", Sociology, Vol. 36/4, https://doi.org/10.1177/003803850203600405.

Massey, D. and N. Denton (1988), "The Dimensions of Residential Segregation", Social Forces, Vol. 67/2, p. 281, http://dx.doi.org/10.2307/2579183.

OECD (2017), PISA 2015 Results (Volume IV): Students' Financial Literacy, PISA, OECD Publishing, Paris, https://dx.doi.org/10.1787/9789264270282-en.

Reardon, S. and G. Firebaugh (2002), "2. Measures of Multigroup Segregation", Sociological Methodology, Vol. 32/1, pp. 33-67, http://dx.doi.org/10.1111/1467-9531.00110. 


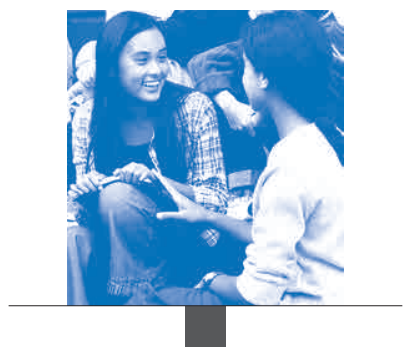

$$
\text { Annex B }
$$

\section{ADDITIONAL FIGURES AND ROBUSTNESS CHECKS}


Figure B.1 - Equity in reading performance and school admissions based on residence

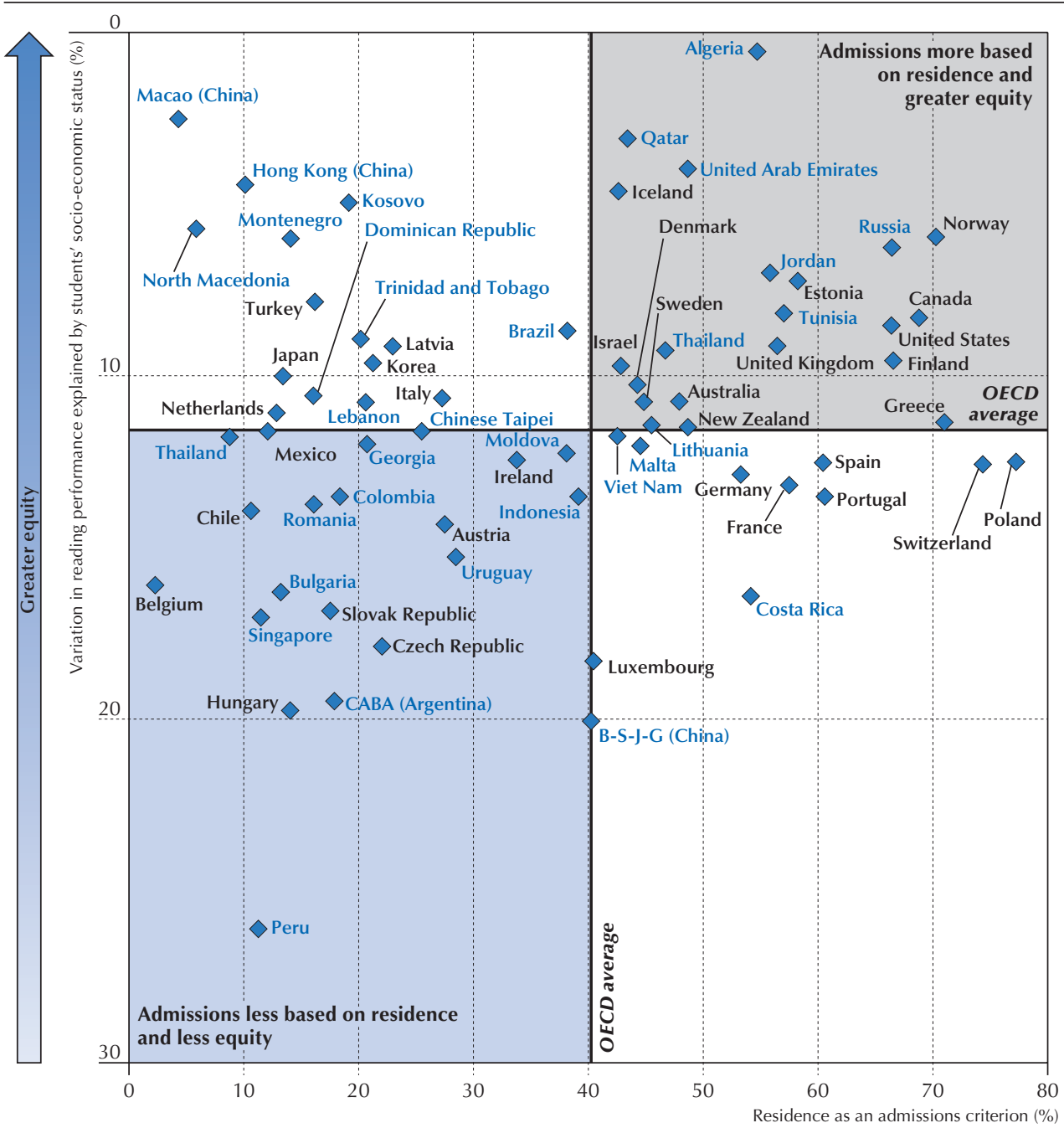

Note: All analyses are restricted to schools with the modal ISCED level for 15-year-old students. Source: OECD, PISA 2015 Database, Table B.4.

StatLink 部正 https://doi.org/10.1787/888933971746 


\section{Figure B.2 - Reading performance and school admissions based on academic performance}

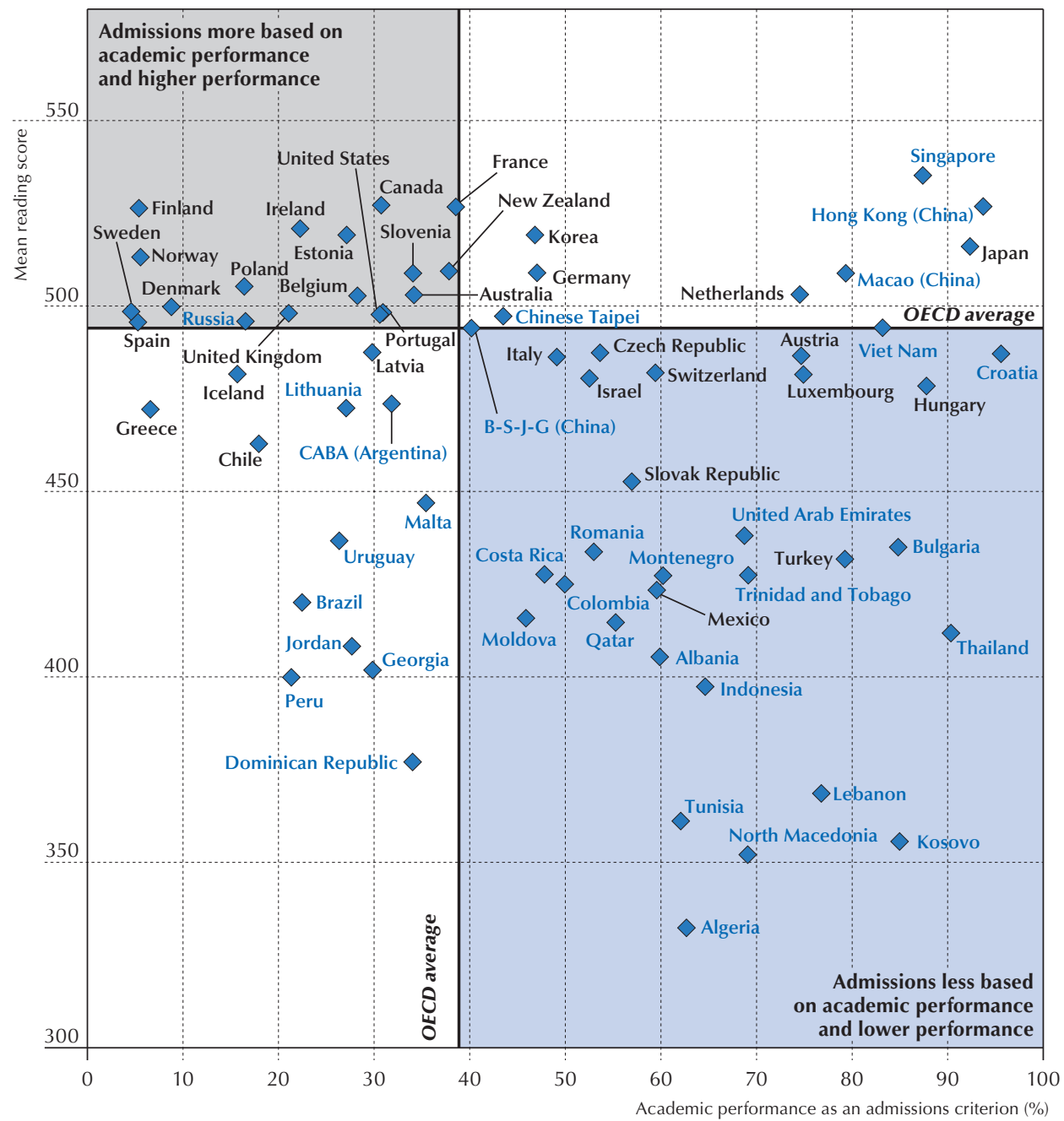

Note: All analyses are restricted to schools with the modal ISCED level for 15-year-old students.

Source: OECD, PISA 2015 Database, Table B.5.

StatLink त्नाड़ https://doi.org/10.1787/888933971765 
Figure B.3 - Percentage of students in schools whose parents/principal reported school competition, 2012

Percentage of students whose parents/school principal reported a certain number of schools competing for students in the same area

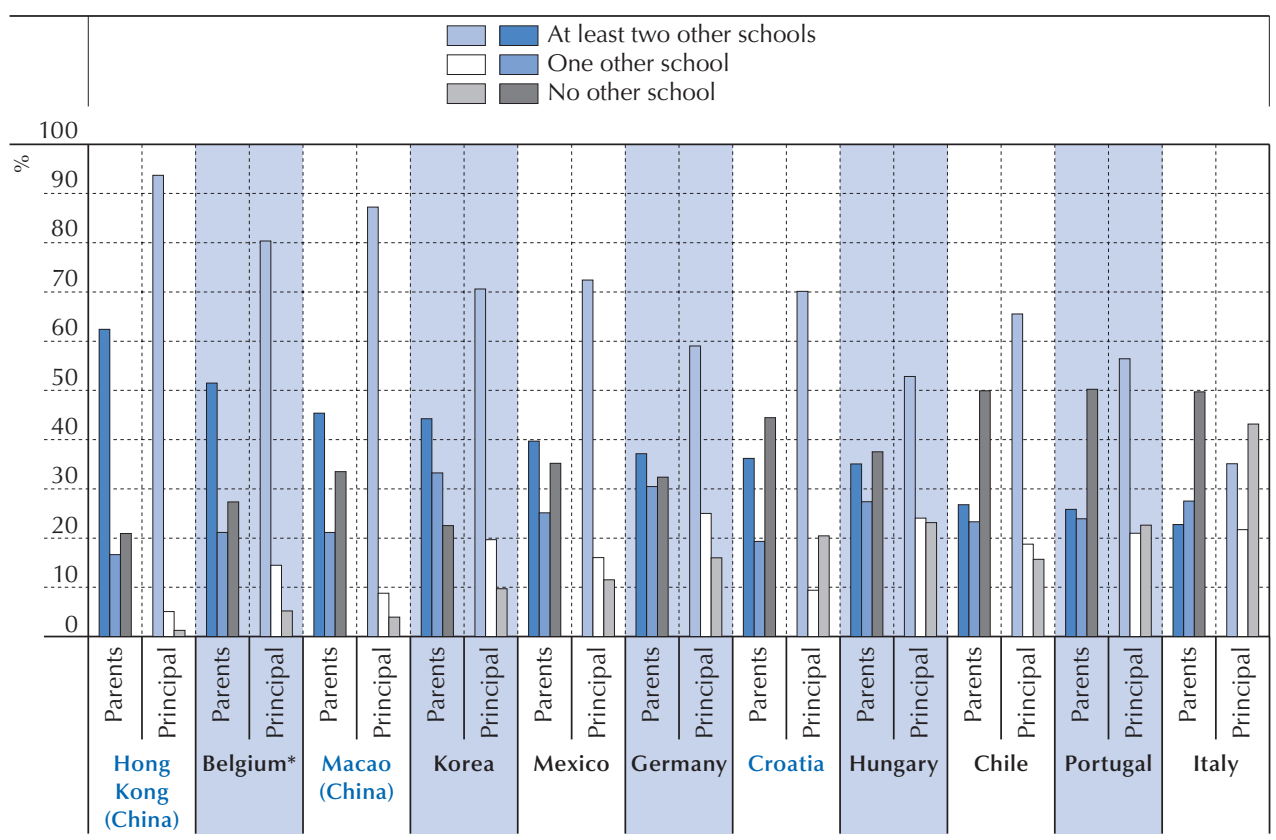

*Parents' reports for Flemish Community only.

Notes: All analyses are restricted to schools with the modal ISCED level for 15-year-old students.

Only countries and economies with available data are shown.

Countries and economies are ranked in descending order of the percentage of students in schools that compete with at least two other schools in the area, according to school principals.

Source: OECD, PISA 2015 Database, Table B.6.

StatLink तiाsh https://doi.org/10.1787/888933971784 


\section{Table B.1 - Reading performance, by school practices and social segregation} Robustness checks

\begin{tabular}{|c|c|c|c|c|c|c|c|c|c|c|}
\hline \multirow[b]{2}{*}{ Boy } & \multicolumn{2}{|c|}{$\begin{array}{l}\text { Admissions } \\
\text { criteria (main) }\end{array}$} & \multicolumn{2}{|c|}{$\begin{array}{l}\text { Admissions } \\
\text { criteria (student } \\
\text { weights) }\end{array}$} & \multicolumn{2}{|c|}{$\begin{array}{c}\text { Admissions } \\
\text { criteria (with } \\
\text { average school } \\
\text { socio-economic } \\
\text { status) }\end{array}$} & \multicolumn{2}{|c|}{$\begin{array}{r}\text { Segregation } \\
(2009-2015)\end{array}$} & \multicolumn{2}{|c|}{$\begin{array}{l}\text { Segregation } \\
(2003-2015)\end{array}$} \\
\hline & -35.094 & $(0.259)$ & -29.464 & $(0.507)$ & -32.982 & $(0.233)$ & -35.121 & $(0.257)$ & -35.871 & $(0.210)$ \\
\hline Immigrant & -5.214 & $(0.520)$ & -11.844 & $(1.426)$ & -4.312 & $(0.494)$ & -5.231 & $(0.518)$ & -10.147 & $(0.496)$ \\
\hline Disadvantaged & -46.575 & $(1.132)$ & -45.126 & (1.943) & -18.298 & (1.088) & -31.740 & $(1.303)$ & -28.507 & (1.109) \\
\hline Advantaged & 53.704 & $(1.370)$ & 45.558 & $(2.807)$ & 25.049 & $(1.224)$ & 27.391 & (1.263) & 27.302 & $(1.089)$ \\
\hline $\begin{array}{l}\text { School admissions based on } \\
\text { academic performance (\%) }\end{array}$ & -0.252 & $(0.035)$ & -0.376 & $(0.069)$ & -0.368 & $(0.034)$ & & & & \\
\hline x Disadvantaged & 0.023 & $(0.014)$ & 0.129 & $(0.027)$ & -0.008 & $(0.012)$ & & & & \\
\hline x Advantaged & -0.050 & $(0.013)$ & -0.058 & $(0.032)$ & -0.062 & $(0.012)$ & & & & \\
\hline $\begin{array}{l}\text { School admissions based on } \\
\text { residence }(\%)\end{array}$ & 0.204 & $(0.042)$ & 0.315 & $(0.094)$ & 0.163 & $(0.041)$ & & & & \\
\hline x Disadvantaged & 0.137 & $(0.016)$ & 0.104 & $(0.030)$ & -0.029 & $(0.017)$ & & & & \\
\hline x Advantaged & -0.127 & $(0.021)$ & 0.038 & $(0.041)$ & 0.030 & $(0.019)$ & & & & \\
\hline No-diversity index & & & & & & & 0.095 & $(0.165)$ & 0.301 & $(0.134)$ \\
\hline x Disadvantaged & & & & & & & -0.484 & $(0.078)$ & -0.621 & $(0.069)$ \\
\hline x Advantaged & & & & & & & 1.245 & $(0.083)$ & 1.273 & $(0.071)$ \\
\hline Private schools (\%) & 0.237 & $(0.051)$ & 0.235 & $(0.061)$ & 0.127 & $(0.047)$ & 0.196 & $(0.051)$ & 0.268 & $(0.041)$ \\
\hline x Disadvantaged & 0.136 & $(0.014)$ & 0.170 & $(0.033)$ & 0.063 & $(0.013)$ & 0.095 & $(0.013)$ & 0.069 & $(0.010)$ \\
\hline x Advantaged & -0.199 & $(0.014)$ & -0.055 & $(0.037)$ & -0.177 & $(0.012)$ & -0.173 & $(0.012)$ & -0.157 & $(0.011)$ \\
\hline Vocational programmes (\%) & 0.179 & $(0.079)$ & -0.649 & $(0.187)$ & 0.128 & $(0.078)$ & 0.115 & $(0.075)$ & 0.014 & $(0.038)$ \\
\hline x Disadvantaged & 0.080 & $(0.020)$ & 0.114 & $(0.032)$ & -0.040 & $(0.020)$ & 0.003 & (0.018) & -0.038 & $(0.014)$ \\
\hline x Advantaged & 0.039 & $(0.022)$ & -0.050 & $(0.047)$ & 0.160 & $(0.019)$ & 0.107 & $(0.016)$ & 0.067 & $(0.013)$ \\
\hline Grade repetition (\%) & -0.013 & $(0.015)$ & -0.083 & $(0.030)$ & -0.017 & $(0.014)$ & -0.001 & $(0.013)$ & 0.050 & $(0.010)$ \\
\hline x Disadvantaged & -0.020 & $(0.010)$ & -0.053 & $(0.017)$ & 0.006 & $(0.009)$ & -0.015 & $(0.010)$ & -0.018 & $(0.007)$ \\
\hline x Advantaged & 0.026 & $(0.009)$ & 0.084 & $(0.022)$ & -0.069 & $(0.008)$ & 0.017 & $(0.009)$ & 0.007 & $(0.008)$ \\
\hline Mean school ESCS & & & & & 57.550 & $(0.418)$ & & & & \\
\hline Intercept & 405.906 & $(3.270)$ & 409.321 & (6.186) & 460.651 & $(2.917)$ & 402.838 & $(2.912)$ & 401.019 & $(2.679)$ \\
\hline Number of observations & \multicolumn{2}{|c|}{$1,175,972$} & \multicolumn{2}{|c|}{$1,175,972$} & \multicolumn{2}{|c|}{$1,175,972$} & \multicolumn{2}{|c|}{$1,175,972$} & \multicolumn{2}{|c|}{$1,777,706$} \\
\hline $\mathbf{R}^{2}$ & \multicolumn{2}{|c|}{0.284} & \multicolumn{2}{|c|}{0.311} & \multicolumn{2}{|c|}{0.356} & \multicolumn{2}{|c|}{0.284} & \multicolumn{2}{|c|}{0.302} \\
\hline Country fixed effects & \multicolumn{2}{|c|}{ yes } & \multicolumn{2}{|c|}{ yes } & \multicolumn{2}{|c|}{ yes } & \multicolumn{2}{|c|}{ yes } & \multicolumn{2}{|c|}{ yes } \\
\hline Cycle fixed effects & \multicolumn{2}{|c|}{ yes } & \multicolumn{2}{|c|}{ yes } & \multicolumn{2}{|c|}{ yes } & \multicolumn{2}{|c|}{ yes } & \multicolumn{2}{|c|}{ yes } \\
\hline
\end{tabular}

Notes: All analyses are restricted to schools with the modal ISCED level. The results above may thus differ from those estimated on the entire sample of 15-year-old students.

Disadvantaged students are students in the bottom quarter of the PISA index of economic, social and cultural status (ESCS) in their own country.

In the second column, individual student weights are used, otherwise they are normalised in such a way that the contributions of all countries are equal, regardless of the size of their population

The strength of the social gradient corresponds to the variation in student performance in one country that is explained by socio-economic status; the slope refers to the score-point difference in performance associated with one-unit increase in ESCS (the $\mathrm{R}^{2}$ and coefficient, respectively, of a regression of individual performance on socio-economic status).

For the sake of readability, the strength of the social gradient and the segregation indices have been rescaled from 0 to 100 . Standard errors are indicated in parentheses.

Values that are statistically significant at the $10 \%$ level are indicated in italics and those at the $5 \%$ level are indicated in bold. Source: OECD, PISA 2003, PISA 2009 and PISA 2015 Databases.

StatLink त्ताज़ https://doi.org/10.1787/888933971898 
Table B.2 - Variation in the main variables

\begin{tabular}{|c|c|c|c|c|}
\hline & \multicolumn{2}{|c|}{ Standard deviation } & \multicolumn{2}{|c|}{ Range } \\
\hline & Total & Within country & Total & Within country \\
\hline No-diversity index & 4.0 & 1.2 & 22.0 & 2.4 \\
\hline Academic segregation & 9.0 & 3.0 & 42.2 & 5.7 \\
\hline $\begin{array}{l}\text { School admissions based on } \\
\text { academic performance }(\%)\end{array}$ & 26.4 & 7.3 & 95.6 & 14.0 \\
\hline $\begin{array}{l}\text { School admissions based on } \\
\text { residence }(\%)\end{array}$ & 21.9 & 5.0 & 88.2 & 9.5 \\
\hline Vocational programmes (\%) & 19.6 & 1.9 & 75.6 & 3.5 \\
\hline Grade repetition (\%) & 29.7 & 25.1 & 99.5 & 44.2 \\
\hline Private schools (\%) & 23.1 & 2.5 & 97.3 & 4.7 \\
\hline
\end{tabular}

Notes: All analyses are restricted to schools with the modal ISCED level. The results above may thus differ from those estimated on the entire sample of 15 -year-old students.

The standard deviation and range (maximum value - minimum value) are calculated in the total sample (Total) or separately within each country (Within).

Source: OECD, PISA 2009, PISA 2012 and PISA 2015 Databases.

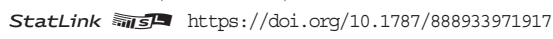

\section{Table B.3 [1/2] - Modal grade by country/economy}

\begin{tabular}{|c|c|c|c|}
\hline \multirow[b]{2}{*}{ OECD } & \multirow[t]{2}{*}{ Modal ISCED level } & \multirow{2}{*}{$\begin{array}{c}\begin{array}{c}\text { Students in the modal ISCED } \\
\text { level in the sample }\end{array} \\
\%\end{array}$} & \multirow{2}{*}{$\begin{array}{c}\begin{array}{c}\text { Students in a modal ISCED } \\
\text { school in the sample }\end{array} \\
\%\end{array}$} \\
\hline & & & \\
\hline Australia & 2 & 86.0 & 99.4 \\
\hline Austria & 3 & 97.9 & 98.5 \\
\hline Belgium & 3 & 90.7 & 97.1 \\
\hline Canada & 3 & 88.4 & 98.4 \\
\hline Chile & 3 & 94.2 & 96.2 \\
\hline Czech Republic & $\begin{array}{l}2 \\
3\end{array}$ & $\begin{array}{l}54.4 \\
45.6\end{array}$ & 100.0 \\
\hline Denmark & 2 & 99.3 & 99.3 \\
\hline Estonia & 2 & 98.7 & 99.5 \\
\hline Finland & 2 & 99.8 & 99.8 \\
\hline France & 3 & 75.9 & 79.6 \\
\hline Germany & 2 & 96.2 & 98.5 \\
\hline Greece & 3 & 95.3 & 95.4 \\
\hline Hungary & 3 & 89.8 & 90.2 \\
\hline Iceland & 2 & 100.0 & 100.0 \\
\hline Ireland & 2 & $\begin{array}{l}62.4 \\
376\end{array}$ & 100.0 \\
\hline Israel & $\begin{array}{l}3 \\
3\end{array}$ & $\begin{array}{l}37.6 \\
89.1\end{array}$ & 97.4 \\
\hline Italy & 3 & 98.9 & 98.9 \\
\hline Japan & 3 & 100.0 & 100.0 \\
\hline Korea & 3 & 90.9 & 90.9 \\
\hline Latvia & 2 & 96.3 & 99.0 \\
\hline Luxembourg & 2 & 56.5 & 100.0 \\
\hline \multirow{2}{*}{ Mexico } & $\begin{array}{l}3 \\
2\end{array}$ & $\begin{array}{l}43.5 \\
39.0\end{array}$ & \multirow{2}{*}{100.0} \\
\hline & 3 & 61.0 & \\
\hline Netherlands & 2 & 70.5 & 100.0 \\
\hline New Zealand & 3 & 93.8 & 100.0 \\
\hline Norway & 2 & 99.9 & 99.9 \\
\hline Poland & 2 & 99.4 & 99.4 \\
\hline \multirow{2}{*}{ Portugal } & 2 & 34.7 & \multirow{2}{*}{100.0} \\
\hline & 3 & $\begin{array}{l}65.3 \\
47.4\end{array}$ & \\
\hline Slovak Republic & $\begin{array}{l}2 \\
3\end{array}$ & $\begin{array}{l}47.4 \\
52.6\end{array}$ & 100.0 \\
\hline Slovenia & 3 & $\begin{array}{l}32.0 \\
94.9\end{array}$ & 94.9 \\
\hline Spain & 2 & 99.9 & 100.0 \\
\hline Sweden & 2 & 98.1 & 98.1 \\
\hline Switzerland & 2 & 77.0 & 84.5 \\
\hline Turkey & 3 & 96.8 & 96.8 \\
\hline United Kingdom & 3 & 99.8 & 100.0 \\
\hline United States & 3 & 89.8 & 99.5 \\
\hline
\end{tabular}

Source: OECD, PISA 2015 Database.

*Argentina, Kazakhstan and Malaysia: Coverage is too small to ensure comparability in 2015.

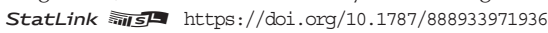


Table B.3 [2/2] - Modal grade by country/economy

\begin{tabular}{|c|c|c|c|}
\hline \multirow[b]{2}{*}{ Partners } & \multirow[t]{2}{*}{ Modal ISCED level } & \multirow{2}{*}{$\begin{array}{c}\begin{array}{c}\text { Students in the modal ISCED } \\
\text { level in the sample }\end{array} \\
\% \\
\end{array}$} & \multirow{2}{*}{$\begin{array}{c}\begin{array}{c}\text { Students in a modal ISCED } \\
\text { school in the sample }\end{array} \\
\% \\
\end{array}$} \\
\hline & & & \\
\hline Albania & $\begin{array}{l}2 \\
3\end{array}$ & $\begin{array}{l}37.0 \\
63.0\end{array}$ & 100.0 \\
\hline Algeria & 2 & 76.9 & 76.9 \\
\hline Brazil & 3 & 77.7 & 86.4 \\
\hline B-S-J-G (China) & $\begin{array}{l}2 \\
3\end{array}$ & $\begin{array}{l}63.0 \\
37.0\end{array}$ & 100.0 \\
\hline Bulgaria & 3 & 96.9 & 97.8 \\
\hline CABA (Argentina) & 2 & 92.5 & 96.6 \\
\hline Colombia & $\begin{array}{l}2 \\
3\end{array}$ & $\begin{array}{l}40.3 \\
59.7\end{array}$ & 100.0 \\
\hline Costa Rica & $\begin{array}{l}2 \\
3\end{array}$ & $\begin{array}{l}53.2 \\
46.8\end{array}$ & 100.0 \\
\hline Croatia & 3 & 99.8 & 99.8 \\
\hline Dominican Republic & 3 & 79.1 & 80.3 \\
\hline Georgia & 3 & 77.5 & 99.3 \\
\hline Hong Kong (China) & 3 & 67.3 & 99.9 \\
\hline Indonesia & $\begin{array}{l}2 \\
3\end{array}$ & $\begin{array}{l}52.2 \\
47.8\end{array}$ & 100.0 \\
\hline Jordan & 2 & 100.0 & 100.0 \\
\hline Kosovo & 3 & 74.4 & 74.5 \\
\hline Lebanon & 3 & 71.4 & 77.9 \\
\hline Lithuania & 2 & 100.0 & 100.0 \\
\hline Macao (China) & 2 & $\begin{array}{l}44.9 \\
55.1\end{array}$ & 100.0 \\
\hline Malta & 3 & 99.7 & 99.8 \\
\hline Moldova & 2 & 92.4 & 96.0 \\
\hline Montenegro & 3 & 97.4 & 97.4 \\
\hline North Macedonia & 3 & 99.8 & 99.8 \\
\hline Peru & 3 & 74.7 & 97.2 \\
\hline Qatar & 3 & 79.3 & 88.0 \\
\hline Romania & 2 & 100.0 & 100.0 \\
\hline Russia & 2 & 86.5 & 95.5 \\
\hline Singapore & 3 & 97.9 & 100.0 \\
\hline Chinese Taipei & $\begin{array}{l}2 \\
3\end{array}$ & $\begin{array}{l}35.4 \\
64.6\end{array}$ & 100.0 \\
\hline Thailand & 3 & 75.4 & 92.2 \\
\hline Trinidad and Tobago & $\begin{array}{l}2 \\
3\end{array}$ & $\begin{array}{l}41.3 \\
58.7\end{array}$ & 100.0 \\
\hline Tunisia & 2 & $\begin{array}{l}34.5 \\
65.5\end{array}$ & 100.0 \\
\hline United Arab Emirates & 3 & 86.5 & 96.0 \\
\hline Uruguay & $\begin{array}{l}2 \\
3\end{array}$ & $\begin{array}{l}37.9 \\
62.1\end{array}$ & 100.0 \\
\hline Viet Nam & 3 & 90.9 & 91.4 \\
\hline Argentina* & $\begin{array}{l}2 \\
3\end{array}$ & $\begin{array}{l}38.7 \\
61.3\end{array}$ & 100.0 \\
\hline Kazakhstan* & $\begin{array}{l}2 \\
3\end{array}$ & $\begin{array}{l}63.3 \\
36.7\end{array}$ & 100.0 \\
\hline Malaysia* & 3 & 96.8 & 100.0 \\
\hline
\end{tabular}

Source: OECD, PISA 2015 Database.

*Argentina, Kazakhstan and Malaysia: Coverage is too small to ensure comparability in 2015.

StatLink तiा 



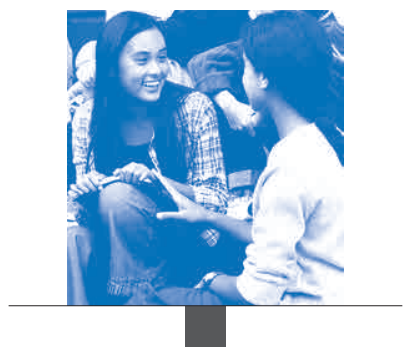

Annex C

LIST OF TABLES AVAILABLE ON LINE 
Chapter 2 How school choice can be measured by PISA and how these indicators have evolved over time https://doi.org/10.1787/888933971955

WEB Table 2.2 Change between 2000 and 2015 in the percentage of students enrolled in a private school

WEB Table 2.3 Percentage of students in schools that compete with at least one other local school, 2012

WEB Table 2.4a Change between 2000 and 2015 in school admissions based on residence

WEB Table 2.4b Change between 2000 and 2015 in lower secondary school admissions based on residence

WEB Table 2.4c Change between 2000 and 2015 in upper secondary school admissions based on residence

WEB Table 2.5a Change between 2000 and 2015 in school admissions based on academic performance

WEB Table 2.5b Change between 2000 and 2015 in lower secondary school admissions based on academic performance

WEB Table 2.5c Change between 2000 and 2015 in upper secondary school admissions based on academic performance

WEB Table 2.6 School admissions based on academic performance, by school type

Chapter 3 The level of social and academic segregation across schools

\begin{tabular}{|lll}
\hline \multicolumn{2}{|c}{ https://doi.org/10.1787/888933971955 } \\
\hline WEB & Table 3.1 & Dissimilarity index for low-achieving students in reading and for disadvantaged students \\
\hline WEB & Table 3.2 & Isolation of low-achieving and high-achieving students in reading \\
\hline WEB & Table 3.3 & Isolation of disadvantaged and advantaged students \\
\hline WEB & Table 3.4 & Isolation of disadvantaged students from national high achievers in reading
\end{tabular}

Chapter 4 How social and academic segregation are related to school-choice policies

\begin{tabular}{|c|c|}
\hline \multicolumn{2}{|c|}{ https://doi.org/10.1787/888933971955 } \\
\hline WEB Table 4.2 & Contributions of public and private schools to social segregation amongst schools \\
\hline WEB Table 4.3 & Social segregation, by type of school \\
\hline WEB Table 4.4 & Dissimilarity index for low-achieving students in reading and school admissions based on academic performanc \\
\hline WEB Table 4.5 & Dissimilarity index for disadvantaged students and school admissions based on residence \\
\hline
\end{tabular}

Chapter 5 How school-choice policies are related to quality and equity in education

https://doi.org/10.1787/888933971955

WEB Table 5.4 Equity in reading performance and no-diversity index for disadvantaged students

WEB Table 5.5 Equity in reading performance and school admissions based on academic performance

Annex A Measures of segregation

https://doi.org/10.1787/888933971955

WEB Table A.1 Dissimilarity index, no-diversity index and isolation of students with an immigrant background

Annex B Additional figures and robustness checks

\begin{tabular}{|l|ll}
\hline \multicolumn{2}{|l}{ https://doi.org/10.1787/888933971955 } \\
\hline WEB & Table B.4 & Equity in reading performance and school admissions based on residence \\
\hline WEB & Table B.5 & Reading performance and school admissions based on academic performance \\
\hline WEB & Table B.6 & Percentage of students in schools whose parents/principal reported school competition, 2012
\end{tabular}




\section{ORGANISATION FOR ECONOMIC CO-OPERATION AND DEVELOPMENT}

The OECD is a unique forum where governments work together to address the economic, social and environmental challenges of globalisation. The OECD is also at the forefront of efforts to understand and to help governments respond to new developments and concerns, such as corporate governance, the information economy and the challenges of an ageing population. The Organisation provides a setting where governments can compare policy experiences, seek answers to common problems, identify good practice and work to co-ordinate domestic and international policies.

The OECD member countries are: Australia, Austria, Belgium, Canada, Chile, the Czech Republic, Denmark, Estonia, Finland, France, Germany, Greece, Hungary, Iceland, Ireland, Israel, Italy, Japan, Korea, Latvia, Lithuania, Luxembourg, Mexico, the Netherlands, New Zealand, Norway, Poland, Portugal, the Slovak Republic, Slovenia, Spain, Sweden, Switzerland, Turkey, the United Kingdom and the United States. The European Union takes part in the work of the OECD.

OECD Publishing disseminates widely the results of the Organisation's statistics gathering and research on economic, social and environmental issues, as well as the conventions, guidelines and standards agreed by its members. 


\section{Balancing School Choice and Equity AN INTERNATIONAL PERSPECTIVE BASED ON PISA}

Many countries are struggling to reconcile greater flexibility in school choice with the need to ensure quality, equity and coherence in their school systems. This report provides an international perspective on issues related to school choice, especially how certain aspects of school-choice policies may be associated with sorting students into different schools. A key question fuelling the school-choice debate is whether greater competition among schools results in more sorting of students by ability or socio-economic status. At the macro level, school segregation can deprive children of opportunities to learn, play and communicate with other children from different social, cultural and ethnic backgrounds, which can, in turn, threaten social cohesion. The report draws a comprehensive picture of school segregation, using a variety of indicators in order to account for the diversity of the processes by which students are allocated to schools.

Consult this publication on line at: $\boldsymbol{h t t p s : / / d o i . o r g / 1 0 . 1 7 8 7 / 2 5 9 2 c 9 7 4 - e n ~}$

This work is published on the OECD iLibrary, which gathers all OECD books, periodicals and statistical databases.

Visit www.oecd-ilibrary.org for more information. 